\title{
Plant Secondary Metabolites \\ Allelopathic Functions and Biomedical Potential
}

\author{
Dissertation \\ to obtain the Ph. D. degree \\ in the International Ph. D. Program for Agricultural Sciences in Goettingen \\ (IPAG) \\ at the Faculty of Agricultural Sciences, \\ Georg-August-University Göttingen, Germany
}

presented by

\section{Mohammad Alhussein}

born in Syria

Göttingen, June 2019 
D7

1. Name of supervisor: Prof. Dr. Petr Karlovsky

2. Name of co-supervisor: Dr. Franz Hadacek

Date of dissertation: 11 July 2019 


\section{Contents}

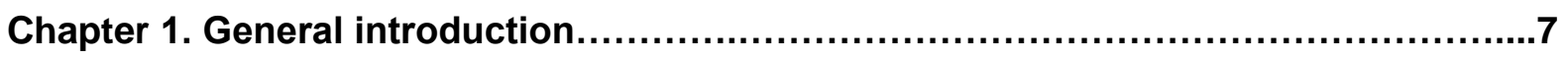

1. Introduction to plant secondary metabolites............................................................. 7

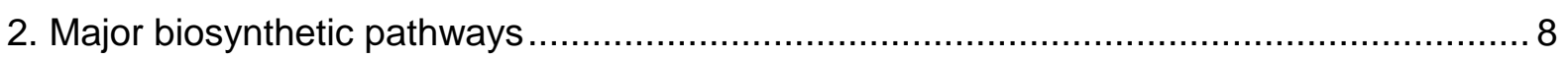

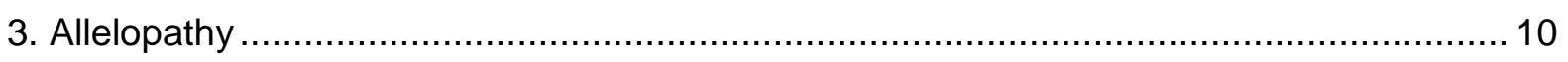

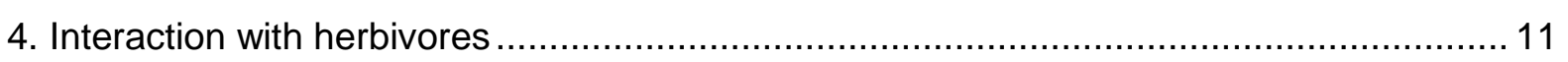

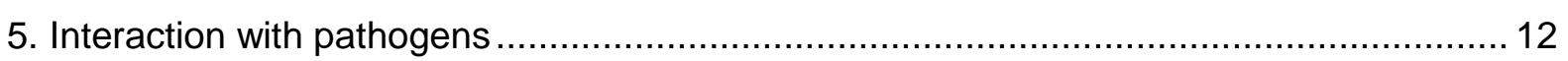

6. Pharmaceutical properties of secondary plant metabolites ...................................... 12

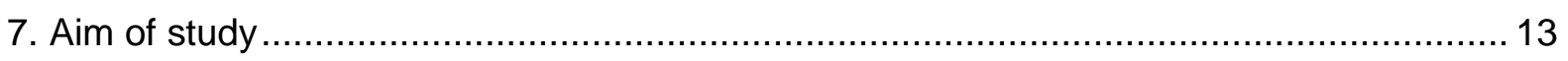

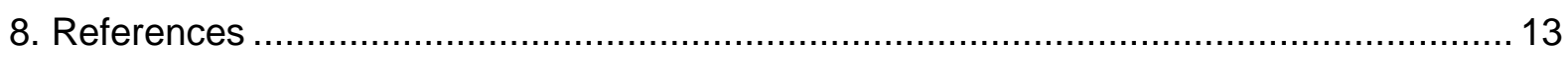

Chapter 2. The biological properties of secondary metabolites in root exudates of Galanthus nivalis and their impact on the rhizosphere microorganisms ...............16

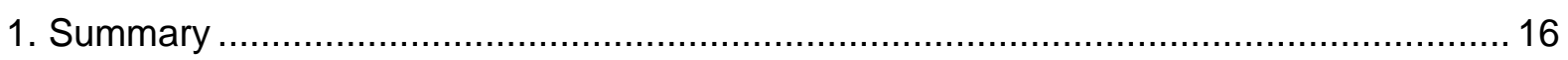

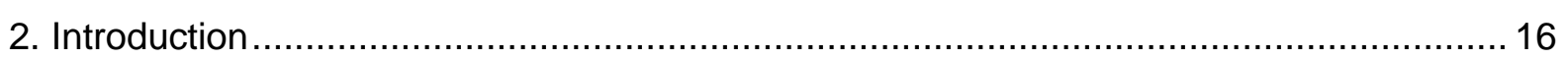

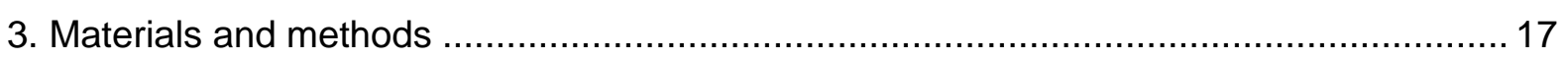

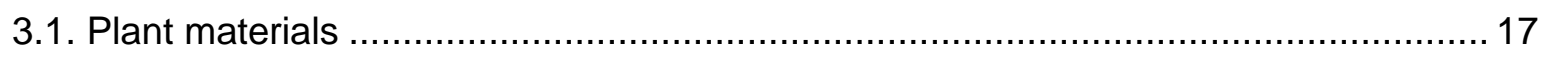

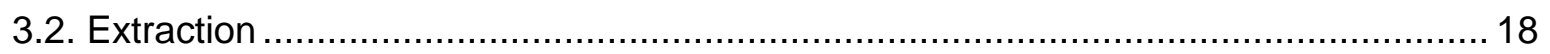

3.3. Purification and chemical analysis............................................................... 18

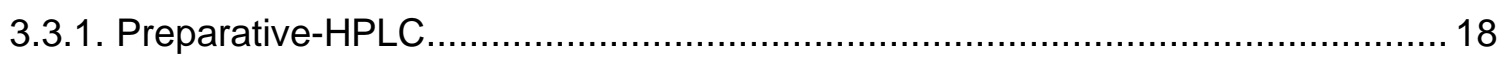

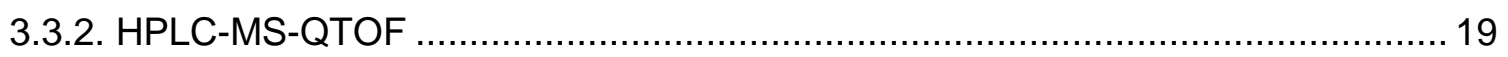

3.3.3. Structure elucidation of isolated compounds by NMR .................................... 19

3.4. Secondary metabolites extraction from the rhizosphere ..................................... 20

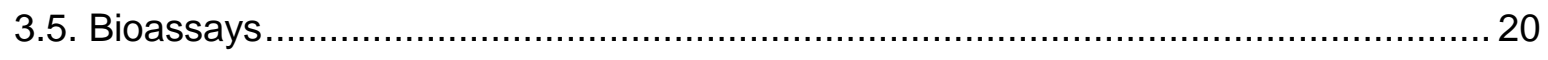

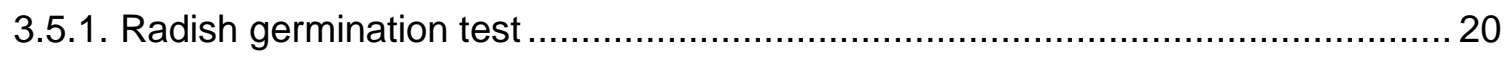

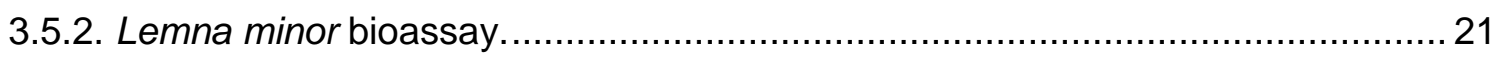

3.5.3. Brine shrimp (Artemia salina) cytotoxicity bioassay. .................................... 21

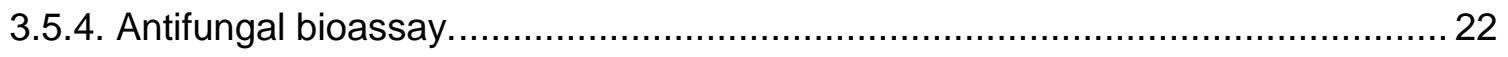

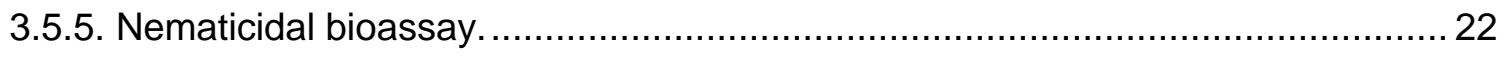

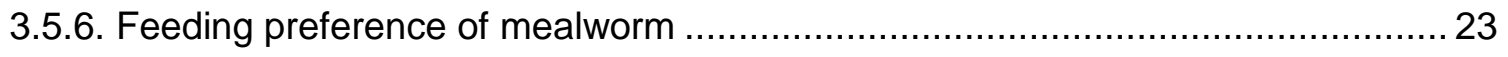

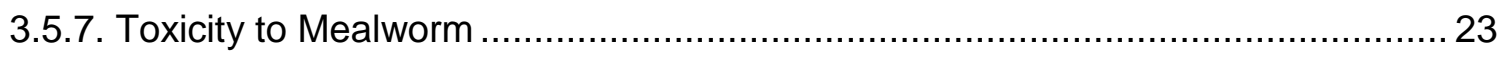

3.6. Impact of secondary metabolites on microorganisms in the soil ................................ 24

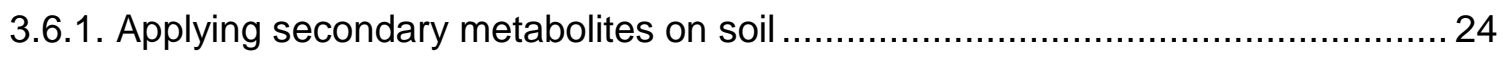

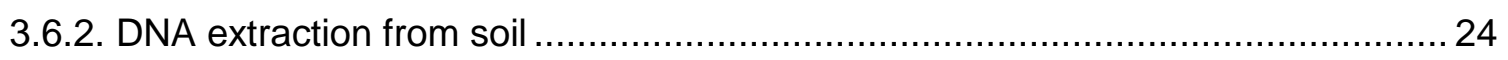


3.6.3. Quantification of bacterial and fungal taxonomic groups in soil by real-time PCR

3.6.4. Enumeration of soil bacteria communities by amplicon sequencing ................... 25

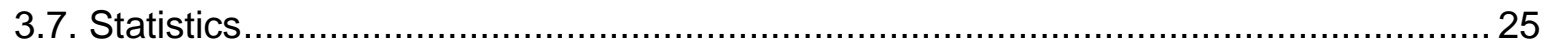

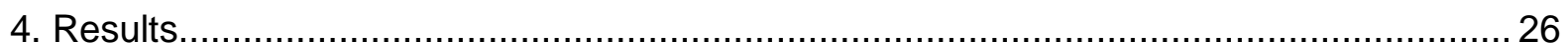

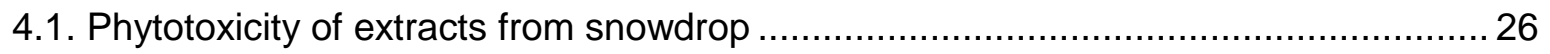

4.2. Purification and characterization of secondary metabolites from snowdrop bulbs ..... 27

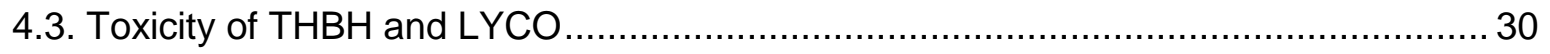

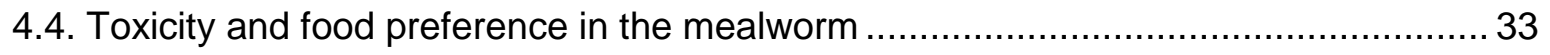

4.5. Quantification of the metabolites in plant bulbs and root exudates .......................... 35

4.6. Impact of secondary metabolites from snowdrop on soil microorganisms .................. 35

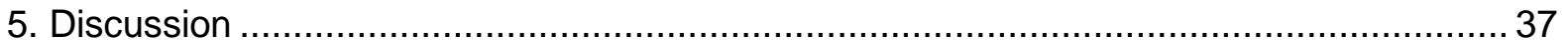

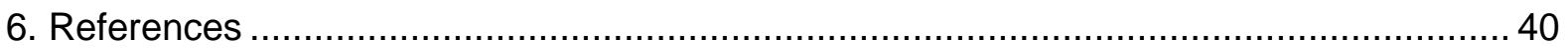

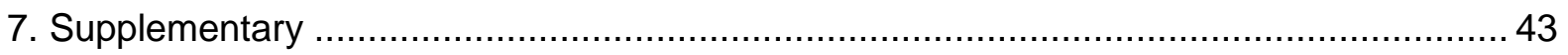

Chapter 3. Investigation of allelochemicals leaching and exuding from Melilotus albus into the soil and their impact on weed suppressiveness and soil microorganisms....50

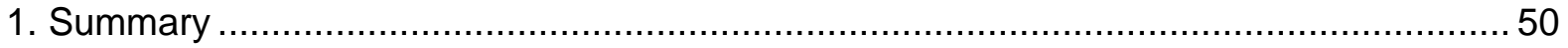

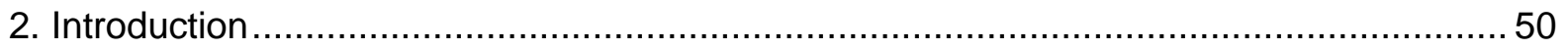

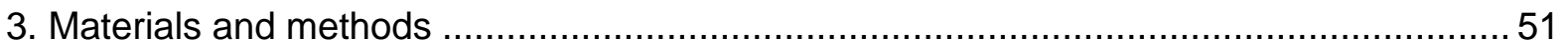

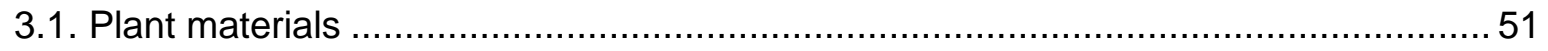

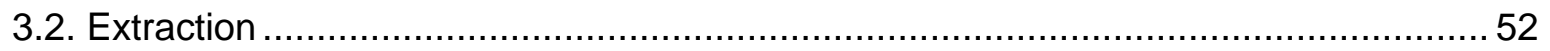

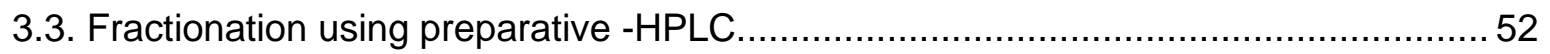

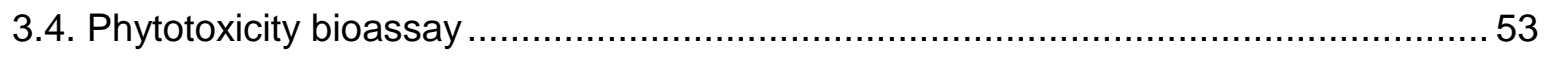

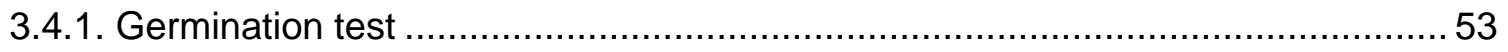

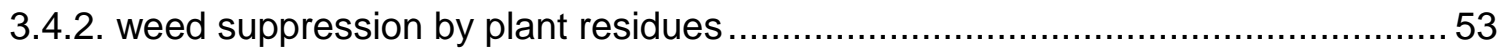

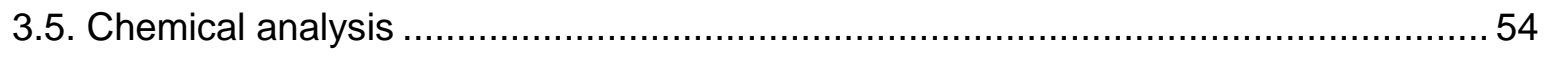

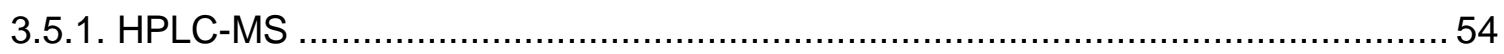

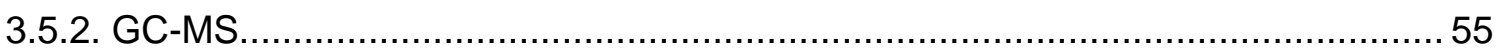

3.6. Leaching of allelochemicals from living sweet clover plants by simulated rain ..........55

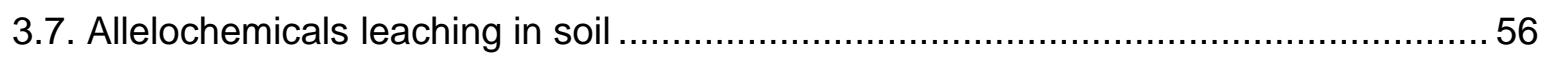

3.8. Impact of allelochemicals on soil microorganisms ......................................... 57

3.9. Soil DNA extraction and quantification of bacterial and fungal taxonomic groups by

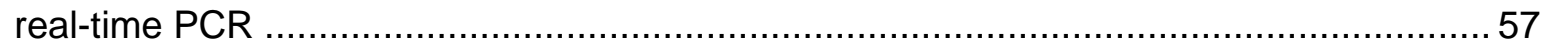

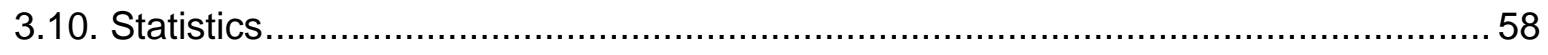

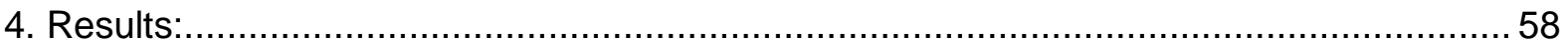

4.1. Bioassay-guided fractionation and chemical analysis........................................ 58 
4.3. Natural release of allelochemicals from living sweet clover plants ...........................63

4.4. Allelochemicals leaching in soil and their impact on microorganisms ........................ 65

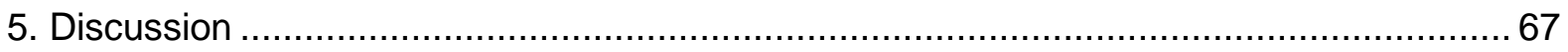

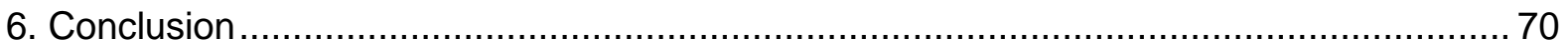

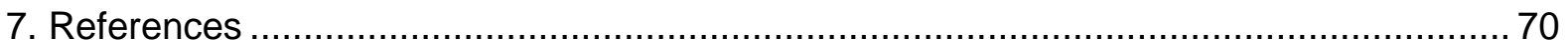

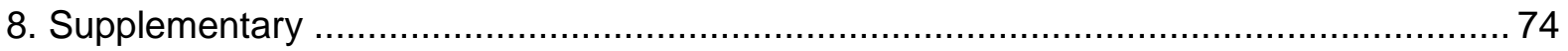

Chapter 4. Chemical composition and biological effects of volatiles released by heated henbane (Hyoscyamus niger) seeds used in folk medicine......................81

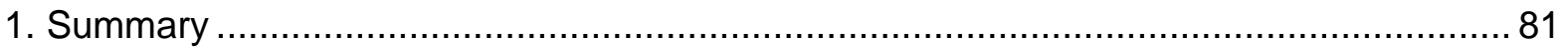

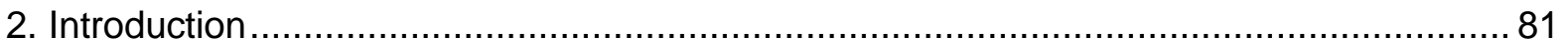

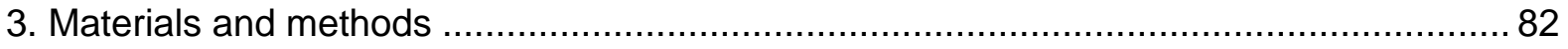

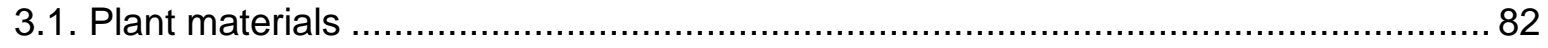

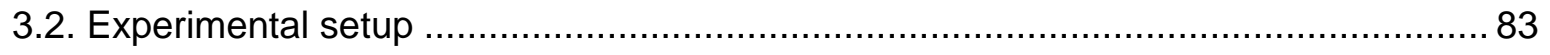

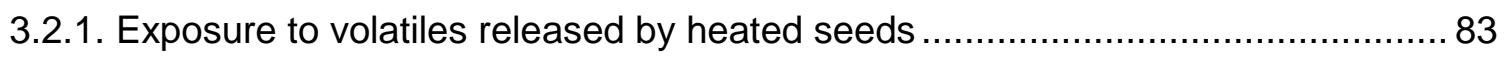

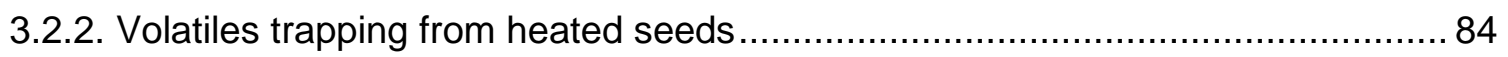

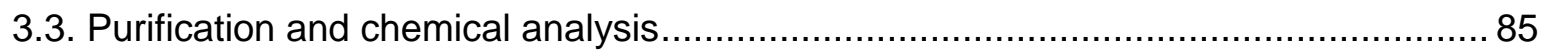

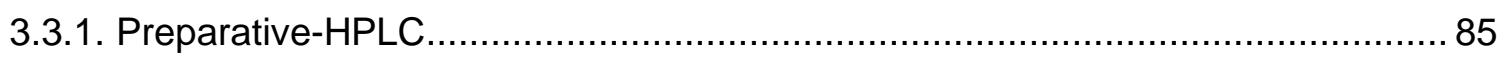

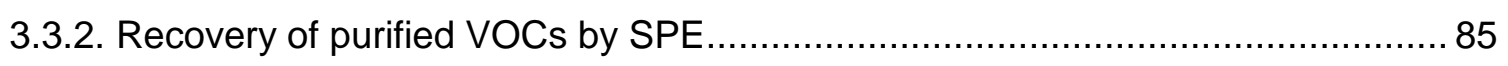

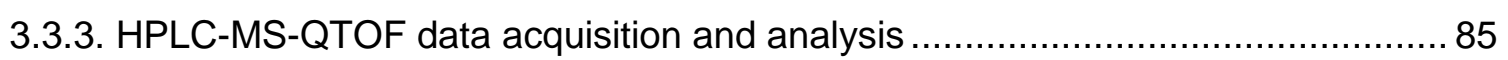

3.3.4. Nuclear Magnetic Resonance spectroscopy................................................. 86

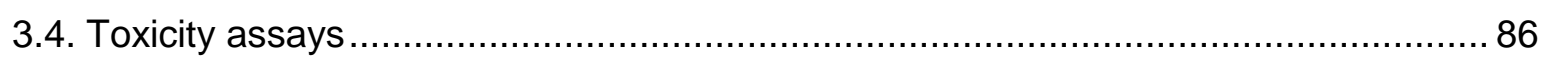

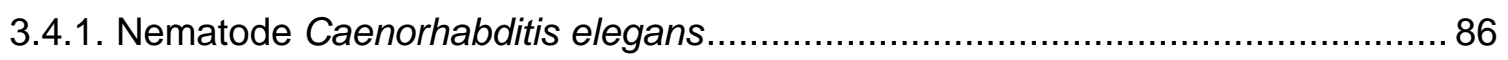

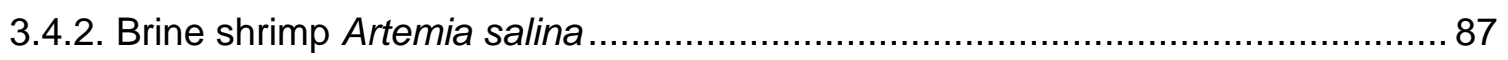

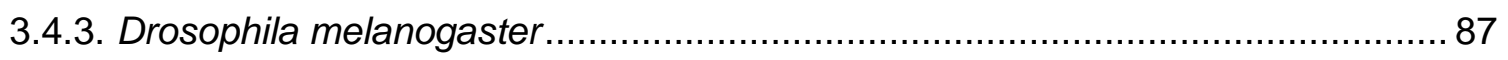

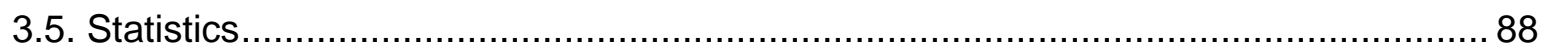

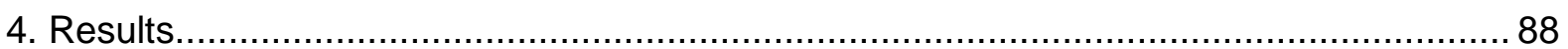

4.1. Ethnopharmacological uses of henbane in northern Iraq ..................................... 88

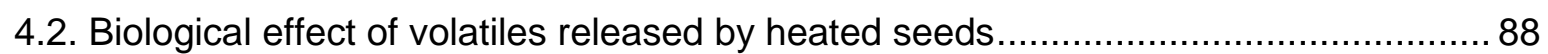

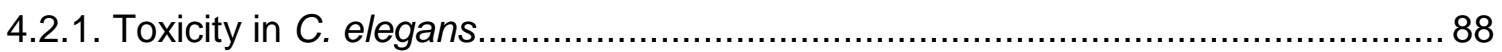

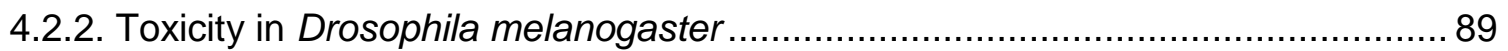

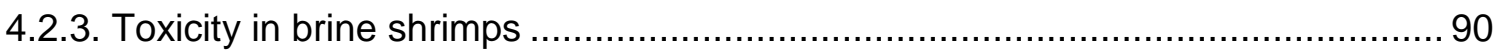

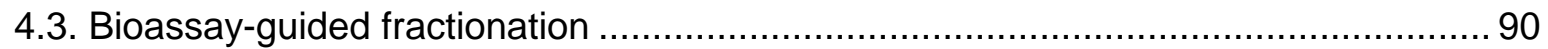

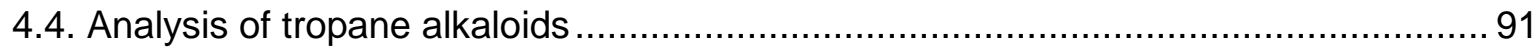

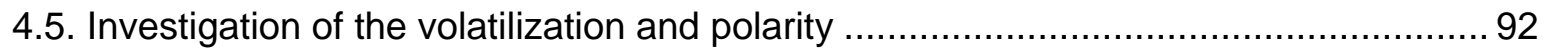

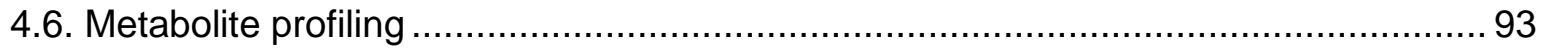


4.7. Purification and characterization of the potentially bioactive metabolites 94

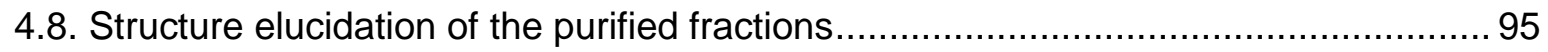

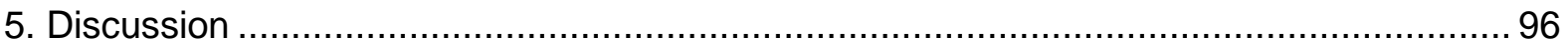

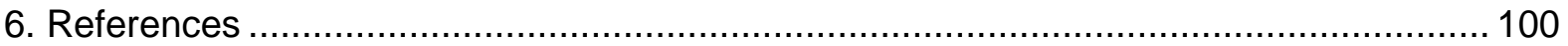

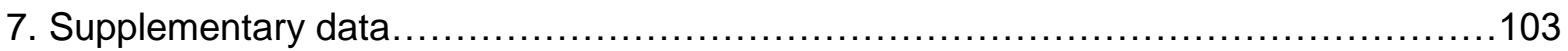

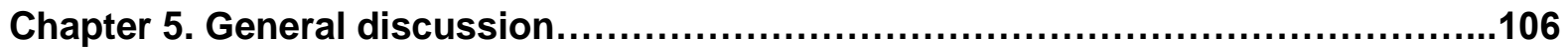

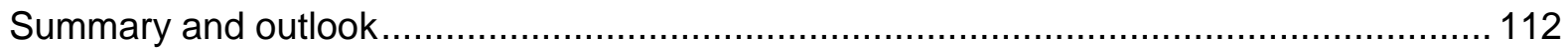

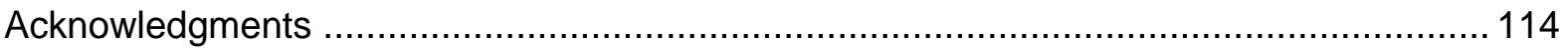

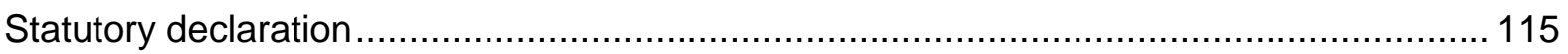




\section{Chapter 1. General introduction}

\section{Introduction to plant secondary metabolites}

Motility is the hallmark character of animals, it helps them to escape from external dangers, and the immune system provides them with a powerful defense strategy against pathogens. By contrast, plants are immobile and have no immune system. Alternatively, plants produce secondary metabolites as an efficient defense mechanism against biotic stresses (herbivores and pathogens), and they can play a crucial role in tolerating abiotic environmental stresses. Generally, secondary metabolites are compounds that are not required to maintain growth and reproduction in plants. They are not involved directly in many fundamental physiological processes such as photosynthesis, plant nutrition, and respiration, but they can contribute to the plant's survival in the ecosystem (Bartwal et al. 2013).

Plants can benefit from secondary metabolites in various ways. They include allelochemicals involved in interactions with microorganisms, herbivores, and other plants sharing the same ecological niche. Not only defense is essential, but many volatile secondary metabolites can also represent essential odor cues to pollinating insects (Hadacek 2002).

So far, more than 100,000 secondary metabolites have been characterized in plants, and their actual number can be significantly higher because only 20-30\% of the existing plant species have been studied to some extent. The most diverse groups of secondary metabolites are terpenoids and alkaloids, with a number of known structures exceeds 20000 compounds in each group (Wink 2010).

Apart from the direct benefits of secondary metabolites, they provide a significant source of lead structures for therapeutic agents to humankind. The prominent presence of plants in ethnobotany reflects this impressively. The vast diversity of plant secondary metabolites has enabled humans to develop an effective treatment for many health disorders. Few secondary metabolites, such as some alkaloids, target neurotransmitter receptors, whereas the majority of them act unspecifically, or their modes of action are still not fully understood (Wink 2015). 


\section{Major biosynthetic pathways}

Although the diversity of secondary metabolites is vast, their biosynthesis starts from a comparatively small number of precursors from primary metabolism, such as acetate, pyruvate, amino acids, intermediaries of the Calvin cycle, and end products of the shikimate pathway (Figure. 1) (Herbert 1989; Wink 2010). 


\section{A}

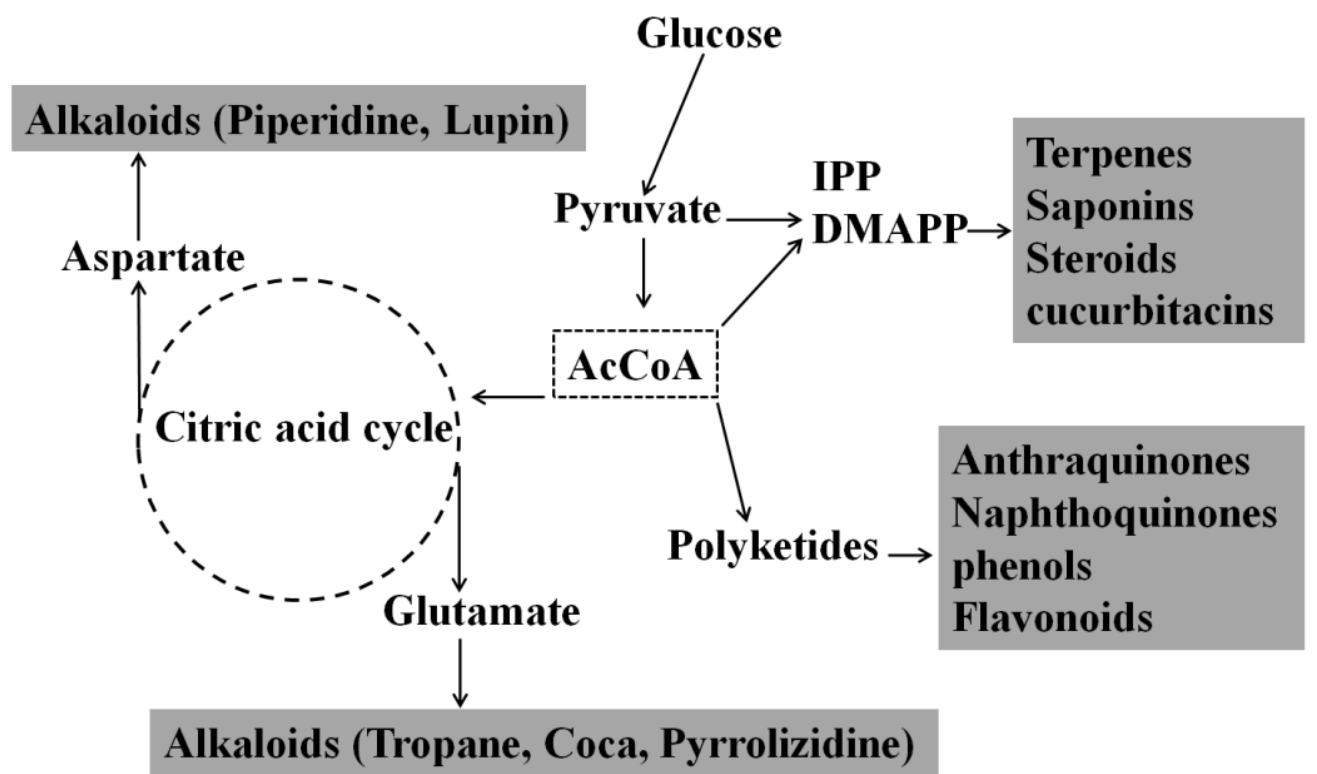

B

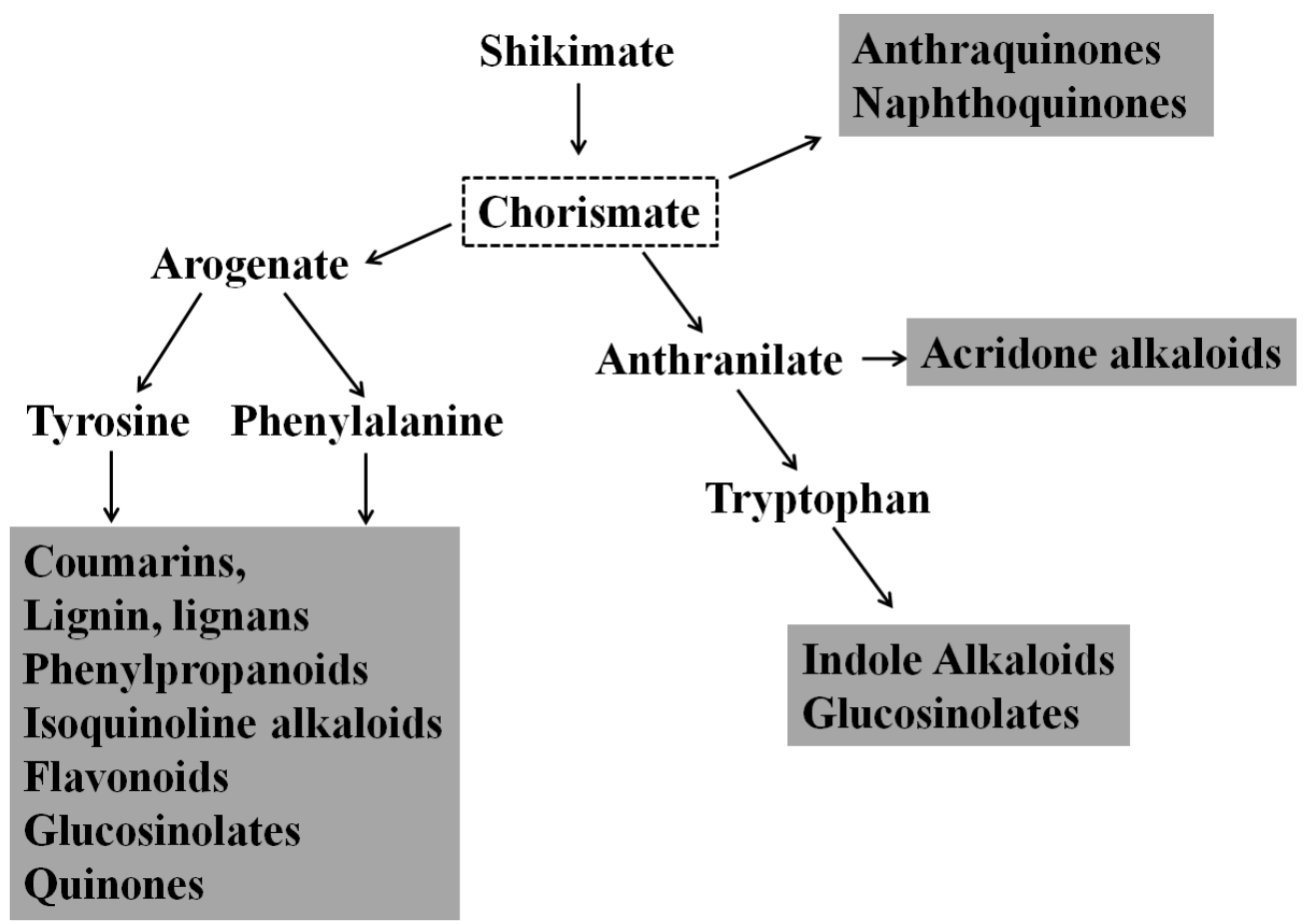

Figure 1. Biosynthesis pathways of major secondary metabolites groups (based on Wink 2010). Some steps are omitted for clarity. (A) Groups of secondary metabolites derived from glycolysis, acetyl-coenzyme A, and citric acid cycle, Abbreviations: IPP, isopentenyl diphosphate; DMAPP, dimethylallyl diphosphate. (B) Groups of secondary metabolites derived from the shikimate pathway. 


\section{Allelopathy}

The concept of allelopathy has changed during the existence of its term. It was applied to plant ecology in explaining the interference of the plants in their natural habitats. This interference occurs due to the release of chemical compounds into the environment, which inhibit the growth of the neighboring plants (Chou 2006; Muller 1969). The term "allelochemics" was firstly used about fifty years ago. It referred to the chemical interactions by which organisms of one species can affect the health, growth, and behavior of another species (Whittaker and Feeny 1971). Then, the term was changed to "allelochemical" by Chou and Waller (1983). The International Allelopathy Society considered the concept of allelopathy as "any process involving secondary metabolites produced by plants, algae, bacteria, and fungi that influences the growth and development of agriculture and biological systems" (Chou 2006).

Generally, higher plants can release organic compounds into the environment through volatilization, leaching from leaves, or being exuded from roots (Einhellig 1994). Zhu et al. (2016) opined that specific secondary metabolites, which might have a role in plant defense interference and invasion success, accumulate in the root under the influence of biological and chemical stimulation. More recently, the phenomenon of allelopathy has been linked to the success of some invasive weed species in colonizing new areas. The hypothesis supposed that the invasive species release allelochemicals to the environment as novel weapons to cope with the native species, which have not yet adapted to tolerate these compounds as efficiently as the invasive plants (Callaway and Aschehoug 2000). However, allelopathy is a multifaceted phenomenon in which several factors can be involved, such as environmental conditions and the interaction with untargeted microorganisms, amongst others (Hadacek 2002).

In classical phytochemical studies, allelochemicals have been extracted with organic solvents. Artificial extraction methods can lead to various types and quantities of secondary metabolites that can differ from those released naturally in the field. However, even if phytotoxins or antimicrobials are extracted from plant organs, that does not infer automatically that those compounds will be constituents of leaf leachates or root exudates (Cantor et al. 2011; Lorenzo et al. 2011; E.L. Rice 1984; Song et al. 2018). The leaching phenomenon was defined as the removal of metabolites from plant foliage by aqueous solutions, including rain, dew, fog, and mist (Tukey 1970). Rice $(1979 ; 1984)$ has reviewed several studies in which allelochemicals were detected in the leachate of living plants and plant residues and were explored in terms of their phytotoxic effects. The investigation of rain leachate is a reliable ecological approach for studying allelopathy because it resembles natural field conditions (Lorenzo et al. 2011). 
Recently, Song et al. (2018) collected rain leachates from living plants to identify and quantify the allelochemicals using GC-MS, as well as to assess their phytotoxicity.

Soil acts as a medium for the diffusion of allelochemicals. Exuded or leached chemicals can affect not only the germination of seeds and plant health in general but also impact soil microorganisms and other processes in soil, such as nitrogen fixation, mineralization, amongst others (Lalljee and Facknath 2000). Conversely, microorganisms have an exceptional ability to convert and detoxify plant-derived secondary metabolites or even utilize them as carbon sources (Vokou et al. 2006). Zackrisson and Nilsson (1992) showed that microorganisms could detoxify allelochemicals even under environmental conditions. Phytotoxic extracts passed through living soil were detoxified, while sterilization of soil caused this effect to disappear. In contrast to these findings, transformation products of allelochemicals via microorganisms have been proven as strong allelochemicals with the potential to intensify the activity of the original compounds (Ambika 2013).

Consequently, the interaction between soil microorganisms and the released secondary metabolites cannot be neglected when studying allelopathy. In this context, Lou et al. (2016) explored the interaction between soil microorganisms and cover crop-derived allelochemicals and their effect on weed germination. The study showed that microorganisms could directly suppress weed germination and growth but can also indirectly support weed development by degrading allelochemicals derived from cover crops.

\section{Interaction with herbivores}

In the earlier research, the mechanism of plant defense against herbivores was associated mainly with the activity of secondary metabolites. However, more recent studies suggest that the role of secondary metabolites probably had been exaggerated in the earlier studies. Nevertheless, there are still strong proofs to support the hypothesis of the essential role of secondary metabolites in defense against herbivores (Agrawal and Weber 2015). Herbivores are confronted by a wide range of toxic secondary metabolites, which can strongly affect their fundamental physiological processes and decrease diet digestibility (Howe and Jander 2008). The toxic secondary metabolites are stored in the vacuoles or excreted to the apoplast (Sirikantaramas et al. 2007).

Furthermore, secondary metabolites can accumulate in different specialized plant tissues, such as trichomes, glands, latex tubes, and special cells. Still, some herbivores have developed a 
particular feeding strategy to avoid these toxic tissues (see review by Städler 1992). Many insect herbivores tolerate the plant's toxic metabolites through a toxins sequestration strategy. These herbivores can accumulate the toxins in particular tissues using specific transporters and reuse them to defend themselves. Moreover, some herbivores have enzymes to increase the activity of sequestered toxins (Erb and Robert 2016).

On the other hand, plants can positively affect the third trophic level by releasing signals to attract the natural enemies of the herbivores. They can also provide these enemies with refuge or a supportive diet such as nectar and pollen (Rahier and Pasteels 1992).

\section{Interaction with pathogens}

The first studies that documented the role of plant metabolites in defense against pathogenic microorganisms appeared in the 1940s (Bailey and Mansfield 1982; Städler 1992). A considerable number of studies proved the antibacterial and antifungal activities of a plant secondary metabolites have been published. Despite the enormous number of metabolites, which have been reported in vitro as active compounds against pathogens, it is usually difficult to confirm their assumed role in vivo (Bednarek et al. 2009). Phytoalexins are among the apparent evidence for a defensive role of secondary metabolites in the interaction with pathogens. They are antimicrobial plant secondary metabolites, which are synthesized and accumulate quickly after inoculation with the pathogen (Paxton 1981). Camalexin is an indole alkaloid, and it has been confirmed as phytoalexin in Arabidopsis (Tsuji et al. 1992).

\section{Pharmaceutical properties of secondary plant metabolites}

Plants have provided therapeutic agents to humankind since ancient times. In fact, the oldest records for the use of plants in medicine probably date back to the Sumerians, the earliest civilization of Mesopotamia. Numerous prescriptions that include medicinal plants such as thyme, willow, and Prosopis are described on Sumerian clay tablets (ca. 2200 B.C.) (Kramer 1971). However, the origin of folk medicine is probably far beyond written history. In an interesting study of the ancient DNA from the dental calculus of 43,000 years old Neanderthal fossils, Weyrich et al. (2017) proposed that the Neanderthal used poplar tree (source of the natural painkiller salicylic acid) and Penicillium rubens (natural antibiotic) as a medicinal 
treatment. This study supports the previous suggestions of Hardy et al. (2012) about selfmedication in Neanderthals.

The medicinal plants have been used in folk medicine mainly in the form of alcoholic or water extracts against a broad spectrum of health problems. Those extracts may include hundreds of active secondary metabolites, and their activity originated mainly from the synergistic effect, and when purifying, these metabolites lose the effectiveness of the crude extract (Wink 2015). In seeking to develop new drugs, pharmaceutical research companies have primarily depended on the synthetic compounds libraries during the last decades. Despite that, natural products continue to play a vital role in the drug market. However, with a reduction in the number of new drugs becoming registered, the scientific interest in natural products has increased again (Atanasov et al. 2015). Of the total low-molecular-weight drugs that have been approved between 1981 and 2014, the pure synthetic drugs represented $35 \%$ only. On the other hand, natural products and their derivatives represented $33 \%$ and the drugs, which mimic natural products, represented $27 \%$ (Newman and Cragg 2016).

\section{Aim of study}

I. To investigate the allelopathic properties of the water extracts of selected plant species.

II. To purify and characterize the phytotoxic and cytotoxic secondary metabolites.

III. To study the release of the active secondary metabolites into the environment through the leaching from living plants via rainfall and root exudate.

IV. To investigate the ecological role of the active secondary metabolites by studying their effect on soil microbiota and invertebrates.

V. To investigate the biomedical activities of selected medicinal plant species and to purify and characterize their potentially active secondary metabolites.

\section{References}

Agrawal, Anurag A., and Marjorie G. Weber. 2015. "On the study of plant defence and erbivory sing comparative approaches: How Important Are Secondary Plant Compounds.” Edited by Christoph Scherber. Ecology Letters 18 (10): 985-91. https://doi.org/10.1111/ele.12482.

Ambika, S. R. 2013. "Multifaceted attributes of allelochemicals and mechanism of allelopathy." In Allelopathy: Current Trends and Future Applications, edited by Zahid A1. Cheema, Muhammad Farooq, and Abdul Wahid, 389-405. Berlin, Heidelberg: Springer Berlin Heidelberg. https://doi.org/10.1007/978-3-642-30595-5_16. 
Atanasov, Atanas G., Birgit Waltenberger, Eva-Maria Pferschy-Wenzig, Thomas Linder, Christoph Wawrosch, Pavel Uhrin, Veronika Temml, et al. 2015. "Discovery and resupply of pharmacologically active plant-derived natural products: A Review." Biotechnology Advances 33 (8): 1582-1614. https://doi.org/10.1016/j.biotechadv.2015.08.001.

Bailey, John A, and Mansfield John W. 1982. Phytoalexins. 1St Edition edition. Glasgow: Halsted/Wiley.

Bartwal, Arti, Rakesh Mall, Pushpa Lohani, S. K. Guru, and Sandeep Arora. 2013. "Role of secondary metabolites and brassinosteroids in plant defense against environmental stresses." Journal of Plant Growth Regulation 32 (1): 216-32. https://doi.org/10.1007/s00344-0129272-X.

Bednarek, P., M. Pislewska-Bednarek, A. Svatos, B. Schneider, J. Doubsky, M. Mansurova, M. Humphry, et al. 2009. "A glucosinolate metabolism pathway in living plant cells mmediates broad-spectrum antifungal defense." Science 323 (5910): 101-6. https://doi.org/10.1126/science.1163732.

Callaway, Ragan M., and Erik T. Aschehoug. 2000. "Invasive plants versus their new and old neighbors: A mechanism for exotic invasion." Science 290 (5491): 521-23. https://doi.org/10.1126/science.290.5491.521.

Cantor, Aaron, Alison Hale, Justin Aaron, M. Brian Traw, and Susan Kalisz. 2011. "Low allelochemical concentrations detected in Garlic mustard-invaded forest soils inhibit fungal growth and AMF spore germination.” Biological Invasions 13 (12): 3015-25. https://doi.org/10.1007/s10530-011-9986-x.

Chou, Chang-Hung. 2006. "Introduction to allelopathy." In Allelopathy: A Physiological Process with Ecological Implications, edited by Manuel J. Reigosa, Nuria Pedrol, and Luís González, 1-9. Dordrecht: Springer Netherlands. https://doi.org/10.1007/1-4020-4280-9_1.

Einhellig, Frank A. 1994. "Allelopathy: Current status and future goals." In Allelopathy, edited by Inderjit, K. M. M. Dakshini, and Frank A. Einhellig, 582:1-24. Washington, DC: American Chemical Society. https://doi.org/10.1021/bk-1995-0582.ch001.

Erb, Matthias, and Christelle AM Robert. 2016. "Sequestration of plant secondary metabolites by insect herbivores: Molecular mechanisms and ecological consequences." Current Opinion in Insect Science 14 (April): 8-11. https://doi.org/10.1016/j.cois.2015.11.005.

Hadacek, Franz. 2002. "Secondary metabolites as plant traits: Current assessment and future perspectives." Critical Reviews in Plant Sciences 21 (4): 273-322. https://doi.org/10.1080/0735-260291044269.

Hardy, Karen, Stephen Buckley, Matthew Collins, Almudena Estalrrich, Don Brothwell, Les Copeland, Antonio Garcia-Tabernero, et al. 2012. Neanderthal medics? Evidence for food, cooking, and medicinal plants entrapped in dental calculus. Naturwissenschaften Vol. 99. https://doi.org/10.1007/s00114-012-0942-0.

Herbert, R. B. 1989. The Biosynthesis of Secondary Metabolites. 2nd ed. Springer Netherlands. https://www.springer.com/de/book/9780412277207.

Howe, Gregg A., and Georg Jander. 2008. "Plant immunity to insect herbivores." Annual Review of Plant Biology 59 (1): 41-66. https://doi.org/10.1146/annurev.arplant.59.032607.092825.

Kramer, Samuel Noah. 1971. The Sumerians: Their History, Culture, and Character. Revised ed. edition. Chicago: University of Chicago Press.

Lalljee, B, and S Facknath. 2000. "Allelopathic interactions in soil." In Allelopathy in Ecological Agriculture and Forestry, 47-58. Springer Netherlands. https://www.springer.com/gp/book/9780792363484.

Lorenzo, Paula, Ana Palomera-Pérez, Manuel J. Reigosa, and Luís González. 2011. “Allelopathic interference of invasive Acacia dealbata link on the physiological parameters of native understory species." Plant Ecology 212 (3): 403-12. https://doi.org/10.1007/s11258-0109831-9.

Lou, Yi, Adam S. Davis, and Anthony C. Yannarell. 2016. "Interactions between allelochemicals and the microbial community affect weed suppression following cover crop residue incorporation into soil." Plant and Soil 399 (1): 357-71. https://doi.org/10.1007/s11104-015-2698-8.

Muller, Cornelius H. 1969. "Allelopathy as a factor in ecological process." Vegetatio 18 (1): 348-57. https://doi.org/10.1007/BF00332847. 
Newman, David J., and Gordon M. Cragg. 2016. "Natural products as sources of new drugs from 1981 to 2014." Journal of Natural Products 79 (3): 629-61. https://doi.org/10.1021/acs.jnatprod.5b01055.

Paxton, J. D. 1981. "Phytoalexins - A Working Redefinition." Journal of Phytopathology 101 (2): 106-9. https://doi.org/10.1111/j.1439-0434.1981.tb03327.x.

Rahier, Martine, and Jacques Pasteels. 1992. "Third trophic level influences of plant allelochemicals." In HERBIVORES Their Interactions with Secondary Plant Metabolites. Vol. 2. academic press, INC. https://doi.org/10.1016/B978-0-08-092545-5.50011-0.

Rice, E.L. 1984. Allelopathy. Physiological Ecology. Academic Press. https://books.google.de/books?id=0WKA6fxeXpwC.

Rice, Elroy L. 1979. “Allelopathy-An Update.” The Botanical Review 45 (1): 15-109. https://doi.org/10.1007/BF02869951.

Sirikantaramas, Supaart, Mami Yamazaki, and Kazuki Saito. 2007. "Mechanisms of resistance to selfproduced toxic secondary metabolites in plants." Phytochemistry Reviews 7 (3): 467. https://doi.org/10.1007/s11101-007-9080-2.

Song, Qingmei, Fangcuo Qin, He He, Hecong Wang, and Shixiao Yu. 2018. "Allelopathic potential of rain leachates from Eucalyptus urophylla on four tree species." Agroforestry Systems, May. https://doi.org/10.1007/s10457-018-0240-8.

Städler, Erich. 1992. "Chapter 2 - Behavioral responses of insects to plant secondary compounds." In Herbivores: Their Interactions with Secondary Plant Metabolites (Second Edition), edited by Gerald A. Rosenthal and May R. Berenbaum, 45-88. San Diego: Academic Press. https://doi.org/10.1016/B978-0-08-092545-5.50007-9.

Tsuji, J., E. P. Jackson, D. A. Gage, R. Hammerschmidt, and S. C. Somerville. 1992. "Phytoalexin accumulation in Arabidopsis thaliana during the hypersensitive reaction to Pseudomonas syringae Pv syringae." Plant Physiology 98 (4): 1304-9. https://doi.org/10.1104/pp.98.4.1304.

Vokou, D., D. Chalkos, and K. Karamanoli. 2006. "Microorganisms and allelopathy: A One-sided approach." In Allelopathy: A Physiological Process with Ecological Implications, edited by Manuel J. Reigosa, Nuria Pedrol, and Luís González, 341-71. Dordrecht: Springer Netherlands. https://doi.org/10.1007/1-4020-4280-9_15.

Weyrich, Laura S., Sebastian Duchene, Julien Soubrier, Luis Arriola, Bastien Llamas, James Breen, Alan G. Morris, et al. 2017. "Neanderthal behaviour, diet, and disease inferred from ancient DNA in dental calculus." Nature 544 (March): 357. https://doi.org/10.1038/nature21674.

Whittaker, R. H., and P. P. Feeny. 1971. "Allelochemics: Chemical interactions between species." Science 171 (3973): 757-70. https://www.jstor.org/stable/1730763.

Wink, Michael. 2010. "Introduction: Biochemistry, physiology and ecological functions of secondary metabolites." In Biochemistry of Plant Secondary Metabolism, edited by Michael Wink, 119. Oxford, UK: Wiley-Blackwell. https://doi.org/10.1002/9781444320503.ch1.

Wink, M. 2015. "Modes of action of erbal medicines and plant secondary metabolites." Medicines 2 (3): 251-86. https://doi.org/10.3390/medicines2030251.

Zackrisson, O, and M.C. Nilsson. 1992. "Allelopathic effects by Empetrum hermaphroditum on seed germination of two boreal tree species - Canadian Journal of Forest Research." http://www.nrcresearchpress.com/doi/abs/10.1139/x92-174\#.XHB0N-hKiUl.

Zhu, Xiaocheng, Dominik Skoneczny, Jeffrey D. Weidenhamer, James M. Mwendwa, Paul A. Weston, Geoff M. Gurr, Ragan M. Callaway, and Leslie A. Weston. 2016. "Identification and localization of bioactive aphthoquinones in the roots and rhizosphere of paterson's curse (Echium plantagineum), a noxious invader." Journal of Experimental Botany 67 (12): 377788. https://doi.org/10.1093/jxb/erw182. 


\title{
Chapter 2. The biological properties of secondary metabolites in root exudates of Galanthus nivalis and their impact on the rhizosphere microorganisms
}

\author{
Mohammad Alhussein ${ }^{1}$, Lukas Beule ${ }^{1}$, Hartmut Laatsch², Albatol Alsarrag ${ }^{1}$, Franz Hadacek ${ }^{3}$, \\ Petr Karlovsky ${ }^{1}$ \\ ${ }^{1}$ Molecular Phytopathology and Mycotoxin Research, University of Göttingen, Göttingen, Germany, \\ ${ }^{2}$ Department of Organic Chemistry, University of Göttingen, Göttingen, Germany, ${ }^{3}$ Department of Plant \\ Biochemistry, Albrecht-von-Haller-Institute for Plant Sciences, University of Göttingen, Göttingen, Germany.
}

\section{Summary}

Secondary metabolites in the bulbs of G. nivalis and metabolites secreted by the bulbs and roots into the soil are characterized. Amaryllidaceae alkaloids secreted into soil strongly affect gram-negative soil bacteria, as shown by the quantification of major groups of soil bacteria by taxon-specific real-time PCR and by sequencing amplified bacterial rRNA genes extracted from soil treated with the dominant secreted metabolite. Non-secreted bulb metabolites do not affect bacteria and fungi but are toxic to invertebrates, which suggests that they may confer to protection against soil-dwelling herbivores.

Key message: Bulbs and roots of G. nivalis produce two groups of alkaloids. The first group is retained within the tissue, while the second is secreted to the soil. Our results indicate that the metabolites retained in the tissue protect plants from herbivores, while the secreted metabolites affect soil microbes.

\section{Introduction}

The rhizosphere is the active boundary of the interactions between roots and soil microbes, other plants, and invertebrates. In this interaction, exuded or leached metabolites can confer protection against pathogens, competing plants, and herbivores. On the other hand, the exuded metabolites can also affect plant-symbiont associations and other processes in soil, such as nitrogen fixation, mineralization, amongst others, positively (Bais et al. 2006; Hirsch et al. 
2003; Lalljee and Facknath 2000). More studies recently reinforced the evidence that secondary metabolites of root exudates such as phenolic acids and coumarins can directly affect root-associated microbial community structure (Zhalnina et al. 2018; Lundberg and Teixeira 2018). In the same context, benzoxazinoids which are defense metabolites in root exudates of cereals, can play multiple ecological roles not only in shaping the rhizosphere microbiota but also in increasing plant defenses, reducing plant growth, and suppressing herbivorous in the next plant generation (L. Hu et al. 2018).

Galanthus nivalis L. (snowdrop) is a perennial herb that forms bulbs for survival. It inhabits a large area of Europe and the northeastern United States. Snowdrop has been used as a cure for neurological disorders since Greek time. By the end of the last century, the alkaloid galantamine was found out to constitute an effective treatment for early Alzheimer's disease (Donald and Barceloux 2008; Lee 1999). Plants of the genus Galanthus produce a considerable diversity of alkaloids. Berkov et al. (2012) have reviewed studies in which approximately 80 different alkaloids have been isolated from Galanthus using organic solvents as an extraction medium. However, the biological activity and pharmaceutical application potential of only a few of them have been explored until now.

Expert snowdrop gardeners know that snowdrop is almost pest- and disease-free (Slade 2014). The high diversity of bioactive secondary metabolites may contribute to this fact. Nevertheless, even if the plant tissues are rich in secondary metabolites, only those compounds that are released into the environment undergo interactions with another organism, either positive or negative (Li et al. 2010).

To our knowledge, no studies exist exploring the release of alkaloids in the root exudates of snowdrops. Thus, this study has the following objectives:

(1) To characterize the secondary metabolites in root exudates of snowdrop, as well as the water-soluble secondary metabolites in its bulbs.

(2) To investigate the effect of the exuded secondary metabolites and the metabolites retained within the bulbs tissue on soil microbiota, invertebrates, and competitor plants.

\section{Materials and methods}

\subsection{Plant materials}

Galanthus nivalis (Snowdrop) plants were collected from two different locations over three seasons. Location A is a private vegetable garden located in Goettingen, Germany (51 ${ }^{\circ} 34^{\prime}$ 
12.6696" N $9^{\circ}$ 55' 42.7116" E). In March 2016, approximately 500 plants were carefully uprooted by hand, by which the preliminary experiments have been achieved. In March 2018, 500 plants and rhizosphere samples were also collected from location A to confirm the results. Location B is a private garden located in Verl, Germany (51 52' 38.0" N 8 29' 26.3 "E). In March 2017, approximately 5000 plants were uprooted from this garden for extraction and purification purposes.

\subsection{Extraction}

The bulbs were rinsed with tap water. Several types of extracts were prepared: i) the root exudate, where the bulbs and roots of the whole plants were soaked in tap water, ii) the extract from the whole plant, where the entire intact plants were soaked in tap water, and iii) extraction by soaking separate plant parts (bulbs and leaves) in tap water. All extractions were performed for $12 \mathrm{~h}$ in the dark at $5^{\circ} \mathrm{C}$. Subsequently, the aqueous extract was filtrated through filter paper (Rotilabo ${ }^{\circledR}$ folded filters, type 113 p, Carl Roth GmbH, Karlsruhe, Germany). The filtrated extracts were partitioned with ethyl acetate (EtOAc) $(1: 1, \mathrm{v} / \mathrm{v})$ in $1 \mathrm{~L}$ separation funnels. The funnels were vigorously shaken and were kept under a fume hood in the dark for $2 \mathrm{~h}$. The EtOAc fraction was collected, and additional EtOAc was added to the water fraction to repeat the partition procedure.

The EtOAc fractions and the water fractions were concentrated to approximately $100 \mathrm{~mL}$ using a rotary evaporator R-100 (BÜCHI Inc., Flawil, Switzerland). The fractions were divided into pre-weighed $50 \mathrm{~mL}$ falcon tubes and were evaporated using a speed vacuum concentrator (RVC 2-25 CD plus, Christ, Osterode am Harz, Germany) at $28^{\circ} \mathrm{C}$, and their weights were determined.

\subsection{Purification and chemical analysis}

\subsubsection{Preparative-HPLC}

Preparative high-pressure liquid chromatography (HPLC) was applied to fractionate snowdrop extract with the highest phytotoxicity. The stationary phase was reversed-phase silica (Nucleodur C18 HTec, 5 m, 250 x 10mm, Macherey Nagel, Düren, Germany). A flow rate of

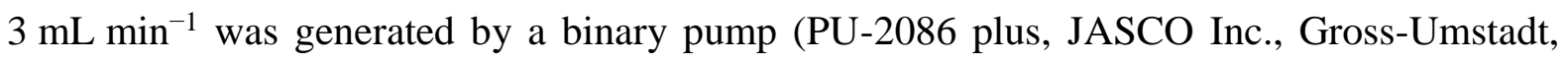
Germany). Solvent A consisted of water with $0.25 \%$ acetic acid (v/v) and B of methanol $(\mathrm{MeOH})$ with $0.25 \%$ acetic acid (v/v). The gradient was as follows: 0-10 min, $5 \% \mathrm{~B} ; 10-70$ $\min , 5 \%$ to $100 \% \mathrm{~B} ; 70-80 \mathrm{~min}, 100 \% \mathrm{~B} ; 80-90 \mathrm{~min}, 100 \%$ to $5 \% \mathrm{~B} ; 90-100 \mathrm{~min}, 5 \% \mathrm{~B}$. 
A UV/VIS detector (Jasco UV-970, JASCO Inc., Gross-Umstadt, Germany) was set to $290 \mathrm{~nm}$ as a detection wavelength. A fraction collector (CHF122SC, Advantec MFS Inc., Japan) was used to collect eluting peaks. Aliquots of $10 \mathrm{mg}$ extract were dissolved in $3 \mathrm{~mL} \mathrm{MeOH} / \mathrm{water}$ $(1: 1, \mathrm{v} / \mathrm{v})$ for repeated injection. The system was operated by the software JASCO ChromPass v. 1.8.6.1. The collected fractions were evaporated using a speed vacuum concentrator at 28 ${ }^{\circ} \mathrm{C}$ and stored at $-20{ }^{\circ} \mathrm{C}$ for further use. Fractions for bioassays were selected depending on the fractions' weight and the UV absorbance. The same preparative HPLC method was applied for purifying all compounds within this study.

\subsubsection{HPLC-MS-QTOF}

A high-performance liquid chromatography system coupled to a quadrupole time-of-flight mass detector (HPLC-MS-QTOF, Agilent, Darmstadt, Germany) was used for chemical analysis. The HPLC system based on Agilent 1290 Infinity II series equipment and consisted of a quaternary pump, an autosampler, a thermostatted column compartment, and a diode-array detector (DAD). The HPLC is coupled to a quadrupole time-of-flight high-resolution mass detector (Agilent 6545 LC/Q-TOF) with dual Jet Stream electrospray ionization (AJS ESI). Chromatographic separation was performed on a reversed-phase column (ZORBAX Eclipse plus C18, 50 x $2.1 \mathrm{~mm}, 1.8 \mu \mathrm{m}$, Agilent) supported with a guard column (ZORBAX Eclipse plus C18, $5 \times 2.1 \mathrm{~mm}, 1.8 \mu \mathrm{m}$, Agilent) and maintained at ambient temperature $35^{\circ} \mathrm{C}$. The mobile phase A was water, and $\mathrm{B}$ was $\mathrm{MeOH}$ to both $0.1 \%$ formic acid (v/v) was added. The gradient was as follows: initial condition $5 \%$ B, $10 \min 98 \%$ B, $12 \min 98 \%$ B, $13 \min 5 \%$ $\mathrm{B}, 16 \min 5 \% \mathrm{~B}$. The injection volume was $2 \mu \mathrm{L}$, and the flow rate $0.4 \mathrm{~mL}$. $\mathrm{min}^{-1}$. The measurement took place under both positive and negative ionization mode with full MS and MSMS scans. The system was operated by the software (Mass Hunter Workstation Software, LC/MS Data Acquisition for 6500 Series Q-TOF, Version B.08.00, Agilent). The results were analyzed by the software (Mass Hunter Workstation Software, Qualitative Analysis Navigator Version B.08.00, Agilent). The metabolites were identified tentatively by comparing the MS/MS and UV spectra with the known metabolites from the family Amaryllidaceae and the METLIN MS/MS metabolite database.

The target metabolites were quantified relatively using purified standards.

\subsubsection{Structure elucidation of isolated compounds by NMR}

The chemical structures of the purified compounds were determined by Prof. Dr. Hartmut Laatsch (Department of Organic Chemistry, University of Göttingen, Göttingen, Germany) 
The NMR spectra ( 1H, gCOSY, NOESY, TOCSY, gHMBCAD, and gHSQCAD.) were recorded on a Varian Inova (i600) $600 \mathrm{MHz}$; while the 13C spectrum was taken on a Varian Inova $500 \mathrm{MHz}$.

\subsection{Secondary metabolites extraction from the rhizosphere}

The soil was collected carefully by hand from the rhizosphere of the bulbs and roots using a fine brush. The soil was suspended in acetonitrile 1:3 (w/v). The samples were shaken at 220 rpm for $5 \mathrm{~h}$ and kept undisturbed for sedimentation by gravity for $1 \mathrm{~h}$. Subsequently, the supernatants were filtrated through filter paper (Rotilabo ${ }^{\circledR}$ folded filters, type $113 \mathrm{p}$, Carl Roth, Karlsruhe, Germany). The filtrate was transferred into $50 \mathrm{~mL}$ falcon tubes and centrifuged at 4,500 rpm for $15 \mathrm{~min}$. The supernatants were collected and merged in one fraction. The fraction was filtered by $200 \mu \mathrm{m}$ membrane filters (Sartorius, Goettingen, Germany) and was dried using a rotary evaporator R-100 (BÜCHI Inc., Flawil, Switzerland). The weight was determined, and the fraction was resuspended in $\mathrm{MeOH}$ and analyzed as described in section 2.3.2.

\subsection{Bioassays}

\subsubsection{Radish germination test}

A preliminary assessment of phytotoxicity was carried out for the extracts using a modified germination test as described by Wolf et al. (1984). Due to the low amounts of the extract, the test was downscaled and performed in 24-well plates instead of Petri dishes. Seeds of Raphanus sativus (radish) variety Saxa3 (Bruno Nebelung GmbH, Everswinkel, Germany) were purchased from a local store. Seeds were sterilized with $1 \%$ sodium hypochlorite solution (v/v) and washed with sterile deionized water. Following this, the seeds were placed under a sterile bench for drying. The fractions were dissolved in sterile tap water with $1 \%$ dimethyl sulfoxide $(\mathrm{DMSO})(\mathrm{v} / \mathrm{v})$ as a surfactant. A single seed was placed on a sterile filter paper disc $(\varnothing: 1 \mathrm{~cm})$ in each well of the 24 -well plate, and $125 \mu \mathrm{L}$ of the treatment solution was added. Two dilutions, 1000 and $200 \mu \mathrm{g} \mathrm{mL}^{-1}$ of the treatments (whole plant crude, whole plant EtOAc fraction, bulbs crude, bulbs EtOAc fraction, leaves and flowers crude) were tested. In each treatment, 12 seeds were used in four replicates. Sterile tap water with $1 \%$ dimethyl sulfoxide (DMSO) (v/v) served as a control. The plates were incubated in the dark at $25^{\circ} \mathrm{C}$ and randomly redistributed once a day. The germination rate was scored after three days of incubation.

The extract that showed the highest phytotoxicity at a dose of $200 \mu \mathrm{g} \mathrm{mL}^{-1}$ was fractionated using prep-HPLC, and the phytotoxicity of this extract and its purified fractions were tested in 
three dilutions per treatment 500, 250, $125 \mu \mathrm{g} \mathrm{mL} \mathrm{m}^{-1}$. In each treatment, 6 seeds were used in five replicates except for $500 \mu \mathrm{g} \mathrm{mL} \mathrm{L}^{-1}$, for which three replicates were used.

\subsubsection{Lemna minor bioassay.}

Lemna minor (common duckweed) plants were purchased from Aquarienpflanzen-Shop (Viersen, Germany). The plants were surface-sterilized by soaking them in $0.5 \%$ sodium hypochlorite solution (v/v) for $5 \mathrm{~min}$. Following this, the plants were washed vigorously with sterile tap water and transferred into glass Petri dishes (Ø: $20 \mathrm{~cm}$, height: $4 \mathrm{~cm}$ ) filled with Swedish standard Lemna growth medium (SIS), which was prepared as described (OECD Guideline, 2006), but without 3-(N-morpholino)propane sulfonic acid (MOPS) buffer. The plants were incubated for two weeks at $25^{\circ} \mathrm{C}$ with continuous fluorescent lighting before the test. The purified compounds were dissolved in SIS medium with $1 \%$ DMSO as an emulsifier $(\mathrm{v} / \mathrm{v})$.

Three dilutions $\left(100,20\right.$, and $\left.4 \mu \mathrm{g} \mathrm{mL}^{-1}\right)$ were prepared. One \% aqueous DMSO (v/v) served as control. $1 \mathrm{~mL}$ of solutions were transferred to glass vials $(\varnothing: 1 \mathrm{~cm}$, height: $3 \mathrm{~cm})$ in 8 replicates per treatment. Healthy L. minor colonies, composed of approximately 3 fronds, were incubated in each vial for 6 days at $25^{\circ} \mathrm{C}$ with continuous light. Photos were taken immediately after the treatment and at the end of the incubation period using a stereomicroscope equipped with a digital camera. Leaves area was determined employing ImageJ software (Rasband, 1997), and fronds number increase was recorded.

\subsubsection{Brine shrimp (Artemia salina) cytotoxicity bioassay.}

Brine shrimp bioassay was used as described by Molina-Salinas et al. (2006) with some modifications. A commercial mixture of salt and dry Artemia cysts (Artemio ${ }^{\circledR}$ Mix, JBL, Neuhofen, Germany) was purchased from a local shop. The assay was validated and optimized before use. Depending on the optimization results, $30 \mathrm{~g}$ of the shrimps salt nutrient mixture was dissolved in $1 \mathrm{~L}$ demineralized water in a separation funnel and incubated at $28{ }^{\circ} \mathrm{C}$ under $55 \mathrm{~W}$ light. Sufficient amounts of air were bubbled continuously through the solution. After $24 \mathrm{~h}$, the hatched nauplius larvae were collected at the bottom of the funnel. The purified compounds were dissolved first in DMSO and then diluted with filtrated shrimp nutrient solution to a final DMSO content of $2.5 \%(\mathrm{v} / \mathrm{v})$.

The experiment was performed in 96-well plates. In each well, $50 \mu \mathrm{L}$ of shrimp solution was placed containing approximately 30 naupliae. The number of dead naupliae was recorded before the application of the compound solution. In each well, $150 \mu \mathrm{L}$ of the compound 
solution was added. Seven concentrations were prepared in a 1:1 dilution series (from 1000 to $15 \mu \mathrm{g} \mathrm{mL} \mathrm{m}^{-1}$ with a constant DMSO content of $2.5 \%(\mathrm{v} / \mathrm{v})$. Five replicates from each concentration were prepared. Filtrated shrimps water with $2.5 \% \mathrm{DMSO}(\mathrm{v} / \mathrm{v})$ served as control. The plates were incubated at $28{ }^{\circ} \mathrm{C}$ under classic light $55 \mathrm{~W}$. The number of dead shrimps and total shrimp's number was recorded after $24 \mathrm{~h}$ of incubation to calculate the mortality rate.

\subsubsection{Antifungal bioassay.}

The assay was first validated with a serial dilution of the fungicide tebuconazole (SigmaAldrich Chemie GmbH, Steinheim, Germany) against the filamentous fungus Fusarium graminearum IFA 66. After the method was optimized, the antifungal activity of snowdrop bulbs EtOAc extract and the purified compounds were assessed. Potato dextrose broth (PDB) medium was inoculated with $F$. graminearum spores suspension to yield a final spore concentration of $10^{5}$ colony forming units $(\mathrm{CFU}) \mathrm{mL}^{-1}$. One hundred $\mu \mathrm{L}$ were placed in each well of a 96-well plate. The tested compounds were dissolved in water with $1 \%$ DMSO $(\mathrm{v} / \mathrm{v})$ and mixed with the inoculated medium to yield concentrations of 500, 250, 125, and 62.5 $\mu \mathrm{g} \mathrm{mL}^{-1}$. Water with $1 \%$ DMSO served as a negative control. Finally, each well contained 100 $\mu \mathrm{L}$. Ten replicates were prepared for each concentration. Tebuconazole $\left(5 \mu \mathrm{g} \mathrm{mL}^{-1}\right)$ served as a positive control. The plates were incubated at $20{ }^{\circ} \mathrm{C}$ in the dark for 4 days. The measurements were taken by recording the optical density (OD) through a spectrophotometer (Epoch, BioTek, U.S.A) at $450 \mathrm{~nm}$ each 12 to $16 \mathrm{~h}$ starting from 0 until $96 \mathrm{~h}$ after applying the compounds.

\subsubsection{Nematicidal bioassay.}

Nematicidal activities of the purified compounds were evaluated using the model nematodes Caenorhabditis elegans ( Ura et al. 2002) with some modifications. C. elegans and Escherichia coli OP50 were kindly provided by the Faculty of Forest Sciences and Forest Ecology of the University of Goettingen, Germany. C. elegans was sub-cultured onto freshly prepared nematode growth medium (NGM) that had been seeded E. coli OP50 weekly following recommended procedures (Stiernagle 2006). Ten adults of $C$. elegans were transferred to an NGM plate and were incubated at $18^{\circ} \mathrm{C}$ in the dark. After 3 days, age-synchronous nematodes dominated by growth stage L4 were obtainable. They were washed out by tap water onto a tissue paper that was placed in a glass funnel equipped with a valve. The funnel was filled with water, and 30 minutes later, the living nematodes passed through the tissue and aggregated in the bottom of the funnel. Afterward, the nematode pellet was collected in a $50 \mathrm{~mL}$ falcon tube. Water was added to the nematodes, and the nematodes were gently shaken to wash off 
remaining E. coli cells. Following this, the nematodes were kept to deposit by gravity. The nematodes pellet was collected and re-suspended in tap water to obtain a concentration of approximately 1000 nematodes $\mathrm{mL}^{-1}$. The purified compounds were dissolved in water with $1 \%$ DMSO (v/v). Fifty $\mu \mathrm{L}$ aliquots of nematodes suspension were transferred to microtiter 96well plates, and the number of dead nematodes was recorded. Afterward, $150 \mu \mathrm{L}$ of the compounds solutions were mixed with the nematodes in each well. Five concentrations of the compounds were prepared in 1:1 dilution series (from 200 to $12 \mu \mathrm{g} \mathrm{mL}^{-1}$ of the final nematodecompound mixture) with a constant DMSO content of $1 \%(\mathrm{v} / \mathrm{v})$. Water with $1 \%$ DMSO (v/v) served as control. The plates were incubated at $20^{\circ} \mathrm{C}$ in the dark. The mortality ratio of nematodes was calculated after $24 \mathrm{~h}$. Only stationary individuals that showed a bacillary shape were considered as dead.

\subsubsection{Feeding preference of mealworm}

Mealworm (Tenebrio molitor) was used to perform a food choice experiment on wheat flour amended with EtOAc fraction of water extract of snowdrop bulbs. One single three-month-old $(2.5 \pm 0.8 \mathrm{~mm})$ larva was used per replicate $(\mathrm{n}=20)$. The extract was dissolved in chloroform and mixed with wheat flour (summer wheat variety: Taifun) to obtain a final concentration of $500 \mu \mathrm{g} \mathrm{g}^{-1}$ flour. The mixture evaporated overnight under a fume hood to get rid of the chloroform. Wheat flour samples mixed with pure chloroform and treated in the same manner served as control. Portions of $100 \mathrm{mg}$ of wheat flour with and without extract were set on the opposite sides of the 20 Petri dishes $(135 \mathrm{~mm})$. A single larva was placed in the center of 20 Petri dishes and retained in the dark at room temperature for 6 days. At fixed intervals, the location of every single larva was recorded.

\subsubsection{Toxicity to Mealworm}

Wheat flour was mixed with the extract-chloroform solution to reach final concentrations of 1000, 500, $100 \mu \mathrm{g} \mathrm{g}^{-1}$ flour separately. The combinations evaporated overnight under a fume hood. Wheat flour samples amended with pure chloroform and dried in the same manner served as a control. Groups of five few-week-old mealworms were individually weighted and set to optically clear $9 \mathrm{~cm}$ petri dish amended with a portion of $500 \mathrm{mg}$ wheat flour $(\mathrm{n}=5)$ per concentration. Two weeks after the treatment at $25^{\circ} \mathrm{C}$ and darkness, the individual groups of mealworms re-weighted. 


\subsection{Impact of secondary metabolites on microorganisms in the soil}

\subsubsection{Applying secondary metabolites on soil}

Soil samples were collected from an organic vegetable garden that is described above in 2.1. The soil was collected from the upper $20-\mathrm{cm}$ top soil, well homogenized, and sieved at $2 \mathrm{~mm}$ to remove stones and plant debris. Soil characteristics were determined as described by Allen et al. (2015) (Table S1). The gravimetric water content was adjusted to 10\%. $2 \mathrm{~g}$ soil was placed in glass vials (height: $40 \mathrm{~mm}, \varnothing: 15 \mathrm{~mm}$ ). Two mixtures of the purified metabolites were prepared. The first mixture reflected the ratio of the major secondary metabolites in the bulbs extract. The second mixture mimicked the ratio of the major secondary metabolites in the root exudate. From the first mixture, $100 \mu \mathrm{g} \mathrm{g}^{-1}$ fresh soil (equivalent to $112 \mu \mathrm{g} \mathrm{g}^{-1}$ dry soil) were dissolved in $400 \mu \mathrm{L}$ water with $1 \%$ DMSO (v/v) and equally applied on the soil surface of each soil column. Three dilutions were prepared from the second mixture, 100, 50, $25 \mu \mathrm{g} \mathrm{g}^{-1}$ fresh soil (which were approximately equivalent to $112,56,28 \mu \mathrm{g} \mathrm{g}^{-1}$ dry soil). Tap water with $1 \%$ DMSO served as a control. Seven replicates from each treatment and the control were prepared. The soil columns were incubated at $20{ }^{\circ} \mathrm{C}$ in the dark. The columns were randomly redistributed once a day. After seven days of incubation, the samples were lyophilized for 48 h.

\subsubsection{DNA extraction from soil}

DNA from freeze-dried soil was extracted using a slightly modified protocol of Beule et al. (2017). Briefly, $50 \mathrm{mg}$ finely ground soil was suspending in $1 \mathrm{~mL} \mathrm{CTAB}$ with proteinase $\mathrm{K}$ and incubated at $42{ }^{\circ} \mathrm{C}$ and $65^{\circ} \mathrm{C}$ for $10 \mathrm{~min}$ each. Following incubation, a phenol purification with two subsequent chloroform-isoamylalcohol steps was performed. DNA was precipitated with polyethylene glycol, pelleted by centrifugation, and washed with ethanol twice before drying using vacuum centrifugation. Pellets were resuspended in $50 \mu \mathrm{L}$ TE buffer $(10 \mathrm{mM}$ Tris, $1 \mathrm{mM}$ EDTA, $\mathrm{pH}$ 8.0) and incubated at $42{ }^{\circ} \mathrm{C}$ for $2 \mathrm{~h}$ to facilitate the dissolution of the DNA. The quality and quantity of the extracted DNAs were evaluated on $0.8 \%(\mathrm{w} / \mathrm{v})$ agarose gels stained with ethidium bromide.

\subsubsection{Quantification of bacterial and fungal taxonomic groups in soil by real-time PCR}

Standard curves for the real-time PCR (qPCR) assays were generated in two replicates using 1:10 serial dilutions of spectrophotometrically quantified PCR products in $0.5 \mathrm{X}$ TE buffer. 
DNA from representatives of the different taxonomic groups (Table S2) was extracted using a CTAB protocol (Brandfass and Karlovsky 2008) and used for standard generation. To increase the accuracy of the quantification of the PCR products serving as standards, all products used for the quantification were reamplified from their specific bands excised from $1.7 \%(\mathrm{w} / \mathrm{v})$ agarose gels stained with ethidium bromide and purified using isopropanol precipitation with two $80 \%(\mathrm{v} / \mathrm{v})$ ethanol washing steps.

All qPCR reactions were carried out in a CFX384 Thermocycler (Biorad, Rüdigheim, Germany) in 384-well microplates. Amplification was performed with 1:50 dilutions of the DNA extracts in $4 \mu \mathrm{L}$ reaction volume containing $3 \mu \mathrm{L}$ mastermix (1X reaction buffer (Table $\mathrm{S} 3$ ); 2.0 or $2.5 \mathrm{mM}$ final $\mathrm{MgCl} 2$ concentration (Table S3); $100 \mu \mathrm{M}$ of each deoxyribonucleoside triphosphate (Bioline, Luckenwalde, Germany); $0.3 \mu \mathrm{M}$ of each primer (Table S2), $1 \mathrm{mg} / \mathrm{ml}$ bovine serum albumin; 0.03 u DNA Polymerase (Table S3)) and $1 \mu \mathrm{L}$ template DNA solution or double-distilled $\mathrm{H} 2 \mathrm{O}$ for negative controls. The PCR conditions are presented in Table S3. Specific melting curves were obtained by heating the samples to $95^{\circ} \mathrm{C}$ for $60 \mathrm{~s}$ and cooling to $55^{\circ} \mathrm{C}$ for $60 \mathrm{~s}$ followed by a temperature increase from $55^{\circ} \mathrm{C}$ to $95{ }^{\circ} \mathrm{C}$ by $0.5^{\circ} \mathrm{C}$ per cycle with continuous fluorescence measurement.

\subsubsection{Enumeration of soil bacteria communities by amplicon sequencing}

Soil DNA was amplified using primers specific for bacteria, and the amplicons were sequenced using Illumina Miseq platform (paired-ends, 2x $300 \mathrm{nt}$ ).

\subsection{Statistics}

The Kruskal-Wallis test with multiple comparison extensions was estimated using the 'kruskalmc'-function in the 'pgirmess' R-package v1.6.9 (Giraudoux et al. 2018). ANOVA, Tukey's HSD test were determined using 'aov'- and 'TukeyHSD'-function in the 'stats' Rpackage v3.4.3 in the R v 3.6.1 (R Core Team, 2019). Box plots and Time-response curves were visualized using JMP® (14.1.0), SAS Institute Inc. Dose-response curves were generated using a four-parameter logistic model in SigmaPlot 14.0 (Systat Software, San Jose, CA). 


\section{Results}

\subsection{Phytotoxicity of extracts from snowdrop}

Whole plants, leaves, and bulbs of snowdrops were extracted in water and partitioned into EtOAc. The phytotoxicity of the extracts to radish seeds was tested (Figure 1A). The EtOAc fraction of the bulb extract was the only one that caused total germination inhibition at the dose of $200 \mu \mathrm{g} \mathrm{mL} \mathrm{m}^{-1}$. Thus this extract was used for further investigation.

The EtOAc fraction of the bulbs was fractionated by preparative HPLC (Figure 2).

The whole extract, as well as fraction A (37-40 min), caused complete inhibition of radish germination at the dose of $250 \mu \mathrm{g} \mathrm{mL}^{-1}$ (Figure 1B), while fraction B (20-36 min and 41-65 min) caused approximately $40 \%$ inhibition at the same dose. Fraction A was selected for further investigations. 


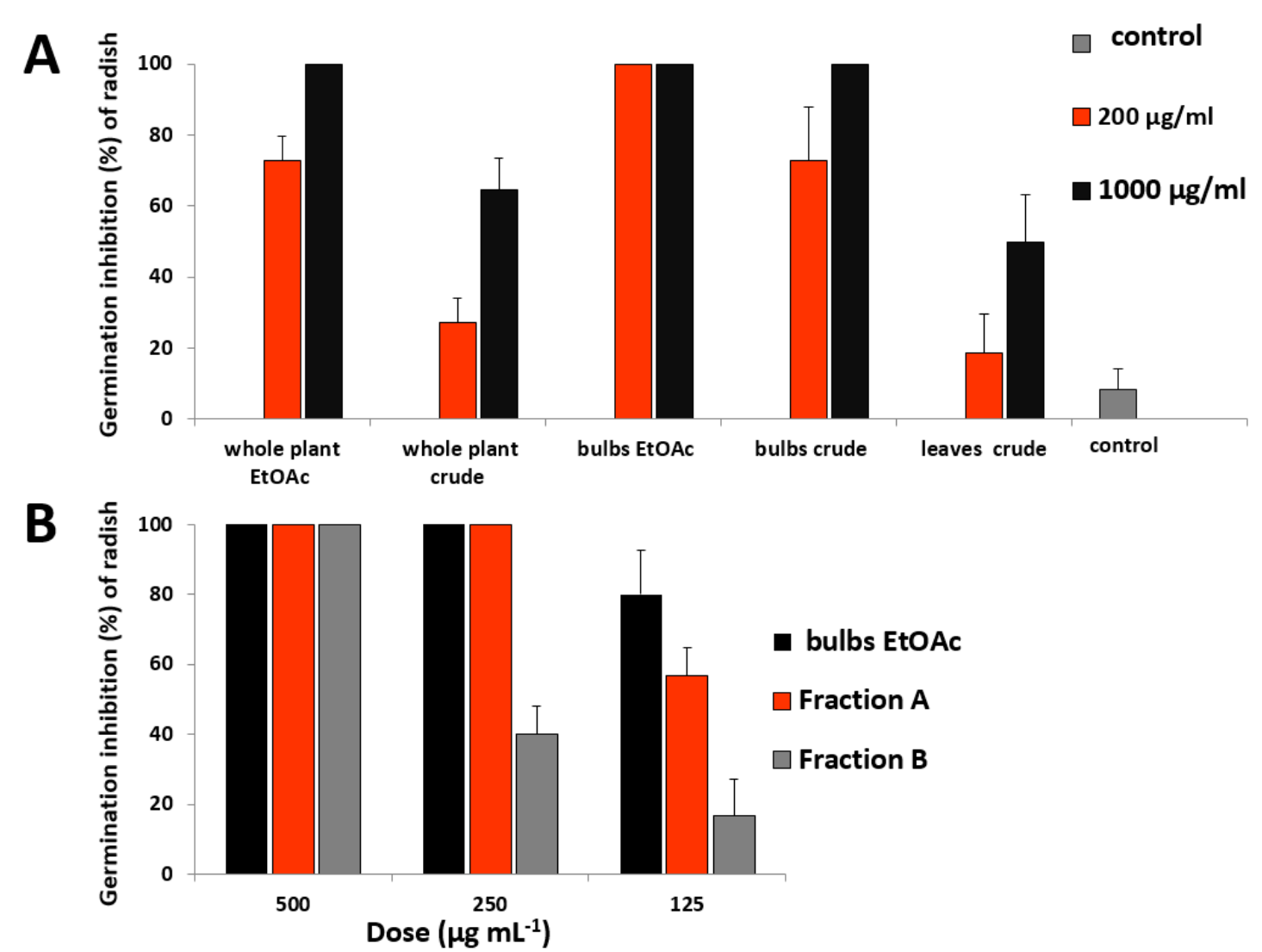

Figure 1. Effect of extracts from snowdrop on the germination of radish seeds. Fresh plant material was extracted with water (crude) and partitioned into EtOAc; dry extracts were redissolved in water with $1 \%$ DMSO (v/v). Water with $1 \%$ DMSO (v/v) served as control. The error bars represent the standard deviation $(n=4)(A)$. Effect of EtOAc fraction of the bulbs extract and its two fractions (A and B) on the germination of radish seeds. The error bars represent the standard deviation, $n=3-5(B)$.

\subsection{Purification and characterization of secondary metabolites from snowdrop bulbs}

Four compounds were purified using preparative HPLC from the EtOAc extract of the bulbs and the rhizosphere extract (Figure 2). The suggested sum formula for compound 1 according to the accurate mass was $\mathrm{C}_{18} \mathrm{H}_{21} \mathrm{NO}_{5}$ (table.1). The corresponding structure was determined by NMR as (3 $\alpha, 8 \beta)$-6a-deoxy-8-hydroxy-tazettine (pretazettine). Compound 2 was tentatively identified depending on its accurate mass, and MS/MS as 3,11-O-(3',3''dihydroxybutanoyl)hamayne (DHBH) (Table.1, Figure 2, Suppl. Figure. 1), and its structure was confirmed by NMR. Compound 3 was identified as lycoricidinol (LYCO) by its accurate mass, MS/MS fragmentation, and UV spectrum (Table 1, Figure 2, Suppl. Figure 1), and its structure was confirmed by NMR. Compound 4 was tentatively identified based on its accurate 
mass and MS/MS fragmentation as 3,11,3''-O-(3', 3', 3','-trihydroxybutanoyal) hamayne (THBH) (Table.1, Figure 2, Suppl. Figure. 1). Its structure was confirmed by NMR. Table 1 provides a summary of the four isolated alkaloids.

Table 1. HPLC-MS-QTOF analysis. Accurate mass and suggested formula

\begin{tabular}{|c|c|c|c|c|c|}
\hline ID & $\begin{array}{l}\text { Suggested } \\
\text { Formula }\end{array}$ & $\begin{array}{l}\text { Calc } \\
(\mathbf{M}+\mathbf{H})^{+}\end{array}$ & $\begin{array}{l}\text { Found } \\
(\mathbf{M}+\mathbf{H})^{+}\end{array}$ & Compound Name & abbr. \\
\hline 1 & $\mathrm{C} 18 \mathrm{H} 21 \mathrm{NO} 5$ & 332.1492 & 332.1497 & $\begin{array}{l}(3 \alpha, 8 \beta)-6 a-d e o x y-8 \text {-hydroxy- } \\
\text { tazettine }\end{array}$ & TAZ \\
\hline 2 & $\mathrm{C} 24 \mathrm{H} 29 \mathrm{NO} 8$ & 460.1966 & 460.1972 & $\begin{array}{l}\text { 3,11-O-(3',3',- } \\
\text { Dihydroxybutanoyl)hamayne }\end{array}$ & $\mathrm{DHBH}$ \\
\hline 3 & C14H13NO7 & 308,0765 & 308,0765 & Lycoricidinol & LYCO \\
\hline 4 & C28H35NO10 & 546.2334 & 546.2334 & $\begin{array}{l}\text { 3,11,3''-O-(3',3',3','- } \\
\text { Trihydroxybutanoyal)- } \\
\text { hamayne }\end{array}$ & THBH \\
\hline
\end{tabular}




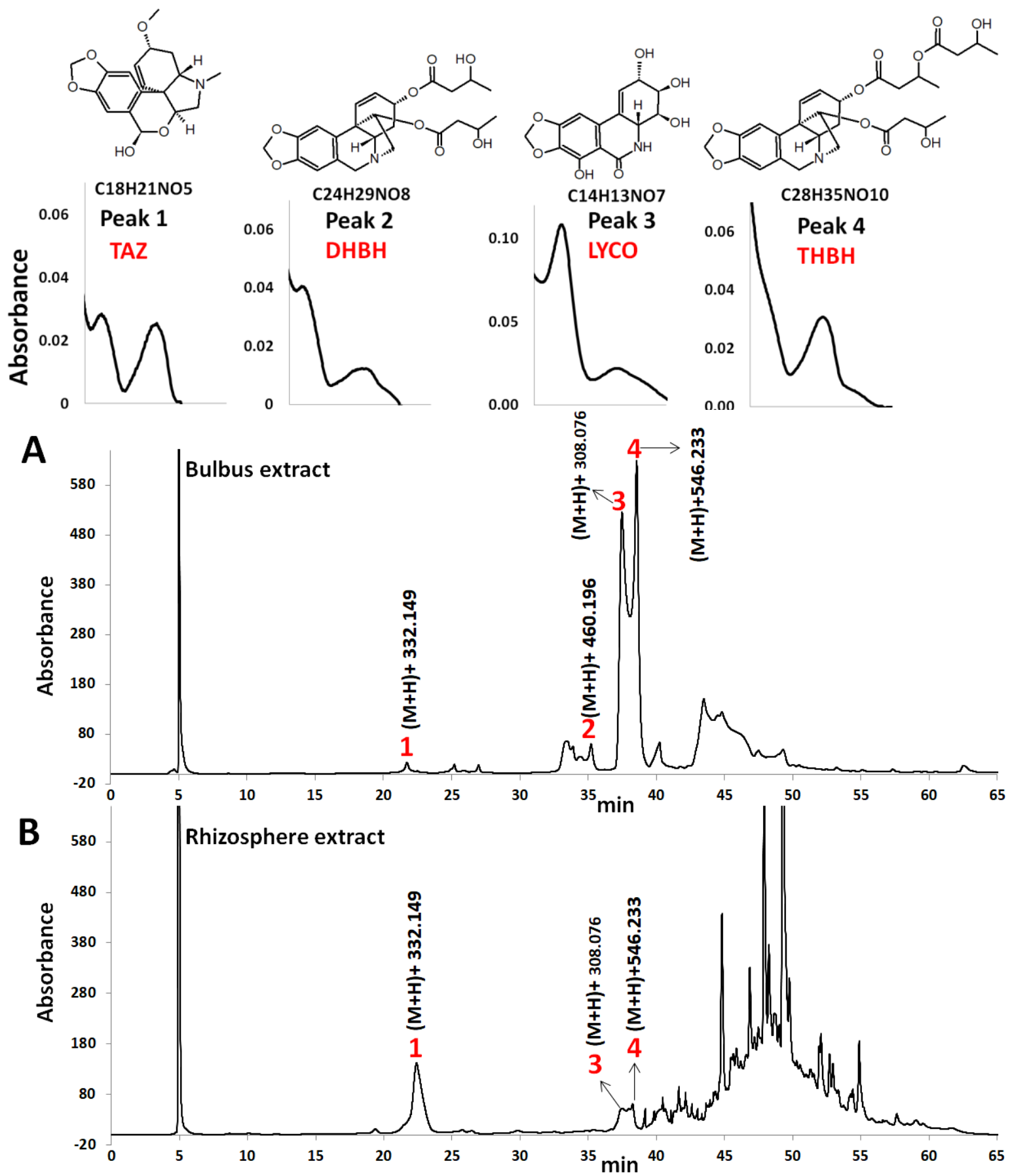

Figure 2. Preparative-HPLC chromatogram of bulbs EtOAc fraction (A) and

rhizosphere extract (B) with UV spectra and chemical properties of the purified compounds.

3,11,3''-O-(3', 3' ', 3','-Trihydroxybutanoyal) hamayne (THBH), 3, 11-O-(3', 3' '-

dihydroxybutanoyl) hamayne (DHBH), Lycoricidinol (LYCO), (3 $\alpha, 8 \beta)$-6a-deoxy-8-

hydroxy-tazettine (TAZ). Fraction A consisted of two compounds (LYCO and THBH). 


\subsection{Toxicity of THBH and LYCO}

Several biological properties of LYCO ( phytotoxic, antifungal, and insects antifeedant ) have been studied (Imaseki and G. Kang 1984; Nair and van Staden 2018; Numata et al. 1983), except for nematodes. At the same time, no information is available about the biological activities of THBH. Therefore, we subjected THBH to a series of toxicity assays and LYCO to a bioassay with the nematode $C$. elegans.

The phytotoxicity of THBH was tested on Lemna minor (Figure 3). The growth inhibition assay indicated strong phytotoxic effects at all tested dosages. Even the lowest dose of $4 \mu \mathrm{g} \mathrm{mL}^{-1}$ caused a significant growth reduction.

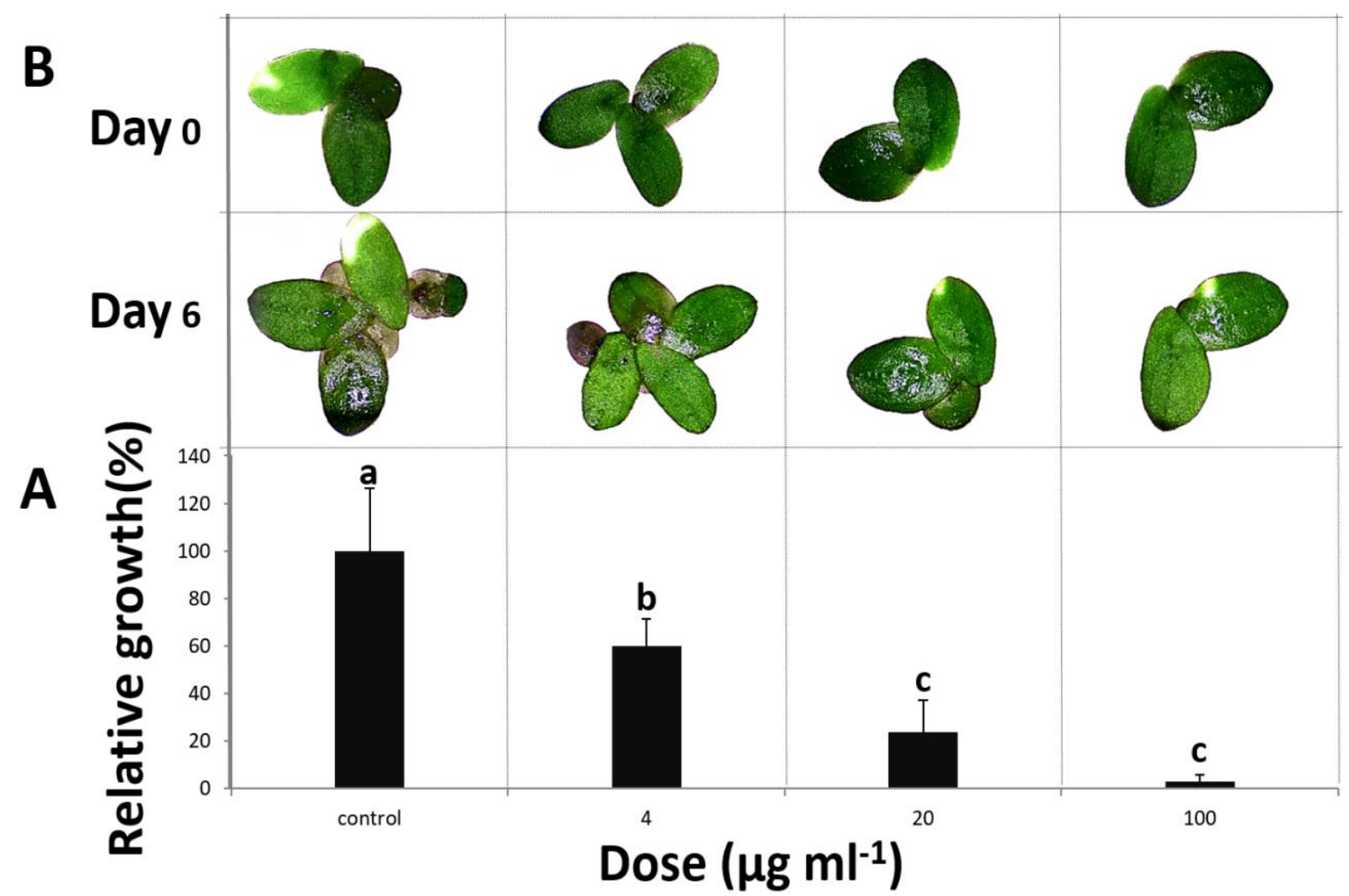

Figure 3. Effect of THBH on Lemna minor growth. Estimated by measuring leaf area 6 days after the treatment. The error bars represent the standard deviation, $\mathrm{n}=7-8$. One-way ANOVA and post-hoc 95\% Tukey, $p<0.05$ (A). Photos of selected samples show the differences in growth among the treatments at day 0 and day $6(\mathbf{B})$. 
In a brine shrimp assay, THBH showed a toxic effect with an $\mathrm{EC}_{50}$ value of $108 \mu \mathrm{g} \mathrm{mL}^{-1}$

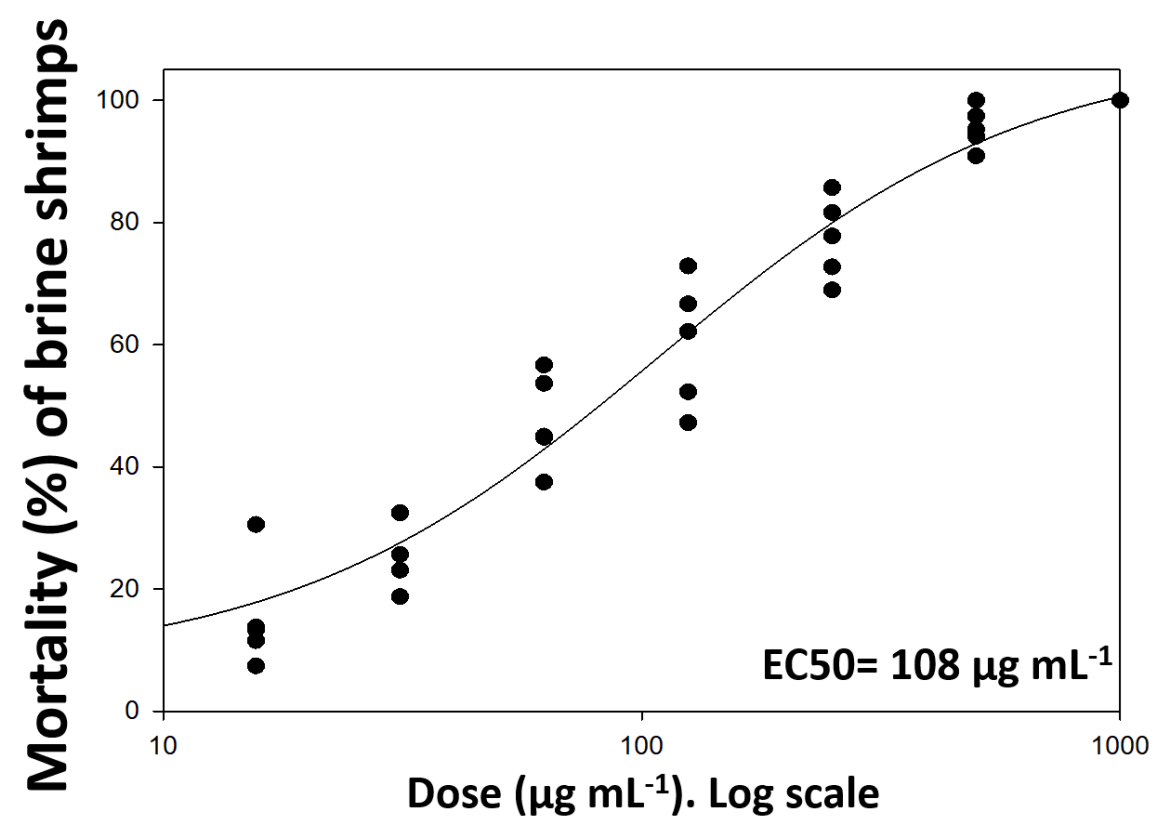

Figure 4. Dose-response curve illustrates the mortality of brine shrimps as a response to the treatment with various doses of THBH. Curve fitting of a non-linear regression using a four-parameter logistic model $(n=5)$. Black dots represent replicates at different concentrations.

The toxicity of THBH and LYCO in nematodes was tested on C. elegans (Figure 5). While LYCO caused a dose-dependent effect with significant mortality even at a dose of $25 \mu \mathrm{g} \mathrm{mL}-$ 1 , THBH was not toxic to the nematodes. 

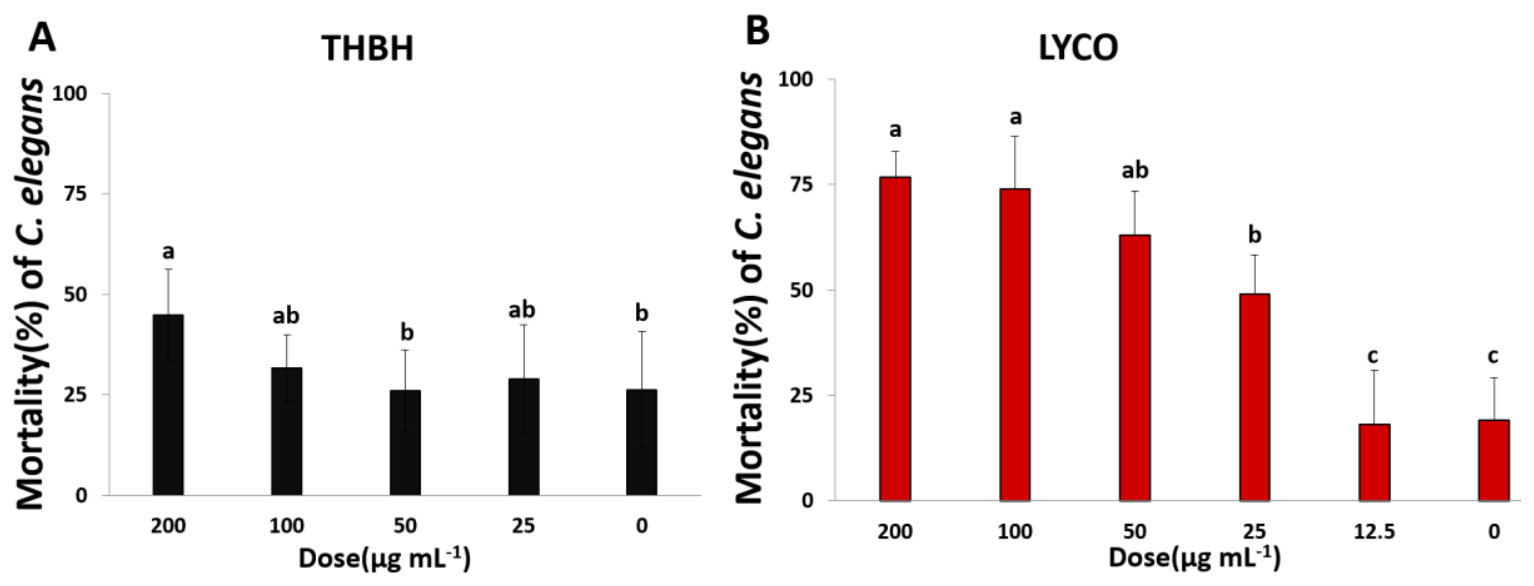

Figure 5. Nematicidal activity of THBH (A) and LYCO (B) in C. elegans (. The error bars represent the standard deviation, $\mathrm{n}=7-10$. One-way ANOVA and post-hoc 95\% Tukey, $\mathrm{p}<$ 0.05 .

Antifungal activity of THBH was tested on F. graminearum. The treatment showed no inhibitory effect at doses of 62 and $125 \mu \mathrm{g} \mathrm{mL}^{-1}$, while the doses 500 and $250 \mu \mathrm{g} \mathrm{mL}^{-1}$ barely slowed the growth of fungi (Figure 6).

The treatment with EtOAc fraction of bulbs extract showed a dose-dependent delay of F. graminearum growth. The dose $250 \mu \mathrm{g} \mathrm{mL}^{-1}$ inhibited the growth until $72 \mathrm{~h}$ after the treatment, while the dose of $500 \mu \mathrm{g} \mathrm{mL}^{-1}$ inhibited the growth completely until $96 \mathrm{~h}$ after the treatment (Suppl. Figure. 2) 


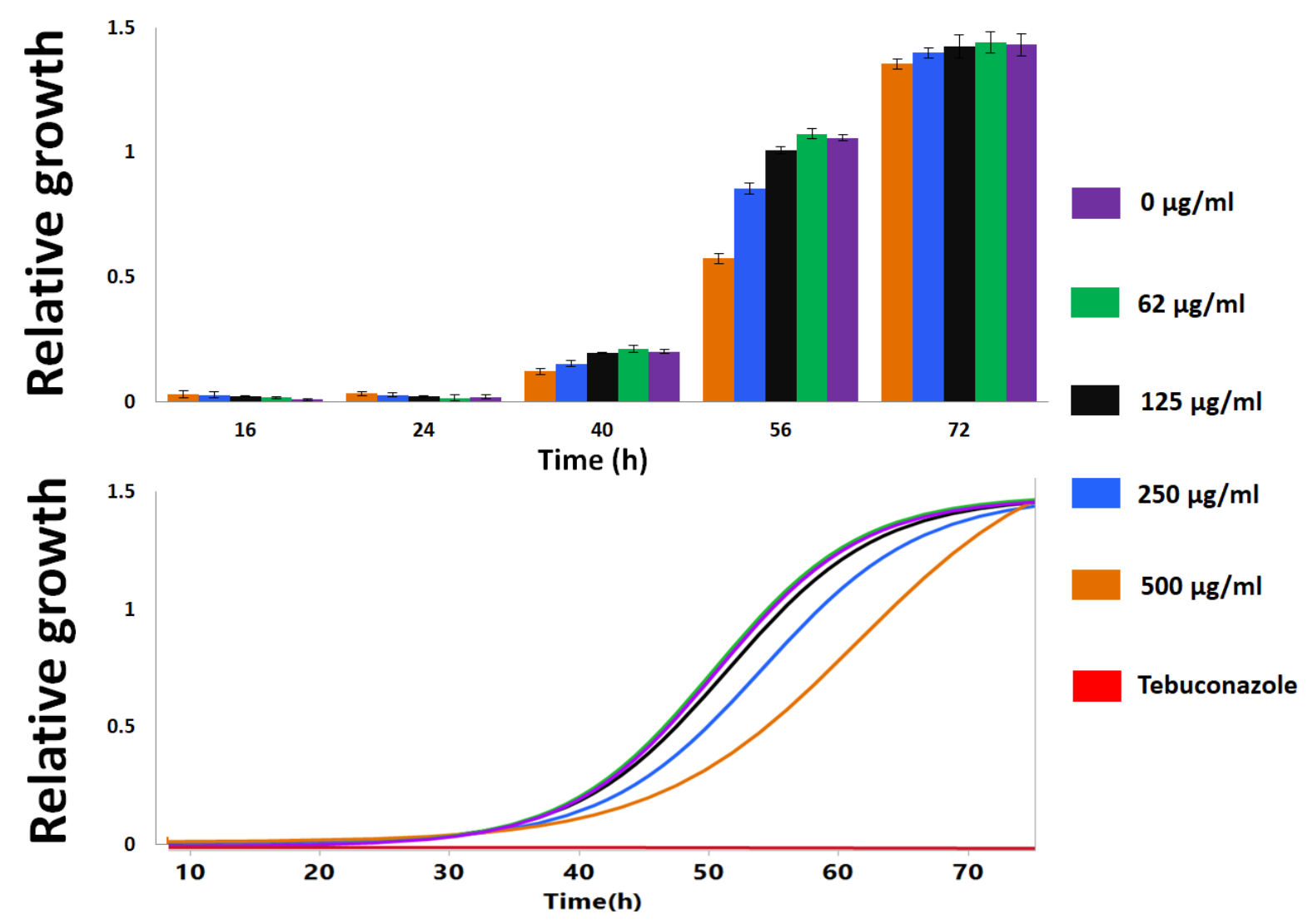

Figure 6. Antifungal activity of THBH. Time-response curves illustrate the delay of $F$. graminearum growth as a response to the treatment with serial dilutions of THBH. Curve fitting by non-linear regression using a four-parameter logistic model. The error bars represent the standard deviation $(n=7)$.

\subsection{Toxicity and food preference in the mealworm}

The EtOAc fraction of the aqueous extract of snowdrop bulbs showed significant inhibition of mealworm growth after feeding for 2 weeks on flour mixed with 1000 and $500 \mu \mathrm{g} \mathrm{g}^{-1}$ flour (Figure 7A). The dose of $100 \mu \mathrm{g} \mathrm{g}^{-1}$ did not cause any significant effect. Moreover, the food choice experiment showed that mealworms preferred to feed on the control comparing to the treatment with $500 \mu \mathrm{g} \mathrm{g}^{-1}$ of the EtOAc fraction (Figure 7B). 

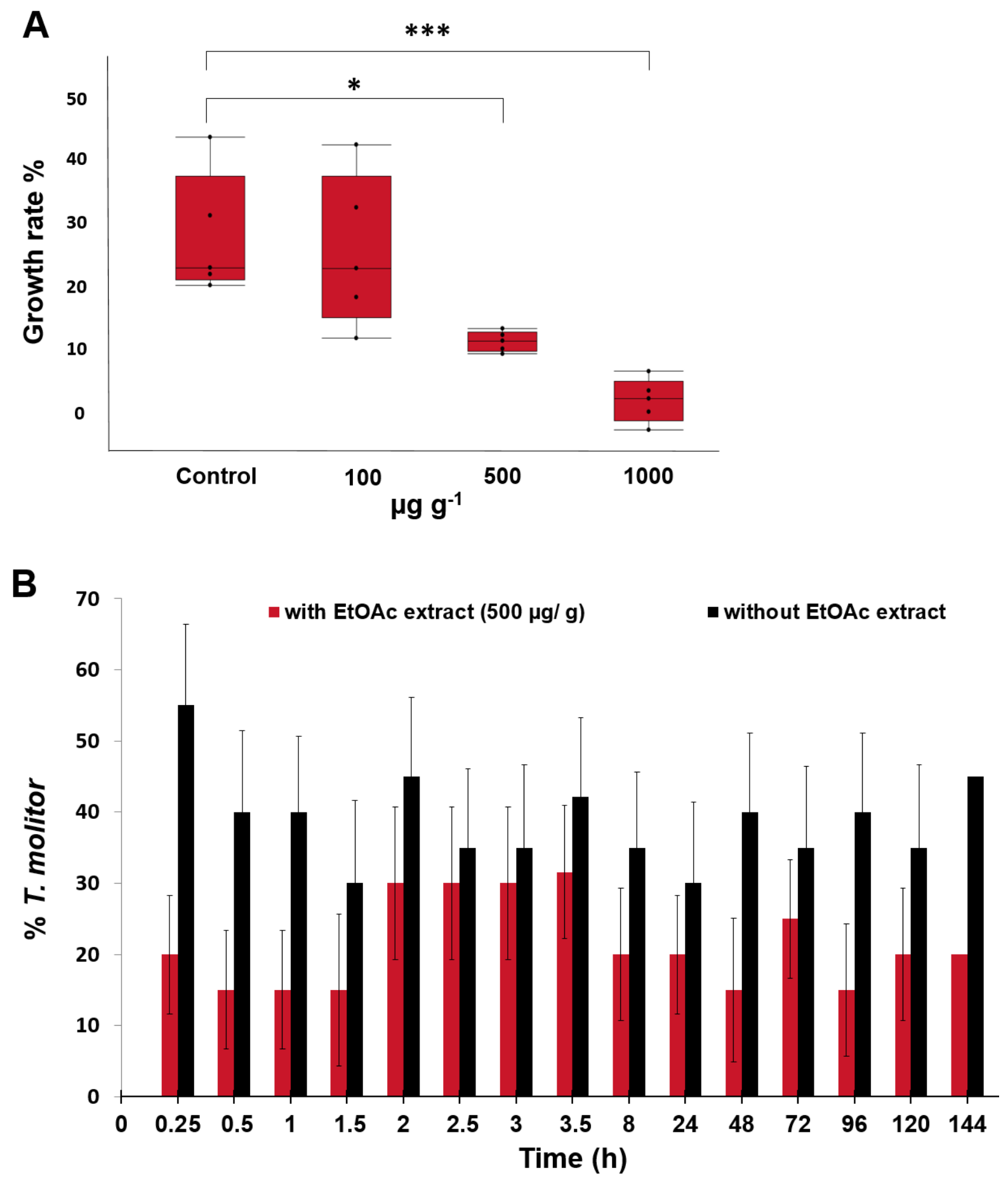

Figure 7. Toxicity and food preference in mealworm. (A) Effect of EtOAc fraction of the aqueous extract of snowdrop bulbs on mealworm growth after feeding for 2 weeks on flour mixed with 100, 500, and $1000 \mu \mathrm{g} \mathrm{\textrm {g } ^ { - 1 }}$ flour. Asterisks indicate statistically significant differences among groups $(* \mathrm{p}<0.05, * * \mathrm{p}<0.01$, *** $\mathrm{p}<0.001)$ one-way ANOVA followed by Tukey's HSD test. Boxes represent the $75^{\text {th }}$ percentile, median, and the $25^{\text {th }}$ percentile. Whiskers range from the $75^{\text {th }}$ percentile to the maximum value and from the $25^{\text {th }}$ percentile to the minimum value. Black dots represent individual data points. (B) Food choice experiment. Treatment is flour with $500 \mu \mathrm{g} \mathrm{g}^{-1}$ of the EtOAc fraction; control is flour. The error bars represent the standard error $(n=20)$. 


\subsection{Quantification of the metabolites in plant bulbs and root exudates}

The ratio of target metabolites (TAZ, THBH, DHBH, and LYCO) varied depending on the type of extract. In the EtOAc fraction of the bulbs extract, LYCO was the major component, followed by DHBH and THBH, while TAZ was a minor component with approximately $3 \%$ of the total target metabolites. In contrast, TAZ was the major component in the root exudates that reached approximately $78 \%$ of the target metabolites (Figure 8)
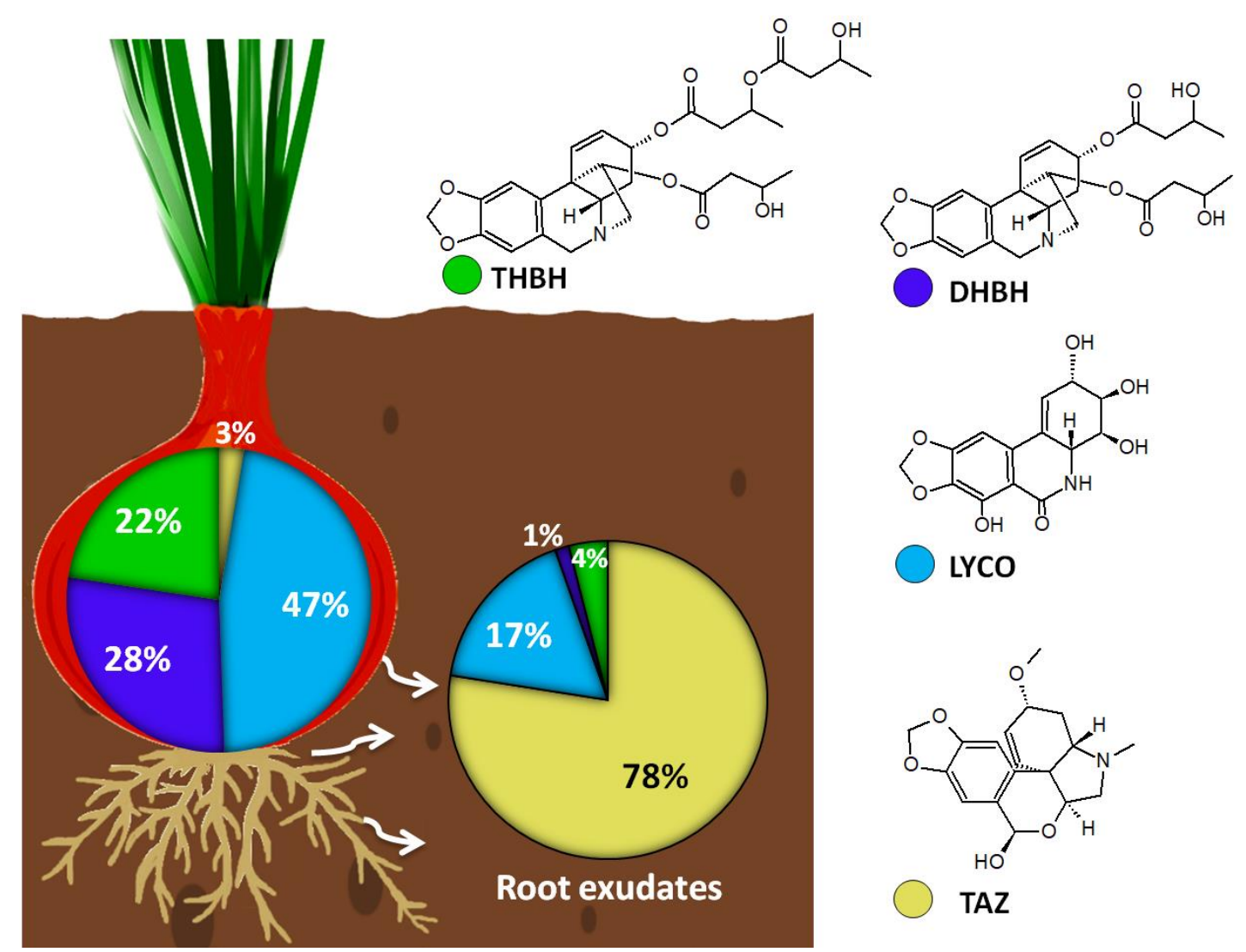

Figure 8. Secondary metabolites of snowdrop bulbs and root exudates. Proportion of the major components in the EtOAc fraction of the aqueous bulbs extract and the root exudates.

\subsection{Impact of secondary metabolites from snowdrop on soil microorganisms}

A mixture of metabolites purified from snowdrop (Figure 7) and mixed by a ratio that reflected their proportion in the root exudates TAZ/ LYCO/ THBH/ DHBH (78: 17: 4: 1) caused a significant inhibition against five soil bacterial groups, Gammaproteobacteria, Betaproteobacteria, Alphaproteobacteria, Bacteroidetes, and Verrucomicrobia. (Figure 9). 


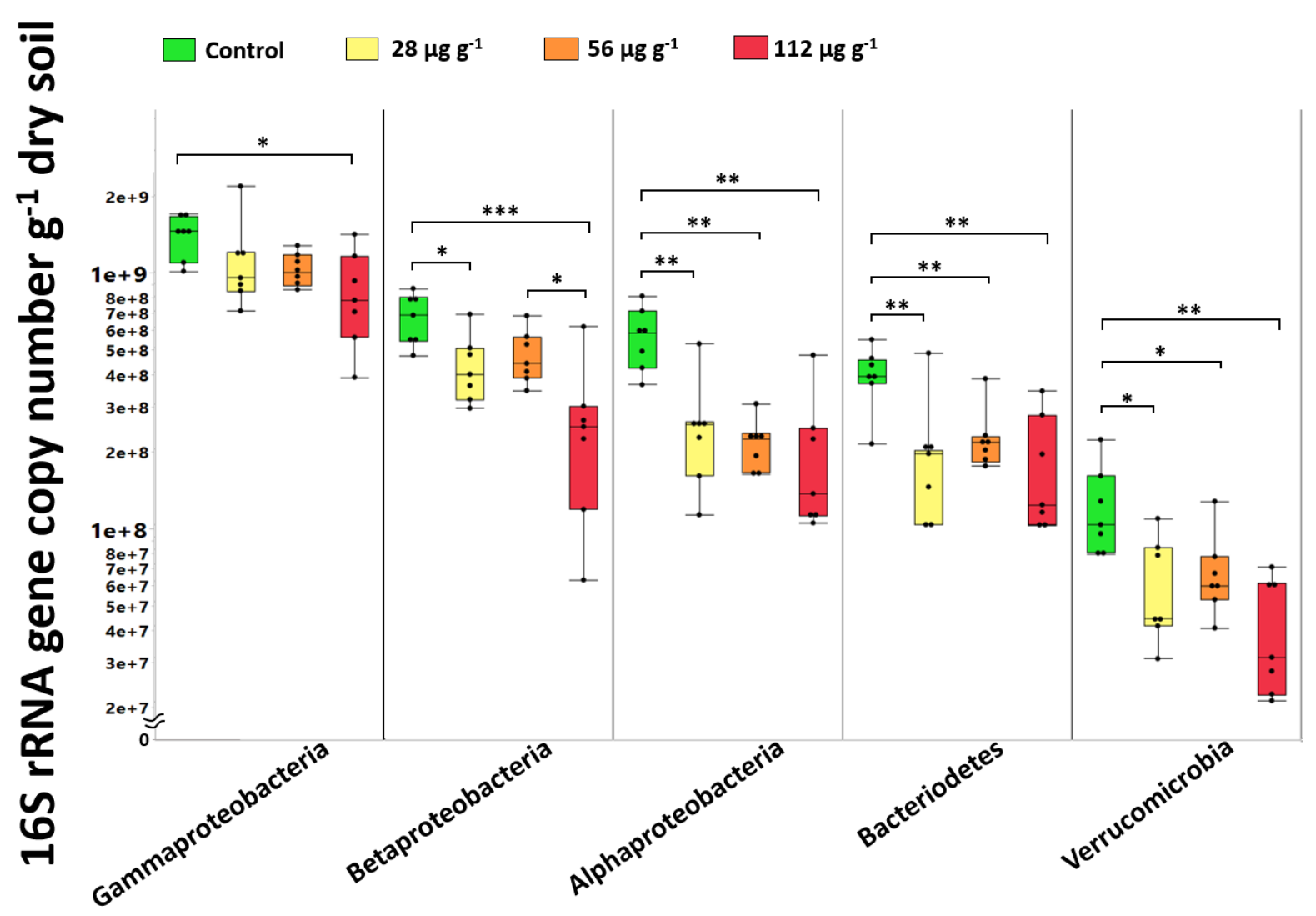

Figure 9. Effect of a mixture of Amaryllidaceae alkaloids from snowdrop on various soil bacterial groups. Studied through the quantification of $16 \mathrm{~S}$ rRNA genes one week after the treatment. Asterisks indicate statistically significant differences among groups $(* \mathrm{p}<0.05$, ** $\mathrm{p}<0.01, * * * \mathrm{p}<0.001$, Kruskal-Wallis test with multiple comparison extension ('kruskalmc'-function in the 'pgirmess' R-package v1.6.9) or one-way ANOVA followed by Tukey's HSD test ('aov'- and 'TukeyHSD'-function in the 'stats' R-package v3.4.3)). Boxes represent the $75^{\text {th }}$ percentile, median, and the $25^{\text {th }}$ percentile. Whiskers range from the $75^{\text {th }}$ percentile to the maximum value and from the $25^{\text {th }}$ percentile to the minimum value. Black dots represent individual data points.

The inhibitory effects were not significant when monitoring (total bacteria, total fungi, Actinobacteria, Firmicutes, Acidobacteria, Gemmatimonadetes, and Ascomycota). On the other hand, the mixture of metabolites that mimicked the proportion of the components in the bulb extract LYCO/DHBH/THBH/TAZ (47: 28: 22: 3) did not cause any significant inhibition to the groups tested. 


\section{Discussion}

The perennial bulb Species of the genus Galanthus produce an abundance of alkaloids, of which approximately 80 compounds have been isolated and characterized. Nevertheless, The biological functions of the majority of these alkaloids are still unclear (Berkov et al. 2012). The traditional approach of phytochemistry is based on extraction techniques like boiling or macerating dried or ground plants tissues with organic solvents such as methanol, ethanol, ethyl acetate, dichloromethane, and chloroform (Jones and Kinghorn 2005); Next, inspecting the pharmacological aspects of the isolated compounds like the anticancer, antiviral, antimalarial, and antioxidant activities.

In this work, we followed a distinct concept to study the alkaloids of Galanthus nivalis. Our concept is aimed to explore the ecological role of these secondary metabolites. Therefore we extracted the compounds from the intact plant parts with water, which is the only solvent available in nature. Furthermore, we studied the effect of the compounds secreted with roots exudation and the compounds that remained in the plant tissues on the organisms that can interfere with G. nivalis in natural conditions, like other plants, soil microorganisms, insects, and nematodes.

Our results showed that the extracts of many parts of G. nivalis possessed phytotoxic effects on radish seeds, especially the bulb extract, which was the most phytotoxic and caused total germination inhibition at the dose of $200 \mu \mathrm{g} \mathrm{mL}^{-1}$. Moreover, the bioassay-guided fractionation showed that fraction A could be the potential source of phytotoxicity. However, two main compounds were isolated from fraction $\mathrm{A}$, and their chemical structures were determined as follows: compound 3): lycoricidinol (synonym narciclasine) (LYCO) and compound 4): 3,11,3''-O-(3',3', 3','-Trihydroxybutanoyal)-hamayne (THBH).

LYCO is an alkaloid that has been isolated from several genera of the family Amaryllidaceae, and the content of LYCO in G. nivalis was estimated to be $10 \mathrm{mg} \mathrm{kg}^{-1}$ (Piozzi et al. 1969). Several studies reported that LYCO possessed a phytotoxic effect on many plant species such as Avena, cabbage, and lettuce, and rice (Hu et al. 2015; Bi, Yung, and Wong 1998; Na et al. 2011; Hu et al. 2014; Imaseki and G. Kang 1984; Okamoto, Torii, and Isogai 1968). However, the mode of action beyond the phytotoxicity of LYCO is not fully uncovered. Relevant studies showed that the phytotoxic effect of LYCO could result from the inhibition of ethylene production induced by auxin (Kang et al. 1984), or from interfering with auxin transport; or from inducing DNA damage in root cells (Hu et al. 2015; 2014). Furthermore, our results showed that LYCO caused mortality to $C$. elegans, even at a dose of $25 \mu \mathrm{g} \mathrm{mL}{ }^{-1}$. Thus, even 
though LYCO has been intensively studied for its biological activity, such as phytotoxicity, antifungal activity, and insect antifeedant activity (Imaseki and G. Kang 1984; Nair and van Staden 2018; Numata et al. 1983), no previous studies reported the nematicidal effect of this compound before, to our knowledge.

The second compound in the phytotoxic fraction was THBH. This alkaloid was reported in Galanthus before (Berkov et al. 2009), but to our knowledge, the biological activity of this compound has never been reported thus far. In this study, we subjected THBH to several toxicity bioassays. The results showed that THBH was strongly phytotoxic to Lemna minor. Even a dose of $4 \mu \mathrm{g} \mathrm{mL}^{-1}$ caused significant growth inhibition in the tested plants. Moreover, THBH showed a moderate cytotoxic effect against brine shrimps with an $\mathrm{EC}_{50}$ value of $108 \mu \mathrm{g} \mathrm{mL}^{-1}$. On the other hand, our results showed that THBH has no effect on the nematode C. elegans or on the filamentous fungi $F$. graminearum.

Our results showed that two other alkaloids were among the major components of the G. nivalis

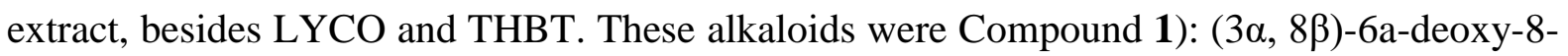
hydroxy-tazettine (pretazettine) (TAZ) and Compound 2): 3,11-O-(3',3'”Dihydroxybutanoyl)-hamayne (DHBH). Pretazettine (TAZ) is one of the most abundant naturally occurring alkaloids in Amaryllidaceae (Wildman and Bailey 1967). It is worth noting that the bulbs of Narcissus tazetta -which is a natural source of TAZ- are used in turkey in folk medicine as a treatment for abscesses due to their antiphlogistic effects(Çakici et al. 1997; Bastida et al. 2006). On the other hand, DHBH has been reported in Galanthus before (Berkov et al. 2009), but to our knowledge, no information about its biological activity is available.

We found that the relative abundance of the alkaloids studied (TAZ, THBH, DHBH, and LYCO) varied according to the type of extract. TAZ was the major component in the root exudates, while it was a minor component in the bulb. Simultaneously, LYCO, DHBH, and THBH were major components in the bulb but not in the root exudates. Interestingly, we revealed that a mixture of the four alkaloids studied, in a ratio that matched their proportion in the root exudates, could cause a significant inhibition against five soil bacterial groups ( Gammaproteobacteria, Betaproteobacteria, Alphaproteobacteria, Bacteroidetes, and Verrucomicrobia). While we could not observe any significant inhibition in soil bacteria when using the mixture that imitates the proportion of components in the bulbs.

It is noteworthy that the phylum Proteobacteria is the most dominant soil bacteria worldwide, and particularly Alpha-, Beta-, and Deltaproteobacteria (Delgado-Baquerizo et al. 2018). Moreover, most genera of the plant pathogenic bacteria belong to Gammaproteobacteria (Mansfield et al. 2012). Therefore, we suppose that the presence of alkaloids (mainly TAZ) in 
root exudates plays an ecological role in shaping the rhizosphere microbiota. However, the role of the exuded and leached Galanthus alkaloids into the soil should get more attention. Furthermore, we observed that the bulb extract possessed antifeedant and toxic effect against mealworm, and this is in line with the hypothesis that alkaloids can protect plants from herbivores (Matsuura and Fett-Neto 2015). 


\section{References}

Allen, K, MD Corre, A Tjoa, and E Veldkamp. 2015. "Soil nitrogen-cycling responses to conversion of lowland forests to oil palm and rubber plantations in sumatra, Indonesia. PLoS ONE 10(7): E0133325." 2015. https://journals.plos.org/plosone/article?id=10.1371/journal.pone.0133325\#sec002.

Bais, Harsh P., Tiffany L. Weir, Laura G. Perry, Simon Gilroy, and Jorge M. Vivanco. 2006. "The role of root exudates in rhizosphere interactions with plants and other organisms." Annual Review of Plant Biology 57 (1): 233-66. https://doi.org/10.1146/annurev.arplant.57.032905.105159.

Bastida, Jaume, Rodolfo Lavilla, and Francesc Viladomat. 2006. "Chemical and biological aspects of Narcissus alkaloids." The Alkaloids. Chemistry and Biology 63: 87-179.

Berkov, Strahil, Carles Codina, and Bastida Jaume. 2012. "The genus Galanthus: A source of bioactive compounds." In Phytochemicals_A Global Perspective of Their Role in Nutrition and Health, Ch. 11. Rijeka: IntechOpen. https://doi.org/10.5772/28798.

Berkov, Strahil, María Cuadrado, Edison Osorio, Viladomat Francesc, Carles Codina, and Jaume Bastida. 2009. "Three new alkaloids from Galanthus Nivalis and Galanthus Elwesii." Planta Medica 75 : 1351-55. https://doi.org/10.1055/s-0029-1185575.

Beule, Lukas, Maren Marine Grüning, Petr Karlovsky, and Anne 1-M-Arnold. 2017. "Changes of scots pine phyllosphere and soil fungal communities during outbreaks of defoliating insects." Forests 8 (9): 316. https://doi.org/10.3390/f8090316.

Bi, Yu-Rong, Kung-Hing Yung, and Yum-Shing Wong. 1998. "Physiological effects of narciclasine from the mucilage of Narcissus Tazetta L. Bulbs.” Plant Science 135 (1): 103-8. https://doi.org/10.1016/S0168-9452(98)00069-7.

Brandfass, Christoph, and Petr Karlovsky. 2008. "Upscaled CTAB-based DNA extraction and RealTime PCR assays for Fusarium culmorum and F. Graminearum DNA in plant material with reduced sampling error.” International Journal of Molecular Sciences 9 (11): 2306-21. https://doi.org/10.3390/ijms9112306.

Çakici, Iclal, Hediye Y Ulug, Sibel Inci, Bahar Tunçtan, Nurettin Abacioglu, Ilker Kanzik, and Bilge Sener. 1997. "Antinociceptive effect of some Amaryllidaceae plants in mice." Journal of Pharmacy and Pharmacology 49 (8): 828-30. https://doi.org/10.1111/j.20427158.1997.tb06121.x.

Delgado-Baquerizo, Manuel, Angela M. Oliverio, Tess E. Brewer, Alberto Benavent-González, David J. Eldridge, Richard D. Bardgett, Fernando T. Maestre, Brajesh K. Singh, and Noah Fierer. 2018. "A global atlas of the dominant bacteria found in soil." Science 359 (6373): 320-25. https://doi.org/10.1126/science.aap9516.

Donald, G, and MD Barceloux. 2008. "Snowdrop (Galanthus Nivalis L.) - Medical Toxicology of Natural Substances - Wiley Online Library." 2008. https://onlinelibrary.wiley.com/doi/abs/10.1002/9780470330319.ch111.

Giraudoux, Patrick, Jean-Philippe Antonietti, Colin Beale, Renaud Lancelot, David Pleydell, and Mike Treglia. 2018. Pgirmess: Spatial Analysis and Data Mining for Field Ecologists (version 1.6.9). https://CRAN.R-project.org/package=pgirmess.

Hirsch, Ann M., W. Dietz Bauer, David M. Bird, Julie Cullimore, Brett Tyler, and John I. Yoder. 2003. "Molecular signals and receptors: controlling rhizosphere interactions between plants and other organisms." Ecology 84 (4): 858-68.

Hu, Lingfei, Christelle A. M. Robert, Selma Cadot, Xi Zhang, Meng Ye, Beibei Li, Daniele Manzo, et al. 2018. "Root exudate metabolites drive plant-soil feedbacks on growth and defense by shaping the rhizosphere microbiota." Nature Communications 9 (1): 2738. https://doi.org/10.1038/s41467-018-05122-7.

Hu, Yanfeng, Jiaolong Li, Lijing Yang, Wenbin Nan, Xiaoping Cao, and Yurong Bi. 2014. "Inhibition of root growth by narciclasine is caused by DNA damage-induced cell cycle arrest in lettuce seedlings." Protoplasma 251 (5): 1113-24. https://doi.org/10.1007/s00709-0140619-y. 
Hu, Yanfeng, Xiaofan Na, Jiaolong Li, Lijing Yang, Jia You, Xiaolei Liang, Jianfeng Wang, Liang Peng, and Yurong Bi. 2015. "Narciclasine, a potential allelochemical, affects subcellular trafficking of auxin transporter proteins and actin cytoskeleton dynamics in Arabidopsis roots." Planta 242 (6): 1349-60. https://doi.org/10.1007/s00425-015-2373-6.

Imaseki, Hide, and Bin G. Kang. 1984. Mechanism of Action of Lycoricidinol, a Plant Growth Inhibitor Isolated from Lycoris Radiata Herb. Vol. 25. https://doi.org/10.1093/oxfordjournals.pcp.a076715.

Jones, William P., and A. Douglas Kinghorn. 2005. "Extraction of plant secondary metabolites." In Natural Products Isolation, edited by Satyajit D. Sarker, Zahid Latif, and Alexander I. Gray, 323-51. Totowa, NJ: Humana Press. https://doi.org/10.1385/1-59259-955-9:323.

Kang, Bin G., June S. Lee, Seung Eun Oh, Yuko Horiuchi, and Hidemasa Imaseki. 1984. "Inhibition of auxin-induced ethylene production by lycoricidinol." Plant and Cell Physiology 25 (2): 249-56. https://doi.org/10.1093/oxfordjournals.pcp.a076708.

Lalljee, B, and S Facknath. 2000. "Allelopathic interactions in soil.” In Allelopathy in Ecological Agriculture and Forestry, 47-58. Springer Netherlands. https://www.springer.com/gp/book/9780792363484.

Lee, MR. 1999. "The snowdrop (Galanthus Nivalis): From Odysseus to alzheimer | Royal College of Physicians of Edinburgh." Proc R Coll Physicians Edinb 1999; 29: 349-352. https://www.rcpe.ac.uk/college/journal/snowdrop-galanthus-nivalis-odysseus-alzheimer.

Li, Zhao-Hui, Qiang Wang, Xiao Ruan, Cun-De Pan, and De-An Jiang. 2010. "Phenolics and plant allelopathy." Molecules 15 (12): 8933-52. https://doi.org/10.3390/molecules15128933.

Lundberg, Derek S., and Paulo J. P. L. Teixeira. 2018. "Root-exuded coumarin shapes the root microbiome." Proceedings of the National Academy of Sciences 115 (22): 5629. https://doi.org/10.1073/pnas.1805944115.

Mansfield, John, Stephane Genin, Shimpei Magori, Vitaly Citovsky, Malinee Sriariyanum, Pamela Ronald, Max Dow, et al. 2012. "Top 10 plant pathogenic bacteria in molecular plant pathology." Molecular Plant Pathology 13 (6): 614-29. https://doi.org/10.1111/j.13643703.2012.00804.x.

Matsuura H.N., Fett-Neto A.G. (2015) Plant Alkaloids: Main Features, Toxicity, and mechanisms of action. In: Gopalakrishnakone P., Carlini C., Ligabue-Braun R. (eds) Plant Toxins. Toxinology. Springer, Dordrecht. https://doi.org/10.1007/978-94-007-6728-7_2-1,

Molina-Salinas, Gloria, Salvador Said-Fernández, División De, Biología Celular, Instituto Mexicano, Seguro Social, Dos De Abril, et al. 2006. "A modified microplate cytotoxicity assay with brine shrimp larvae (Artemia Salina)." Pharmacology on Line 3 (January): 633-38.

$\mathrm{Na}$, Xiaofan, Yanfeng Hu, Kun Yue, Hongxia Lu, Pengfei Jia, Huahua Wang, Xiaomin Wang, and Yurong Bi. 2011. "Concentration-dependent effects of narciclasine on cell cycle progression in Arabidopsis root tips." BMC Plant Biology 11 : 184. https://doi.org/10.1186/1471-2229-11184.

Nair, Jerald J., and Johannes van Staden. 2018. "Insight to the antifungal properties of Amaryllidaceae constituents." Phytomedicine, November, 152753. https://doi.org/10.1016/j.phymed.2018.11.013.

Numata, Atsushi, Tsuruko Takemura, Hideyuki Ohbayashi, Takako Katsuno, Kyoko Yamamoto, Kimihisa Sato, and Shigeru Kobayashi. 1983. "Antifeedants for the larvae of the yellow butterfly, Eurema hecabe mandarina, in lycoris radiata." Chemical and Pharmaceutical Bulletin 31 (6): 2146-49. https://doi.org/10.1248/cpb.31.2146.

OECD Guideline,. 2006. “, Test No. 221: Lemna Sp. Growth Inhibition Test, OECD Guidelines for the Testing of Chemicals, Section 2, OECD Publishing, Paris,." https://doi.org/10.1787/9789264016194-en.

Okamoto, Toshihiko, Yoshihiko Torii, and Yo Isogai. 1968. "Lycoricidinol and Lycoricidine, New Plant-Growth Regulators in the Bulbs of Lycoris Radiata HERB." Chemical \& pharmaceutical bulletin 16 (9): 1860-64. https://doi.org/10.1248/cpb.16.1860.

Piozzi, F., M.L. Marino, C. Fuganti, and A. Di Martino. 1969. "Occurrence of non-basic metabolites in Amaryllidaceae.” Phytochemistry 8 (9): 1745-48. https://doi.org/10.1016/S00319422(00)85963-4. 
Rasband, W.S. 1997. "ImageJ." U. S. National Institutes of Health, Bethesda, Maryland, USA,. https://imagej.nih.gov/ij/.

R Core Team (2019) R: A Language and Environment for Statistical Computing. R Foundation for Statistical Computing, Vienna, Austria. https://www.R-project.org/

Slade, Naomi. 2014. Plant Lovers Guide to Snowdrops. Portland: Timber Press.

Stiernagle, T. 2006. Maintenance of C. Elegans, WormBook, Ed. The C. Elegans Research Community, WormBook, Doi/10.1895/Wormbook.1.101.1, Http://Www.Wormbook.Org. Reprinted from Pp. 51-67, Maintenance of C. Elegans, by T. Steiernagle.

Ura, Kazuhiro, Toshinori Kai, Sachiko Sakata, Taisen Iguchi, and Koji Arizono. 2002. "Aquatic acute toxicity testing using the nematode Caenorhabditis Elegans." Journal of Health Science 48 (6): 583-86. https://doi.org/10.1248/jhs.48.583.

Wildman, William C., and David Tiffany. Bailey. 1967. "Pretazettine." Journal of the American Chemical Society 89 (21): 5514-15. https://doi.org/10.1021/ja00997a074.

Wolf, Rebecca B., Gayland F. Spencer, and William F. Kwolek. 1984. "Inhibition of velvetleaf (Abutilon Theophrasti) germination and growth by benzyl isothiocyanate, a natural toxicant." Weed Science 32 (5): 612-15. https://doi.org/10.1017/S004317450005966X.

Zhalnina, Kateryna, Katherine B. Louie, Zhao Hao, Nasim Mansoori, Ulisses Nunes da Rocha, Shengjing Shi, Heejung Cho, et al. 2018. "Dynamic root exudate chemistry and microbial substrate preferences drive patterns in rhizosphere microbial community assembly." Nature Microbiology 3 (4): 470. https://doi.org/10.1038/s41564-018-0129-3. 


\section{Supplementary}

\begin{tabular}{|l|l|l|l|l|l|l|l|}
\hline Al & Ca & Fe & $\mathrm{K}$ & $\mathrm{Mg}$ & $\mathrm{Mn}$ & $\mathrm{Na}$ & effective cation exchange capacity \\
\hline $\begin{array}{l}\mathrm{mg} \mathrm{kg}^{-1} \\
\text { dry soil }\end{array}$ & $\begin{array}{l}\mathrm{mg} \mathrm{kg}^{-1} \\
\text { dry soil }\end{array}$ & $\begin{array}{l}\mathrm{mg} \mathrm{kg}^{-1} \\
\text { dry soil }\end{array}$ & $\begin{array}{l}\mathrm{mg} \mathrm{kg}^{-1} \\
\text { dry soil }\end{array}$ & $\begin{array}{l}\mathrm{mg} \mathrm{kg} \\
\text { dry soil }\end{array}$ & $\begin{array}{l}\mathrm{mg} \mathrm{kg}^{-1} \\
\text { dry soil }\end{array}$ & $\begin{array}{l}\mathrm{mg} \mathrm{kg}^{-1} \\
\text { dry soil }\end{array}$ & $\mathrm{mmol}_{\mathrm{c}} \mathrm{kg}^{-1} \mathrm{dry} \mathrm{soil}$ \\
\hline 0 & 5,177 & 0 & 336 & 369 & 3 & 10 & 298 \\
\hline
\end{tabular}

Table S1. Soil characteristics

Table S2. Primers and standard organisms used for each quantified target taxonomic group.

\begin{tabular}{|c|c|c|c|c|}
\hline $\begin{array}{l}\text { Forward primer } \\
\text { (sequence) }\end{array}$ & $\begin{array}{l}\text { Reverse Primer } \\
\text { (sequence) }\end{array}$ & Reference & $\begin{array}{l}\text { Target taxonomic } \\
\text { group }\end{array}$ & $\begin{array}{l}\text { Organism used } \\
\text { for standard }\end{array}$ \\
\hline $\begin{array}{l}\text { Eub338 } \\
\text { (ACTCCTACGGGAGGCAGCAG) }\end{array}$ & $\begin{array}{l}\text { Eub518 } \\
\text { (ATTACCGCGGCTGCTGG) }\end{array}$ & $\begin{array}{l}\text { (Lane } \\
\text { 1991)(Muyzer, } \\
\text { Waal, and } \\
\text { Uitterlinden } \\
\text { 1993) }\end{array}$ & Bacteria & $\begin{array}{l}\text { Pseudomonas } \\
\text { stutzeri }^{a}\end{array}$ \\
\hline $\begin{array}{l}\text { Acid31 } \\
\text { (GATCCTGGCTCAGAATC) }\end{array}$ & $\begin{array}{l}\text { Eub518 } \\
\text { (ATTACCGCGGCTGCTGG) }\end{array}$ & $\begin{array}{l}\text { (Barns, Takala, } \\
\text { and Kuske }\end{array}$ & Acidobacteria & Amplified from \\
\hline
\end{tabular}




\begin{tabular}{|c|c|c|c|c|}
\hline & & $\begin{array}{l}\text { 1999)(Muyzer, } \\
\text { Waal, and } \\
\text { Uitterlinden } \\
\text { 1993) }\end{array}$ & & $\begin{array}{l}\text { environmental } \\
\text { DNA }\end{array}$ \\
\hline $\begin{array}{l}\text { Act } 920 \mathrm{F3} \\
\text { (TACGGCCGCAAGGCTA) }\end{array}$ & $\begin{array}{l}\text { Act1200R } \\
\text { (TCRTCCCCACCTTCCTCCG) }\end{array}$ & $\begin{array}{l}\text { (Bacchetti De } \\
\text { Gregoris et al. } \\
2011 \text { ) }\end{array}$ & Actinobacteria & $\begin{array}{l}\text { Clavibacter } \\
\text { michiganensis }^{a}\end{array}$ \\
\hline $\begin{array}{l}\alpha 682 \mathrm{~F} \\
\text { (CIAGTGTAGAGGTGAAATT) }\end{array}$ & $\begin{array}{l}908 \alpha \mathrm{R} \\
\text { (CCCCGTCAATTCCTTTGAGTT) }\end{array}$ & $\begin{array}{l}\text { (Bacchetti De } \\
\text { Gregoris et al. } \\
2011 \text { ) }\end{array}$ & Alphaproteobacteria & $\begin{array}{l}\text { Rhizobium } \\
\text { rhizogenes }\end{array}$ \\
\hline $\begin{array}{l}\text { Cfb319 } \\
\text { (GTACTGAGACACGGACCA) }\end{array}$ & $\begin{array}{l}\text { Eub518 } \\
\text { (ATTACCGCGGCTGCTGG) }\end{array}$ & $\begin{array}{l}\text { (Muyzer, Waal, } \\
\text { and Uitterlinden } \\
\text { 1993)(Manz et al. } \\
\text { 1996) }\end{array}$ & Bacteriodetes & $\begin{array}{l}\text { Amplified from } \\
\text { environmental } \\
\text { DNA }\end{array}$ \\
\hline $\begin{array}{l}\text { Eub338 } \\
\text { (ACTCCTACGGGAGGCAGCAG) }\end{array}$ & $\begin{array}{l}\text { Bet680 } \\
\text { (TCACTGCTACACGYG) }\end{array}$ & $\begin{array}{l}\text { (Overmann, } \\
\text { Coolen, and } \\
\text { Tuschak 1999) }\end{array}$ & Betaproteobacteria & $\begin{array}{l}\text { Burkholderia } \\
\text { cepacia }^{a}\end{array}$ \\
\hline $\begin{array}{l}1080 \gamma \mathrm{F} \\
\text { (TCGTCAGCTCGTGTYGTGA) }\end{array}$ & $\begin{array}{l}\gamma 1202 R \\
(\text { CGTAAGGGCCATGATG) }\end{array}$ & $\begin{array}{l}\text { (Bacchetti De } \\
\text { Gregoris et al. } \\
\text { 2011)(Lane 1991) }\end{array}$ & Gammproteobacteria & $\begin{array}{l}\text { Escheria coli } \\
\text { DH5 } \alpha\end{array}$ \\
\hline
\end{tabular}


Chapter 2

\begin{tabular}{|c|c|c|c|c|}
\hline $\begin{array}{l}\text { G1G3-673F } \\
\text { (GAATGCGTAGAGATCC) }\end{array}$ & $\begin{array}{l}907 \mathrm{R} \\
\text { (CCGTCAATTCMTTTRAGTTT) }\end{array}$ & $\begin{array}{l}\text { (DeBruyn et al. } \\
\text { 2011)(Lane et al. } \\
\text { 1985) }\end{array}$ & Gemmatimonadetes & $\begin{array}{l}\text { Amplified from } \\
\text { environmental } \\
\text { DNA }\end{array}$ \\
\hline $\begin{array}{l}\text { Verr349 } \\
\text { (GYGGCASCAGKCGMGAAW) }\end{array}$ & $\begin{array}{l}\text { Eub518 } \\
\text { (ATTACCGCGGCTGCTGG) }\end{array}$ & $\begin{array}{l}\text { (Philippot et al. } \\
\text { 2009)(Muyzer, } \\
\text { Waal, and } \\
\text { Uitterlinden } \\
\text { 1993) }\end{array}$ & Verrucomicrobia & $\begin{array}{l}\text { Amplified from } \\
\text { environmental } \\
\text { DNA }\end{array}$ \\
\hline $\begin{array}{l}\text { ITS4Asco } \\
\text { (CGTTACTRRGGCAATCCCTGTTG) }\end{array}$ & $\begin{array}{l}\text { ITS5 } \\
\text { (GGAAGTAAAAGTCGTAACAAGG) }\end{array}$ & $\begin{array}{l}\text { (White et al. } \\
\text { 1990)(Nikolcheva } \\
\text { and Bärlocher } \\
\text { 2004) }\end{array}$ & Ascomycota & $\begin{array}{l}\text { Fusarium } \\
\text { graminearum }\end{array}$ \\
\hline
\end{tabular}

${ }^{\mathrm{a}}$ provided by A. Mavridis (University of Goettingen), ${ }^{\mathrm{b}}$ provided by A. von Tiedemann (University of Goettingen). 
Table S3. Real-time PCR conditions for each target taxonomic group.

\begin{tabular}{|c|c|c|c|c|c|c|c|}
\hline \multirow{2}{*}{$\begin{array}{l}\text { Target taxonomic } \\
\text { group }\end{array}$} & \multirow{2}{*}{ Reaction buffer ${ }^{a}$} & \multirow{2}{*}{$\begin{array}{l}\text { DNA } \\
\text { Polymerase }^{b}\end{array}$} & \multirow[b]{2}{*}{ Final MgCl2 } & \multirow[b]{2}{*}{ Initial denaturation } & \multicolumn{3}{|l|}{35 cycles } \\
\hline & & & & & $\begin{array}{l}\text { Denaturatio } \\
\text { n }\end{array}$ & Annealing & Extension \\
\hline Bacteria & $\begin{array}{l}\text { 1X ThermoPol® } \\
\text { Reaction Buffer }\end{array}$ & $\begin{array}{l}\text { Taq DNA } \\
\text { Polymerases }\end{array}$ & 2.0 & $95^{\circ} \mathrm{C}, 120 \mathrm{~s}$ & $94^{\circ} \mathrm{C}, 20 \mathrm{~s}$ & $57^{\circ} \mathrm{C}, 30 \mathrm{~s}$ & $68^{\circ} \mathrm{C}, 20 \mathrm{~s}$ \\
\hline Acidobacteria & $\begin{array}{l}\text { 1X ThermoPol® } \\
\text { Reaction Buffer }\end{array}$ & $\begin{array}{l}\text { Taq DNA } \\
\text { Polymerases }\end{array}$ & 2.0 & $95^{\circ} \mathrm{C}, 120 \mathrm{~s}$ & $94^{\circ} \mathrm{C}, 20 \mathrm{~s}$ & $56^{\circ} \mathrm{C}, 30 \mathrm{~s}$ & $68^{\circ} \mathrm{C}, 35 \mathrm{~s}$ \\
\hline Actinobacteria & $\begin{array}{l}\text { 1X FastGene® } \\
\text { Taq HotStart } \\
\text { Buffer }\end{array}$ & $\begin{array}{l}\text { FastGene }{ }^{\circledR} \text { Taq } \\
\text { DNA } \\
\text { Polymerase }\end{array}$ & 2.0 & $95^{\circ} \mathrm{C}, 120 \mathrm{~s}$ & $94^{\circ} \mathrm{C}, 20 \mathrm{~s}$ & $62^{\circ} \mathrm{C}, 30 \mathrm{~s}$ & $72^{\circ} \mathrm{C}, 20 \mathrm{~s}$ \\
\hline Alphaproteobacteria & $\begin{array}{l}\text { 1X ThermoPol® } \\
\text { Reaction Buffer }\end{array}$ & $\begin{array}{l}\text { NEB Taq DNA } \\
\text { Polymerases }\end{array}$ & 2.0 & $95^{\circ} \mathrm{C}, 120 \mathrm{~s}$ & $94^{\circ} \mathrm{C}, 20 \mathrm{~s}$ & $60^{\circ} \mathrm{C}, 30 \mathrm{~s}$ & $68^{\circ} \mathrm{C}, 20 \mathrm{~s}$ \\
\hline Bacteriodetes & $\begin{array}{l}\text { 1X FastGene }{ }^{\circledR} \\
\text { Taq HotStart } \\
\text { Buffer }\end{array}$ & $\begin{array}{l}\text { FastGene }{ }^{\circledR} \text { Taq } \\
\text { DNA } \\
\text { Polymerase }\end{array}$ & 2.0 & $95^{\circ} \mathrm{C}, 120 \mathrm{~s}$ & $94^{\circ} \mathrm{C}, 20 \mathrm{~s}$ & $62^{\circ} \mathrm{C}, 30 \mathrm{~s}$ & $72^{\circ} \mathrm{C}, 20 \mathrm{~s}$ \\
\hline
\end{tabular}


Chapter 2

\begin{tabular}{|c|c|c|c|c|c|c|c|}
\hline Betaproteobacteria & $\begin{array}{l}\text { 1X FastGene }{ }^{\circledR} \\
\text { Taq HotStart } \\
\text { Buffer }\end{array}$ & $\begin{array}{l}\text { FastGene }{ }^{\circledR} \text { Taq } \\
\text { DNA } \\
\text { Polymerase }\end{array}$ & 2.0 & $95^{\circ} \mathrm{C}, 120 \mathrm{~s}$ & $94^{\circ} \mathrm{C}, 20 \mathrm{~s}$ & $58^{\circ} \mathrm{C}, 30 \mathrm{~s}$ & $72^{\circ} \mathrm{C}, 25 \mathrm{~s}$ \\
\hline $\begin{array}{l}\text { Gammproteobacteri } \\
\text { a }\end{array}$ & $\begin{array}{l}\text { 1X ThermoPol® } \\
\text { Reaction Buffer }\end{array}$ & $\begin{array}{l}\text { Taq DNA } \\
\text { Polymerases }\end{array}$ & 2.0 & $95^{\circ} \mathrm{C}, 120 \mathrm{~s}$ & $94^{\circ} \mathrm{C}, 20 \mathrm{~s}$ & $60^{\circ} \mathrm{C}, 30 \mathrm{~s}$ & $68^{\circ} \mathrm{C}, 20 \mathrm{~s}$ \\
\hline Gemmatimonadetes & $\begin{array}{l}\text { 1X ThermoPol® } \\
\text { Reaction Buffer }\end{array}$ & $\begin{array}{l}\text { Taq DNA } \\
\text { Polymerases }\end{array}$ & 2.0 & $95^{\circ} \mathrm{C}, 120 \mathrm{~s}$ & $94^{\circ} \mathrm{C}, 20 \mathrm{~s}$ & $58^{\circ} \mathrm{C}, 30 \mathrm{~s}$ & $68^{\circ} \mathrm{C}, 20 \mathrm{~s}$ \\
\hline Firmicutes & $\begin{array}{l}\text { 1X ThermoPol® } \\
\text { Reaction Buffer }\end{array}$ & $\begin{array}{l}\text { Taq DNA } \\
\text { Polymerases }\end{array}$ & 2.0 & $95^{\circ} \mathrm{C}, 120 \mathrm{~s}$ & $94^{\circ} \mathrm{C}, 20 \mathrm{~s}$ & $57^{\circ} \mathrm{C}, 30 \mathrm{~s}$ & $68^{\circ} \mathrm{C}, 20 \mathrm{~s}$ \\
\hline Fungi & $\begin{array}{l}\text { 1X Standard Taq } \\
\text { Reaction Buffer }\end{array}$ & $\begin{array}{l}\text { Hot Start Taq } \\
\text { DNA } \\
\text { Polymerase }\end{array}$ & 2.5 & $95^{\circ} \mathrm{C}, 120 \mathrm{~s}$ & $94^{\circ} \mathrm{C}, 20 \mathrm{~s}$ & $55^{\circ} \mathrm{C}, 30 \mathrm{~s}$ & $68^{\circ} \mathrm{C}, 30 \mathrm{~s}$ \\
\hline
\end{tabular}


a $1 \mathrm{X}$ ThermoPol® Reaction Buffer: $20 \mathrm{mM}$ Tris-HCl, $10 \mathrm{mM}$ (NH4)2SO4 ,10 mM KCl, $2 \mathrm{mM} \mathrm{MgSO} 4,0.1 \%$ Triton® X-100, pH 8.8 at 25ㄷ (New England Biolabs, Beverly, MA, USA); 1X FastGene® Taq HotStart Buffer (NIPPON Genetics Europe, Düren, Germany); 1X Standard Taq Reaction Buffer: $10 \mathrm{mM}$ Tris-HCl, $50 \mathrm{mM} \mathrm{KCl}, 1.5 \mathrm{mM} \mathrm{MgCl} 2, \mathrm{pH} 8.3$ at 25 ${ }^{\circ} \mathrm{C}$ (New England Biolabs, Beverly, MA, USA).

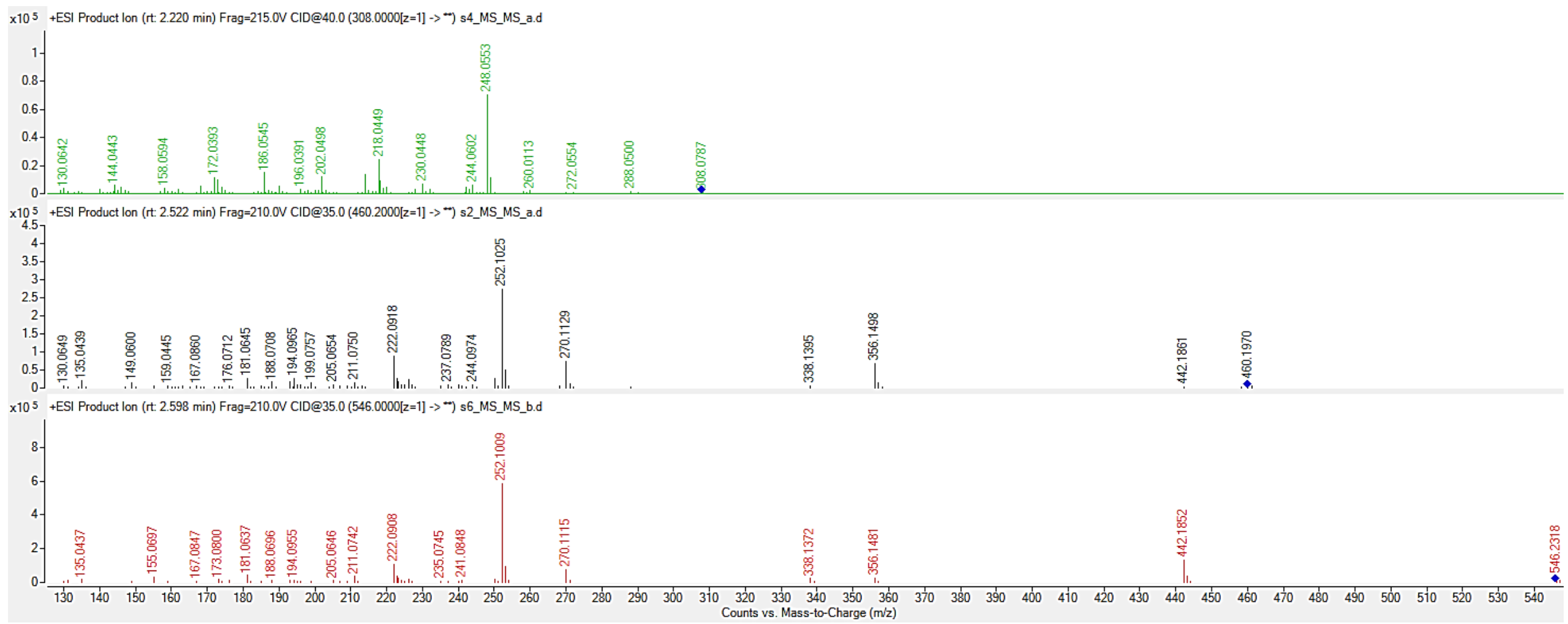

Figure S1. MS/MS Spectra for LYCO (green) @ 40V, DHBH (black) @35V, and THBH (red) @35V. Blue markers show the mother ions 


\section{$-0 \mu \mathrm{g} / \mathrm{ml}=62 \mu \mathrm{g} / \mathrm{ml}-125 \mu \mathrm{g} / \mathrm{ml}-250 \mu \mathrm{g} / \mathrm{ml} \longrightarrow 500 \mu \mathrm{g} / \mathrm{ml} \longrightarrow$ Tebuconazole}
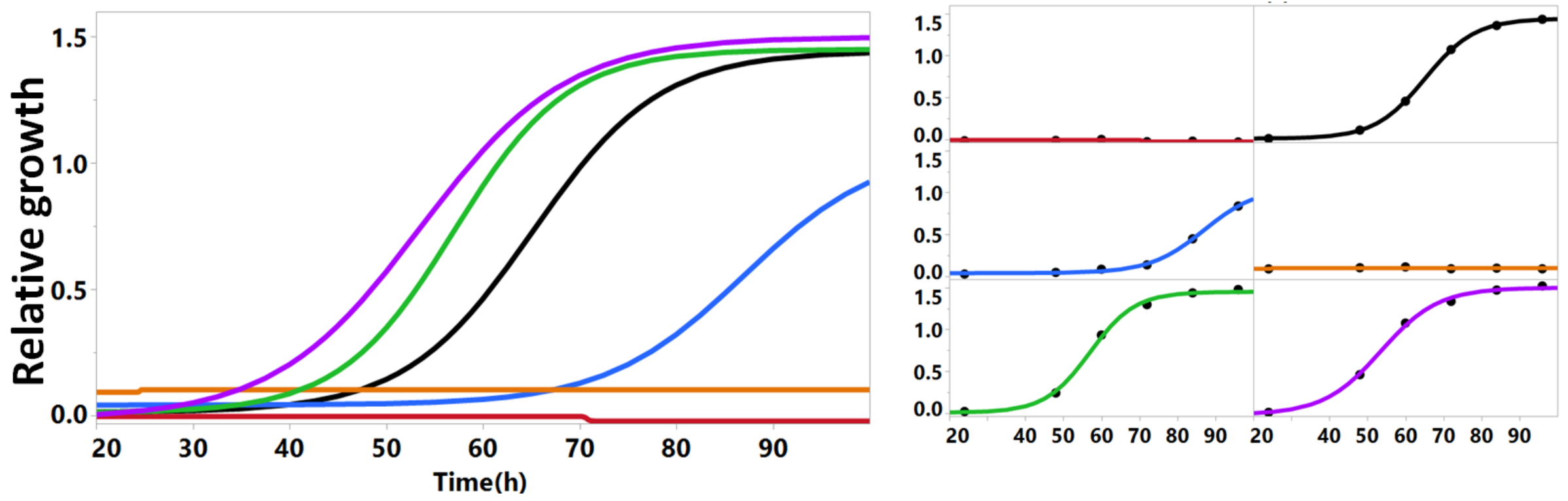

Figure.S2 Antifungal activity of the total bulbs EtOAc fraction: Time-response curves illustrate the delay of $F$. graminearum growth as a response to the treatment with serial dilutions of the total bulbs EtOAc fraction (B). Curve fitting by non-linear regression using a fourparameter logistic model $(\mathrm{n}=7)$. Black dots represent data mean 


\title{
Chapter 3. Investigation of allelochemicals leaching and exuding from Melilotus albus into the soil and their impact on weed suppressiveness and soil microorganisms
}

\author{
Mohammad Alhussein ${ }^{1}$, Albatol Alsarrag ${ }^{1}$, Lukas Beule $^{1}$, Franz Hadacek ${ }^{2}$, Petr Karlovsky ${ }^{1}$ \\ ${ }^{1}$ Molecular Phytopathology and Mycotoxin Research, University of Göttingen, Göttingen, \\ Germany, ${ }^{2}$ Department of Plant Biochemistry, Albrecht-von-Haller-Institute for Plant \\ Sciences, University of Göttingen, Göttingen, Germany.
}

\section{Summary}

Dozens of phenolic compounds were identified in the root exudate and rain leachate of Melilotus albus. Among these phenolics, coumarin and melilotic acid exerted potent inhibition on germination and growth of radish and trans-cinnamic acid, $o$-coumaric acid were less toxic. Furthermore, incorporating sweet clover residues into the soil caused a delay in germination and a significant reduction in plant survival. However, the same allelochemical mixture caused manipulation of the abundance of the bacterial groups in the upper soil layer. The tracking of allelochemicals movement in the soil showed that coumarin and melilotic acid accumulated mainly in the upper $2 \mathrm{~cm}$ of soil.

\section{Introduction}

Higher plants can release organic compounds into the environment through volatilization, leaching from leaves, and root exudation (Einhellig 1994). Artificial extraction methods can lead to various types and quantities of metabolites that can differ from those released naturally in the field. However, even if phytotoxins or antimicrobials are extracted from plant organs, that does not infer automatically that those compounds will be constituents of leaf leachates or root exudates (Cantor et al. 2011; Lorenzo et al. 2011; E.L. Rice 1984; Song et al. 2018). 
Melilotus albus Medik. (Sweet Clover) is an annual to biennial legume species, which is native to much of Asia and Southern Europe. It has been introduced and is naturalized to many other parts of Europe, as well as to North and South America, Australasia, and Southern Africa (Turkington et al. 1978). Sweet clover is an invasive species outside its native range, and it is highly adaptable to different environments (CABI 2019). Conn et al. (2011) reported that sweet clover had invaded Alaskan glacial river floodplains as pioneer species on recently disturbed sites. Nicollier and Thompson (1982) investigated the phytotoxicity of sweet clover and showed that the coumarin derivatives and flavonoids from sweet clover inhibited the growth of tomato and radish seedlings. Stefanović et al. (2015) reported that sweet clover extract was rich in phenolic compounds. Furthermore, they showed that the extract possessed antibacterial activity and could inhibit and prevent bacterial biofilm formation. The high content of coumarin in sweet clover can cause a disease for livestock known as a sweet clover disease, and that was one of the main reasons for the limited use of sweet clover as a pasture in Australia (Evans and Kearney 2003).

To our knowledge, no studies have been conducted on the leaching of allelochemicals from living sweet clover plants via rainfall or the leaching from plant residues incorporated into the soil. There are also no studies about the effects of sweet clover allelochemicals on soil microorganisms.

The objectives of this study are as follows:

i. To prove the role of the phenolic compounds in the phytotoxicity of sweet clover and investigate the leaching of these compounds from living plants via artificial rain and root exudate.

ii. To investigate the effect of sweet clover residues on weed suppression.

iii. To analyze the movement of the phytotoxic leachate from sweet clover residues in the soil.

iv. To assess the impact of the sweet clover leachate on soil microorganisms.

\section{Materials and methods}

\subsection{Plant materials}

Seeds of Melilotus albus (sweet clover) were purchased from (B \& T World Seeds, Paguignan, France). The seeds were sown in a soil mixture consisting of 2:1:1 peat moss/compost/sand $(\mathrm{w} / \mathrm{w} / \mathrm{w})$ in plastic pots. They were incubated in a greenhouse at $25^{\circ} \mathrm{C} / 14^{\circ} \mathrm{C}$ (day/night) with a $16 \mathrm{~h}$ photoperiod and were irrigated every two days. They were fertilized as required using 
mineral fertilizer (Hakaphos ${ }^{\circledR}$ Blue, Compo expert GmbH, Münster, Germany). Commercial seeds of Raphanus sativus (radish) (variety Saxa3, Kiepenkerl ${ }^{\circledR}$, Everswinkel, Germany) were bought from a local store. They were used in the germination bioassays, and the radish plants served as a non-allelopathic control species in the experiment of plant residues incorporation into the soil

\subsection{Extraction}

Sweet clover plants were harvested at the flowering stage. The compound leaves were picked gently with their petioles and were soaked in tap water in $1 \mathrm{~L}$ Erlenmeyer flasks. The flasks were closed with aluminum foil and incubated at room temperature in the dark for $12 \mathrm{~h}$. Following this, the crude extract was filtrated through filter paper (Rotilabo ${ }^{\circledR}$ folded filters, type 113 p, Karl Roth, Karlsruhe, Germany).

The filtrated crude aqueous extract was partitioned with ethyl acetate (EtOAc) (1:1, v/v). After $2 \mathrm{~h}$ phase separation, the EtOAc layer was collected. The remaining lower layer was remixed with EtOAc, and the partition procedure was repeated. The EtOAc fraction was concentrated to approximately $100 \mathrm{~mL}$ using a rotary evaporator R-100 (BÜCHI Inc., Flawil, Switzerland). Next, the fraction was divided into four pre-weighed $50 \mathrm{~mL}$ falcon tubes. The liquid in the tubes was entirely evaporated using a speed vacuum concentrator at $28^{\circ} \mathrm{C}$, and the fraction weight was determined.

Root exudate was extracted by immersing roots of intact fresh plants, uprooted, and wellcleaned in water for $12 \mathrm{~h}$ in the dark at room temperature.

\subsection{Fractionation using preparative -HPLC}

Fractionation was performed using preparative high-pressure liquid chromatography (Prep HPLC). The system consisted of a binary pump (PU-2086 plus, JASCO Inc., Gross-Umstadt, Germany) coupled with a UV/VIS detector (Jasco UV-970, JASCO Inc., Gross-Umstadt, Germany). The fractions were collected using a fraction collector (CHF122SC, Advantec MFS Inc., Japan). The system was operated employing the software JASCO ChromPass Chromatography Data System version 1.8.6.1. The separation column was a preparative reverse phase column (Polaris C18-Ether, 250 x $21.2 \mathrm{~mm}$, Varian, Darmstadt, Germany) with a compatible pre-column (Polaris C18-Ether, 50 x 21.2mm). Aliquots of $20 \mathrm{mg}$ were dissolved in $3 \mathrm{~mL}$ methanol $(\mathrm{MeOH}) /$ water $(1: 1 \mathrm{v} / \mathrm{v})$ and injected. Mobile phase A consisted of water with $0.25 \%$ acetic acid (v/v) and $\mathrm{B}$ of $\mathrm{MeOH}$ with $0.25 \%$ acetic acid (v/v). The flow rate was 
$2 \mathrm{~mL} / \mathrm{min}$. The gradient was as follows: $5 \min 5 \% \mathrm{~B}, 35 \min 30 \% \mathrm{~B}, 225 \min 65 \% \mathrm{~B}, 255$ $\min 100 \% \mathrm{~B}, 280 \min 100 \% \mathrm{~B}, 290 \min 5 \% \mathrm{~B}$, and $300 \min 5 \% \mathrm{~B}$. The separation process was monitored at $275 \mathrm{~nm}$ by UV absorption. The collected fractions were dried using a rotary evaporator and speed vacuum concentrator. Fractions for bioassays were selected depending on the UV absorbance and the weight of the fraction.

\subsection{Phytotoxicity bioassay}

\subsubsection{Germination test}

The phytotoxicity of the EtOAc fraction and the purified fractions was monitored using a radish germination test as described by Wolf et al. (1984) with some modifications. The test was downscaled and conducted in 24-well plates instead of Petri dishes due to low amounts of purified fractions. Radish seeds were surface sterilized with $1 \%$ sodium hypochlorite solution and rinsed with sterile deionized water. Subsequently, seeds were kept under a sterile bench for drying. The fractions were dissolved in sterile tap water with the addition of $1 \%$ dimethyl sulfoxide (DMSO) (v/v) as a surfactant. In each of the 24-wells, a single seed was placed on a sterile filter paper disc $(\varnothing: 1 \mathrm{~cm})$. Serial dilutions of the treatments were prepared in a 1:1 dilution series from 1000 to $62.5 \mu \mathrm{g} \mathrm{mL}^{-1}$. In each well, $125 \mu \mathrm{L}$ of the solution was added. Six seeds per treatment were used in five replicates for the lower concentrations. Four and three replicates were used for 500 and $1000 \mu \mathrm{g} \mathrm{mL}^{-1}$, respectively. Sterile tap water with $1 \%$ DMSO served as a control. The plates were incubated at $25^{\circ} \mathrm{C}$ in the dark and randomly redistributed every $24 \mathrm{~h}$. After three days of incubation, the germination rate was documented.

The allelochemicals in the phytotoxic fraction were identified and quantified as described above. Based on the results, the phytotoxicity of the allelochemicals in the phytotoxic fraction was assessed using the same germination test. The test was conducted in Petri dishes $(\varnothing: 9 \mathrm{~cm})$. Seven seeds were sown in each petri dish in four replicates and watered with $4.5 \mathrm{~mL}$ of the dilutions. After three days, the germination rate was documented, and the length of roots was determined using ImageJ software (Rasband 1997-2019).

\subsection{2. weed suppression by plant residues}

The shoots of sweet clover and radish were harvested, freeze-dried, and milled using mortar and pestle. Radish seeds were placed on the surface of a soil mixture consisting of 2:1:1 peat moss/compost/sand (w/w/w) in ten plastic pots per treatment at a density of nine seeds per pot. The powdered shoot was placed on seeds at a rate of $15 \mathrm{mg}$ per seed, covering an area of 
approximately $1 \mathrm{~cm}^{2}$ around the seed. The surface of the pots was covered with a thin layer of soil (approximately $5 \mathrm{~mm}$ in height). Ten pots were prepared per treatment. Besides, 8 pots without any plant powder incorporation were prepared as a control. The pots were incubated in a greenhouse at $25^{\circ} \mathrm{C} / 14^{\circ} \mathrm{C}$ (day/night) with a $16 \mathrm{~h}$ photoperiod and regularly irrigated from the top. The germination rate was reported daily for 12 days after treatment. The survival rate was documented on the last day since not all the germinated seeds were viable.

\subsection{Chemical analysis}

\subsubsection{HPLC-MS}

Depending on the bioassay results, the phytotoxic fraction was subjected to a high-performance liquid chromatography system coupled to a quadrupole time-of-flight mass detector (HPLCMS-QTOF, Agilent, Agilent, Darmstadt, Germany). The HPLC system based on Agilent 1290 Infinity II series equipment and consisted of a quaternary pump, autosampler, a thermostatted column compartment, and a diode-array detector (DAD). The HPLC coupled to a quadrupole time-of-flight high-resolution mass detector (Agilent 6545 LC/Q-TOF, Agilent, Darmstadt, Germany) with dual Jet Stream electrospray ionization (AJS ESI). The column was (ZORBAX Eclipse plus C18, 50 x $2.1 \mathrm{~mm}, 1.8 \mu \mathrm{m}$, Agilent) with a guard column (ZORBAX Eclipse plus $\mathrm{C} 18,5 \times 2.1 \mathrm{~mm}, 1.8 \mu \mathrm{m})$. The system was operated by Mass Hunter Workstation Software, LC/MS Data Acquisition for 6500 Series Q-TOF, Version B.08.00 (Agilent, Darmstadt, Germany). The mobile phase A was water, and B was MeOH. To both $0.1 \%$ formic acid (v/v) was added. The injection volume was $2 \mu \mathrm{L}$, and the flow rate of $0.4 \mathrm{~mL} / \mathrm{min}$. The initial condition was 5\% B that increased linearly to $95 \%$ in $10 \mathrm{~min}$, which was held for 2 min for purging, and then decreased to the initial condition in $1 \mathrm{~min}$ with $3 \mathrm{~min}$ re-equilibration. The samples were measured in both positive and negative ionization mode with a full MS scan and MSMS scan. The results were analyzed using Mass Hunter Workstation Software, Qualitative Analysis Navigator Version B.08.00 (Agilent, Darmstadt, Germany). The allelochemicals were identified tentatively by comparing the MS/MS spectra with the MS databases (HMDB and KEGG) using the online tool CFM-ID (Competitive Fragmentation Modelling for metabolites identification). The predicted results were confirmed by comparing the MS spectra to those of commercially available analytical standards. The quantity of the detected metabolites in the phytotoxic fraction was estimated based on serial dilutions of the standards. After identification of the compounds, the commercial standards were used for subsequent bioassays. 


\subsubsection{GC-MS}

Five $\mathrm{mg}$ of dried sample was dissolved in $100 \mu \mathrm{L}$ pyridine to which methoxyamine hydrochloride (30 mg mL-1) was added. The solution was kept at room temperature for $12-$ 18 hours. Then $40 \mu \mathrm{L}$ of this solution, $40 \mu \mathrm{L}$ N-methyl-N-(trimethylsilyl) trifluoroacetamide (MSTFA), was added, and the sample well vortexed. GC-MS analysis was performed on a 5977B MSD quadrupole mass detector linked to a 7890B GC (Agilent GmbH, Waldbronn, Germany). The column was an HP5-MS (30 m x $0.25 \mathrm{~mm} \times 0.25 \mu \mathrm{m}$, Agilent $\mathrm{GmbH}$, Waldbronn, Germany) and obtained from the same company. Helium was used as carrier gas $\left(1 \mathrm{~mL}\right.$ min-1). The injector was used in the splitless mode and heated to $230{ }^{\circ} \mathrm{C}$. The temperature gradient was as follows: 0-2 min: $50{ }^{\circ} \mathrm{C}, 3 \neg-58 \mathrm{~min}: 50-330{ }^{\circ} \mathrm{C}, 59-60: 330{ }^{\circ} \mathrm{C}$. Transfer line temperature was $330{ }^{\circ} \mathrm{C}$, the ion source temperature $230{ }^{\circ} \mathrm{C}$, electron energy 70 $\mathrm{eV}$ for EI ionization. Spectra were recorded in the range of 70-600 Da.

Data analysis

The data files were analyzed using MS-DIAL 3.70 (http://prime.psc.riken.jp/ Metabolomics_Software/MS-DIAL/; Lai et al. 2018). After aligning and peak picking, the deconvoluted mass spectra were identified with a combined MS spectral library (Golm metabolome database, Kopka et al. 2005; All records with Kovats RI and Fiehn BinBase DB, both supplied with MS-DIAL). RI values were calculated based on alkane standards and used for identification.

\subsection{Leaching of allelochemicals from living sweet clover plants by simulated rain}

The artificial rainfall was performed inside a closed spray chamber $(150 \times 80 \times 80 \mathrm{~cm})$ made from stainless steel with a glass door and a drainage valve installed at the bottom. Demineralized water was used for spraying. The $\mathrm{pH}$ of the water was adjusted to 5.3 by fresh, prepared carbonic acid. A pH of 5.3 is the approximate average precipitation $\mathrm{pH}$ in Germany from 2014 to 2017 (German Meteorological Office, 2019).

The spray was performed using a hand pressure sprayer, which was calibrated to generate a precipitation rate of $4 \mathrm{~mm} \mathrm{~h}^{-1}$. This rate was considered moderate precipitation (American Meteorological Society, 2019). Three healthy sweet clover plants were placed in the chamber on a metal rack (height: $10 \mathrm{~cm}$ ) to avoid immersing them in the water. The upper side of the pot was sealed with parafilm around the base of the stem to prevent infiltration of the water into the soil. The spraying was performed for $6 \mathrm{~h}$. The water was collected instantly through 
the drainage valve. The experiment was repeated three times with different sweet clover plants. The water was filtered through filter paper $\left(\right.$ Rotilabo $^{\circledR}$ folded filters, type 113 p, Karl Roth, Karlsruhe, Germany). The purification was achieved using flash chromatography (Sepacore ${ }^{\circledR}$ Flash system X10/X50, BUCHI, Flawil, Switzerland) equipped with a binary pump (Module C-601/C-605). The capturing of the allelochemicals was performed with a reverse-phase column (Chromoband ${ }^{\circledR}$ Flash cartridge RS C 18 ec 40-63 $\mu$ m, 240 x 30 mm, MACHEREYNAGEL, Düren, Germany). The mobile phase A was artificial rainwater with $0.1 \%$ acetic acid (v/v), and $\mathrm{B}$ was $\mathrm{MeOH}$ with $0.1 \%$ acetic acid (v/v). $5 \% \mathrm{~B}$ and $95 \%$ A were pumped along the purification process until the whole amount of water was finished. Finally, the captured compounds were eluted by $300 \mathrm{~mL} \mathrm{MeOH}$. The flow rate was $40 \mathrm{~mL} \mathrm{~min}^{-1}$. The fraction was concentrated into $2 \mathrm{~mL}$ using the rotary evaporator, transferred into $2 \mathrm{~mL}$ Eppendorf tube, and dried out via a vacuum concentrator. The chemical analysis was performed as described in 2.5. Recovery efficacy was estimated by spraying artificial rainwater spiked with $1 \mathrm{mg}$ of each allelochemical detected in the sweet clover extract. Three replicates of the spiked water were prepared and purified using the same method as the rainfall samples.

\subsection{Allelochemicals leaching in soil}

For this experiment, soil samples were collected from an organic vegetable garden located in Goettingen, Germany (51³4' 12.6696", N $9^{\circ}$ 55' 42.7116" E). The soil type was classified as a Cambisol. Samples were taken from the upper $20-\mathrm{cm}$ soil layer and homogenized. Soil characteristics (soil pH, exchangeable cations, effective cation exchange capacity, and base saturation) were analyzed as described by Allen et al. (2015) (Table S1). The soil was dried at room temperature, sieved through a $2 \mathrm{~mm}$ sieve, and the gravimetric water content was adjusted to $10 \%$. To follow allelochemicals movement in the soil, a modified method initially described by Xiao et al. (2017) was used. Briefly, $20 \mathrm{~g}$ of fresh soil were placed in cylindrical glass containers (Height: $25 \mathrm{~mm}, \varnothing: 50 \mathrm{~mm}$ ) at the height of approximately $4 \mathrm{~cm}$. Standards of the investigated allelochemicals ( $1 \mathrm{mg}$ from each standard per soil column) were dissolved in 3.5 $\mathrm{mL}$ water with $1 \%(\mathrm{v} / \mathrm{v})$ DMSO and poured on the surface of each soil column. The columns were rinsed with $3.5 \mathrm{~mL}$ each, $1 \mathrm{~h}$ after the treatment. Soil samples were collected at a depth of about 0-2 and 2-4 cm after one day of the treatment. The extraction of the allelochemicals was performed from the whole soil sample using $\mathrm{MeOH}$ in a $50 \mathrm{~mL}$ falcon tube. Samples were shaken at $200 \mathrm{rpm}$ at $20^{\circ} \mathrm{C}$ for $5 \mathrm{~h}$ and subsequently centrifuged at 4,500 rpm for $15 \mathrm{~min}$. The supernatant was collected and concentrated into $2 \mathrm{~mL}$ using a vacuum concentrator. They were 
transferred into $2 \mathrm{~mL}$ Eppendorf tubes and centrifuged at 13,500 rpm for 5 minutes. Following centrifugation, the supernatant was filtered by a $200 \mu \mathrm{m}$ membrane filter (Sartorius, Goettingen, Germany) and subjected to HPLC-MS to quantify the allelochemicals as described in section 2.5.

\subsection{Impact of allelochemicals on soil microorganisms}

A mixture of the allelochemical compounds was prepared. From this mixture, $100 \mu \mathrm{g} \mathrm{g}^{-1}$ fresh soil was dissolved in $3.5 \mathrm{~mL}$ water with $1 \%(\mathrm{v} / \mathrm{v})$ DMSO and poured on the surface of each soil column as described above in 2.7.5. After $1 \mathrm{~h}$ post-application of the allelochemicals mixture, the $3.5 \mathrm{~mL}$ tap water was added. Tap water with $1 \%$ DMSO served as a control. Six replicates from treatments and six from the control were prepared. The soil columns were incubated at $20^{\circ} \mathrm{C}$ in the dark. The columns were randomly redistributed every $24 \mathrm{~h}$. Samples were taken seven days after the treatment at two different depths $(0-2 \mathrm{~cm}$ and $2-4 \mathrm{~cm})$. The samples were lyophilized for $48 \mathrm{~h}$ and ground. Finely ground material was used for both chemical extraction and soil DNA extraction.

\subsection{Soil DNA extraction and quantification of bacterial and fungal taxonomic groups by real-time PCR}

DNA from freeze-dried soil samples was extracted using a slightly modified Beule et al. (2017) protocol. Briefly, $50 \mathrm{mg}$ finely ground soil was suspending in $1 \mathrm{~mL} \mathrm{CTAB}$ with proteinase $\mathrm{K}$ and thoroughly mixed. The mixture was incubated at $42^{\circ} \mathrm{C}$ and $65^{\circ} \mathrm{C}$ for $10 \mathrm{~min}$ each. Following incubation, phenol purification was performed. Following this, two chloroformisoamyl alcohol steps were conducted. DNA was precipitated with polyethylene glycol, pelleted by centrifugation. Pellets were washed with ethanol twice and subsequently dried using vacuum centrifugation. The pellets were resuspended in $50 \mu \mathrm{l}$ TE buffer (10 mM Tris, 1 $\mathrm{mM}$ EDTA, $\mathrm{pH}$ 8.0) and incubated at $42^{\circ} \mathrm{C}$ for $2 \mathrm{~h}$ to facilitate the dissolution of the DNA. Extraction success was assessed on $0.8 \%$ (w/v) agarose gels stained with ethidium bromide. Standard curves for the real-time PCR (qPCR) assays were generated in two replicates using 1:10 serial dilutions quantified PCR products in $0.5 \mathrm{X}$ TE buffer. For a standard generation, DNA from representatives of the different bacterial and fungal taxonomic groups (Table S1) was extracted using a CTAB protocol (Brandfass and Karlovsky 2008). All products used for the quantification were re-amplified from their specific bands excised from 1.7\% (w/v) agarose gels stained with ethidium bromide and purified using isopropanol precipitation with two $80 \%$ 
(v/v) ethanol washing steps to increase the accuracy of the quantification of the PCR products serving as standards.

All qPCR reactions were conducted in a CFX384 Thermocycler (Bio-Rad, Rüdigheim, Germany) in 384-well microplates. Amplification was performed with 1:50 dilutions of the DNA extracts in $4 \mu \mathrm{L}$ reaction volume containing $3 \mu \mathrm{L}$ master mix (1X reaction buffer; 2.0 or $2.5 \mathrm{mM}$ final $\mathrm{MgCl} 2$ concentration (Table S2); $100 \mu \mathrm{M}$ of each deoxyribonucleoside triphosphate (Bioline GmbH, Luckenwalde, Germany); $0.3 \mu \mathrm{M}$ of each primer (Table S2), 1 $\mathrm{mg} / \mathrm{mL}$ bovine serum albumin; $0.03 \mathrm{u}$ DNA polymerase (Table S3) and $1 \mu \mathrm{L}$ template DNA solution or double-distilled $\mathrm{H}_{2} \mathrm{O}$ for negative controls. The PCR conditions are presented in Table S3. Specific melting curves were obtained by heating the samples to $95^{\circ} \mathrm{C}$ for $60 \mathrm{~s}$ and cooling to $55^{\circ} \mathrm{C}$ for $60 \mathrm{~s}$ followed by a temperature increase from $55^{\circ} \mathrm{C}$ to $95^{\circ} \mathrm{C}$ by $0.5^{\circ} \mathrm{C}$ per cycle with continuous fluorescence measurement.

\subsection{Statistics}

ANOVA, Tukey's HSD test were estimated using 'aov'- and 'TukeyHSD'-function in the 'stats' R-package v3.4.3 in the R v 3.6.1 (R Core Team, 2019). Mann-Whitney U test and Box plots were performed using JMP® (14.1.0), SAS Institute Inc. Dose-response curves were generated using a four-parameter logistic model in SigmaPlot 14.0 (Systat Software, San Jose, CA).

\section{Results:}

\subsection{Bioassay-guided fractionation and chemical analysis}

From the EtOAc extract fractions, only fraction 1 and 2 proved as suitable candidates for further work. Bioassay-guided fractionations showed that the EtOAc fraction and its fraction 1 were phytotoxic to radish seeds with an $\mathrm{EC}_{50}$ value of 195 and $285 \mu \mathrm{g} \mathrm{ml}^{-1}$ respectively (Figure 1B, 1C). However, the inhibitory effect of fraction 1 was not significantly different from the EtOAc fraction at 1000 and $500 \mu \mathrm{g} \cdot \mathrm{ml}^{-1}$.

The same experiment showed that the inhibition effect of fraction 2 on radish seeds is significantly lower than fraction 1 at 1000,500 , and $250 \mu \mathrm{g} \cdot \mathrm{ml}^{-1}$ (Figure 1A). Thus, fraction1 was suggested as the phytotoxicity source.

Depending on the accurate mass and MS/MS and the commercial standards, fraction 1 consisted of the following compounds: A, 3-(2-hydroxyphenyl) propanoic acid or (melilotic 
acid); B, trans-cinnamic acid; C, coumarin; D, o-coumaric acid. The sum of these four compounds was considered $100 \%$, and the proportion of each compound was calculated as a percentage. The proportion of these compounds in the EtOAc fraction in the extract from the year 2015 was slightly different from 2016 (Figure 2C); therefore, the average of each compound over the two years was calculated, and the resulted ratio (A:B:C:D, 38:38:20:4, $\mathrm{w} / \mathrm{w} / \mathrm{w} / \mathrm{w}$ ) was used in bioassays as a ratio that mimics the proportion of the compounds in the aqueous extract.

\subsection{Phytotoxicity bioassay of the purified compounds}

Coumarin showed a strong inhibitory effect on seed germination with an $\mathrm{EC}_{50}$ value of $98 \mu \mathrm{g} \mathrm{ml}^{-1}$ followed by melilotic acid with an $\mathrm{EC}_{50}$ value of $388 \mu \mathrm{g} \mathrm{ml}^{-1}$ (Figure $3 \mathrm{~A}$ ). Moreover, both compounds especially affected root growth. The root length of the germinated seeds at the lowest tested dose $\left(62 \mu \mathrm{g} \mathrm{ml}^{-1}\right)$ did not exceed $20 \%$ of that of the control plant. Furthermore, the results indicated that trans-cinnamic acid caused a weak inhibition on seed germination with an $\mathrm{EC}_{50}$ value of $624 \mu \mathrm{g} \mathrm{ml} \mathrm{m}^{-1}$, and $o$-coumaric acid did not disturb germination of radish seed at all. On the other hand, both compounds caused dose-dependent inhibition on the growth of the roots, an $\mathrm{EC}_{50}$ value of $223 \mu \mathrm{g} \mathrm{ml}^{-1}$, and the root growth was inhibited as well.

The incorporation of the sweet clover residues in the soil (Figure 4A) showed an apparent delay in the germination of the radish seeds compared to the same treatment with radish residues and water as a control. Moreover, the survival rate of radish plants after 12 days per treatment (Figure 4B) was calculated by subtracting the non-germinated seeds and the dead seedlings after germination from the total seed number. The results showed that survival rate of the seeds, treated with seeds clover residues were significantly lower than the survival rate of seed with radish residues and water at a significant level of $\alpha=0.05$ (water-Sweet clover $p=0.0004$, radish-Sweet clover $p=0.0157$, water-Radish $\mathrm{p}=0.2609)$. In contrast, no significant difference was recorded through the last two treatments. 

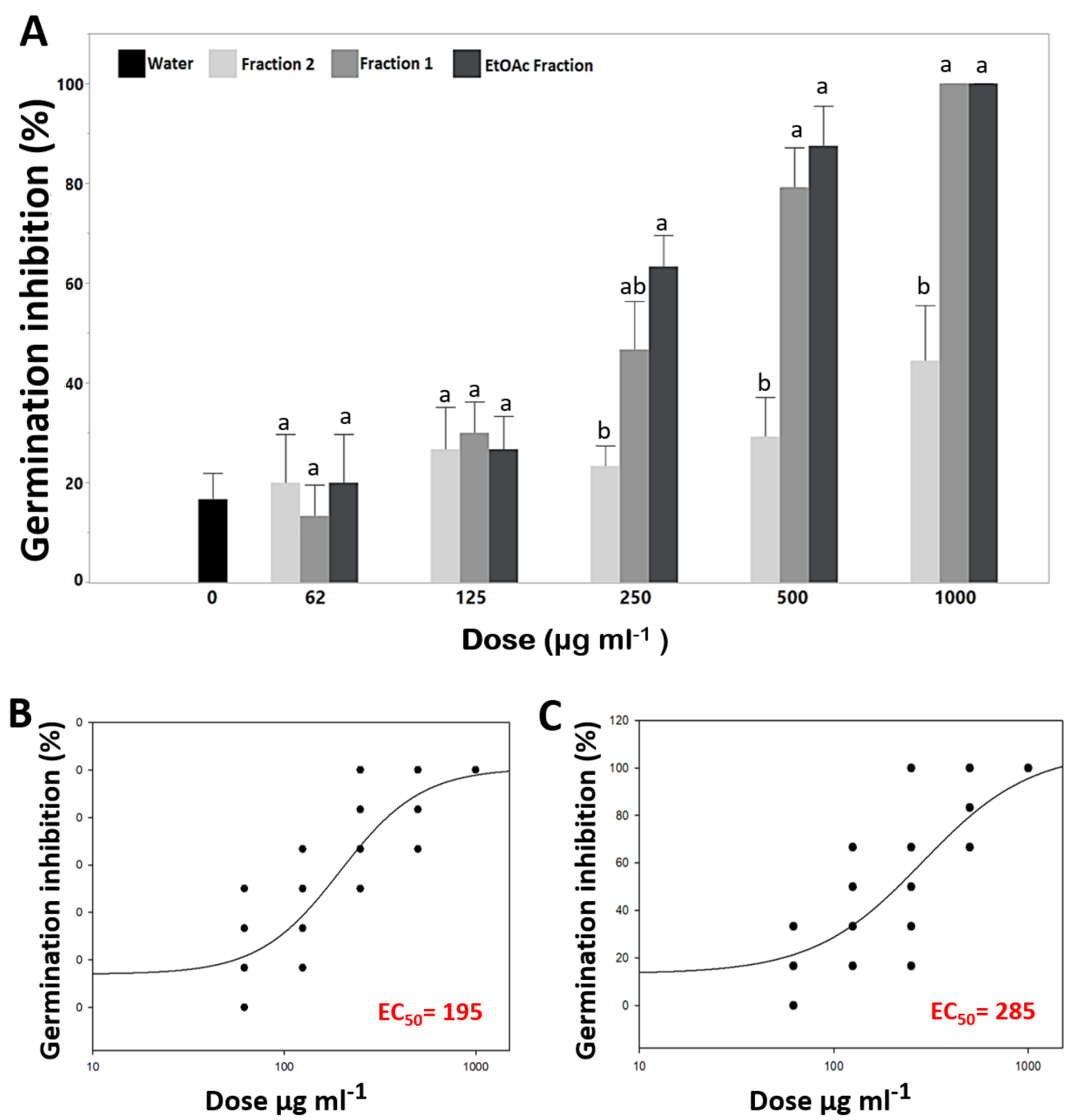

Figure 1. Germination inhibition of Radish Seeds. (A) Effect (mean and standard error) of serial dilutions of total EtOAc fraction, fraction1, fraction2, and water (control) on germination of radish seeds; one-way ANOVA and post-hoc 95\% Tukey, $\mathrm{n}=3-5$. (B, C) dose-response curves of germination inhibition of radish seeds as a response to the treatment with EtOAc fraction (B) and fraction 1 (C). $\mathrm{EC}_{50}$ is calculated by non-linear regression and a four-parameter logistic model. 

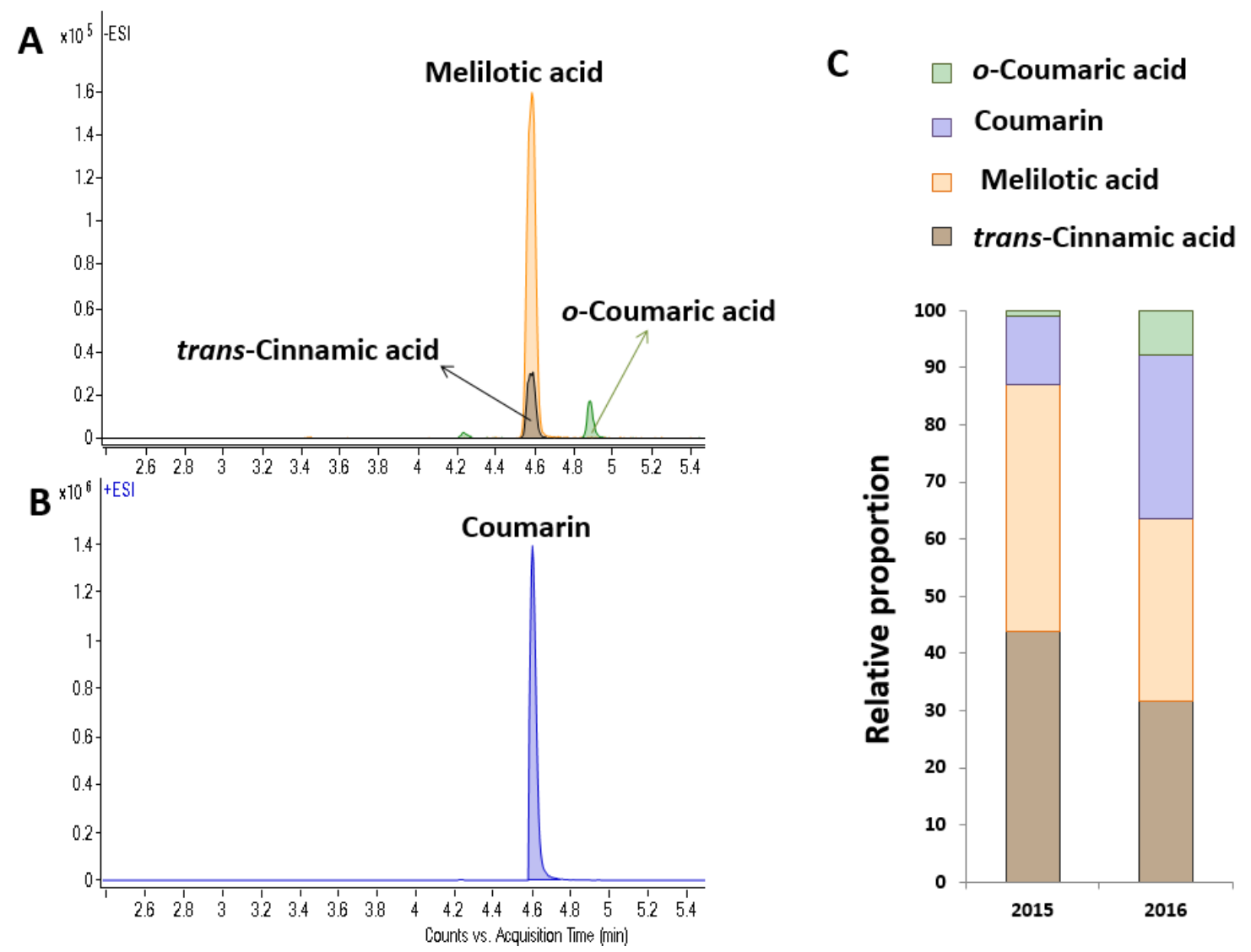

Figure 2. Overlay of Extracted Ion Chromatograms of trans-cinnamic acid, Melilotic acid, and $O$-Coumaric acid obtained by Q-TOF LC/MS from fraction 1 in negative mode (A) and Coumarin in positive mode (B). Percentage of the detected compounds in the EtOAc fraction from sweet clover in 2015 and 2016, the sum of the four compounds was considered as $100 \%$, and the proportion of each compound was calculated as a percentage out of the sum (C) 


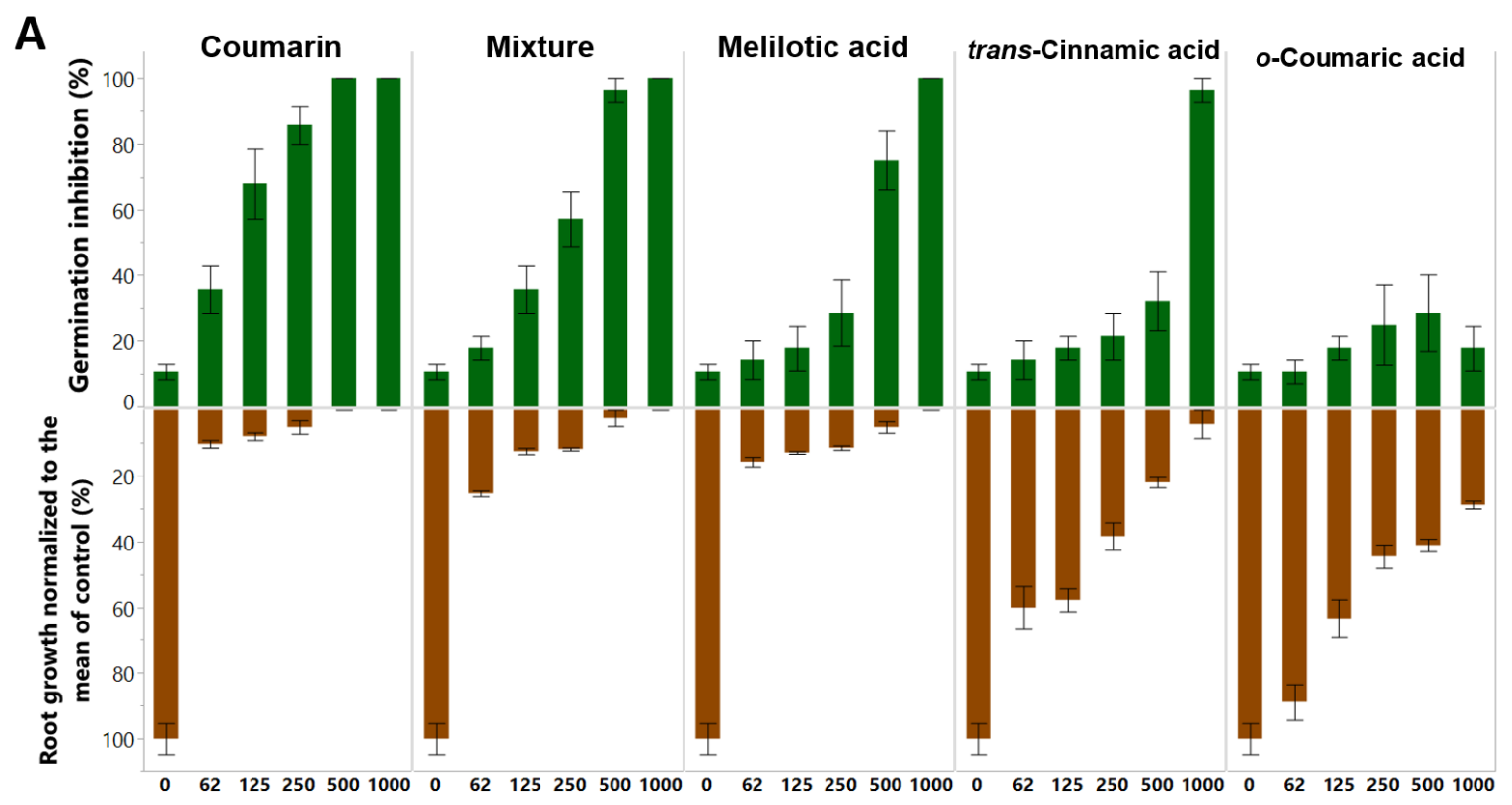

Dose ( $\mathrm{ug} \mathrm{ml}^{-1}$ )

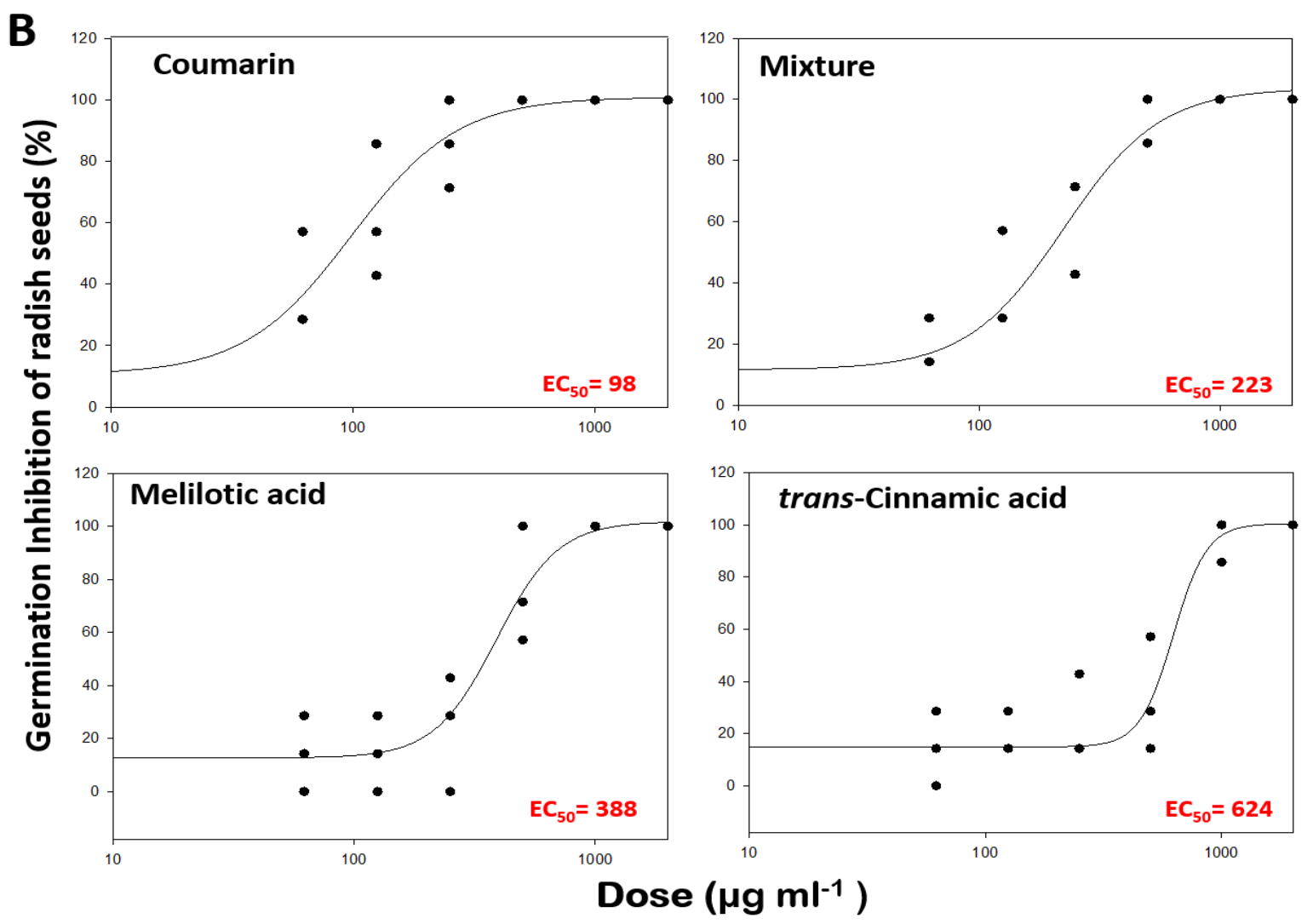

Figure 3. Inhibition of root and shoot growth of Radish. (A) Effect of serial dilutions of coumarin, o-coumaric acid, trans-cinnamic acid, melilotic acid, and their mixture on germination and root length of radish compared to water control. The error bars represent the standard error of the mean, $n=4$. (B) Dose-response curves illustrate the germination inhibition of radish seeds as a response to the treatment with various doses of the investigated compounds. $\mathrm{EC}_{50}$ was calculated by non-linear regression using a four-parameter logistic model. 


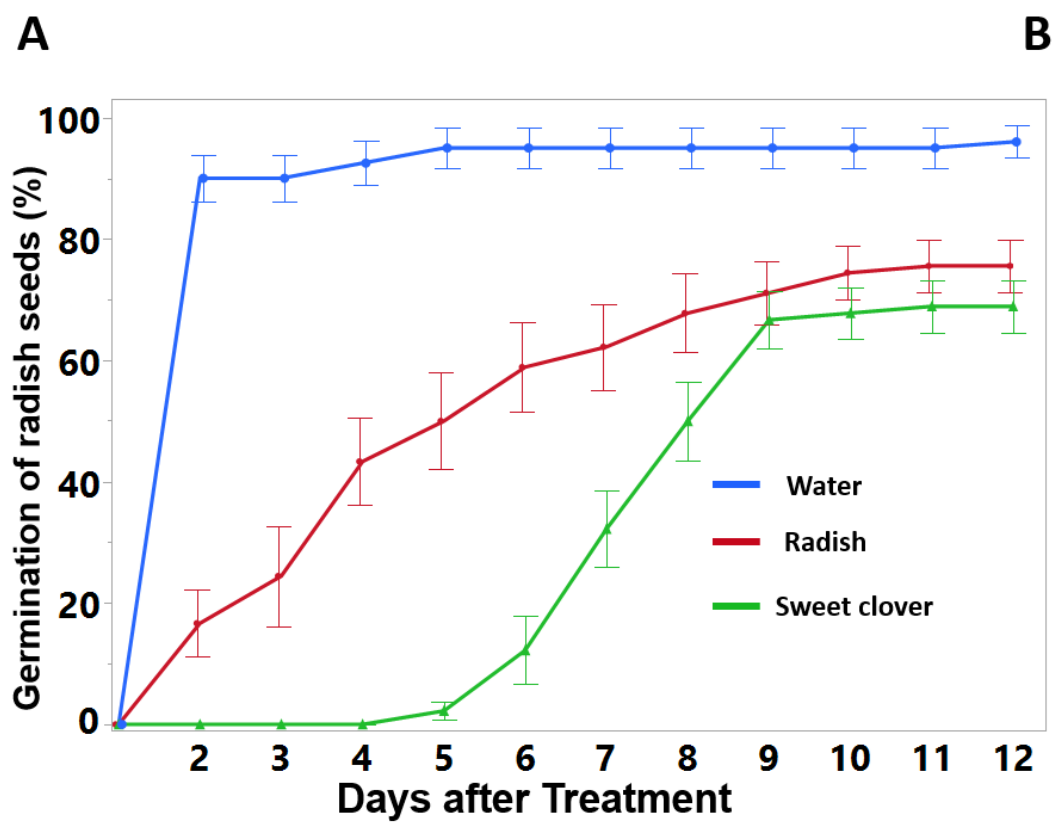

\section{B}

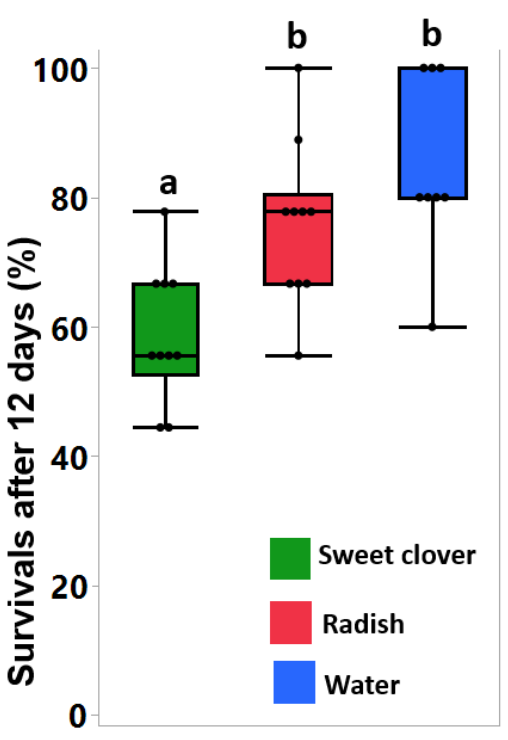

Figure 4. Germination and survival of radish seeds after treatment with grounded shoots of sweet clover while radish and water were used as control (means + standard error, one-way ANOVA, and $95 \%$ Tukey HSD, $n=8-10$ ). (A) Germination of radish seeds; (B) Survival of radish plants after 12 days of treatment. Boxes represent the $75^{\text {th }}$ percentile, median, and the $25^{\text {th }}$ percentile. Whiskers range from the $75^{\text {th }}$ percentile to the maximum value and from the $25^{\text {th }}$ percentile to the minimum value. Black dots represent individual data points.

\subsection{Natural release of allelochemicals from living sweet clover plants}

The rain leachate and root exudate of sweet clover were collected and analyzed using HPLCMS and GC-MS. Various phenolic compounds were identified in both samples (leachate and exudate) see (suppl. Figure.1). Our target compounds were detected in both samples as well. Melilotic acid and o coumaric acid were released mainly as glucosides (Figure. 5). The main free compound in the samples was coumarin. However, the relatively highest abundant glucoside was Melilotoside (o-coumaric acid-glucoside) in the root exudate, where its relative abundance (per g tissue) was $80 \%$ from the original leaves content. 


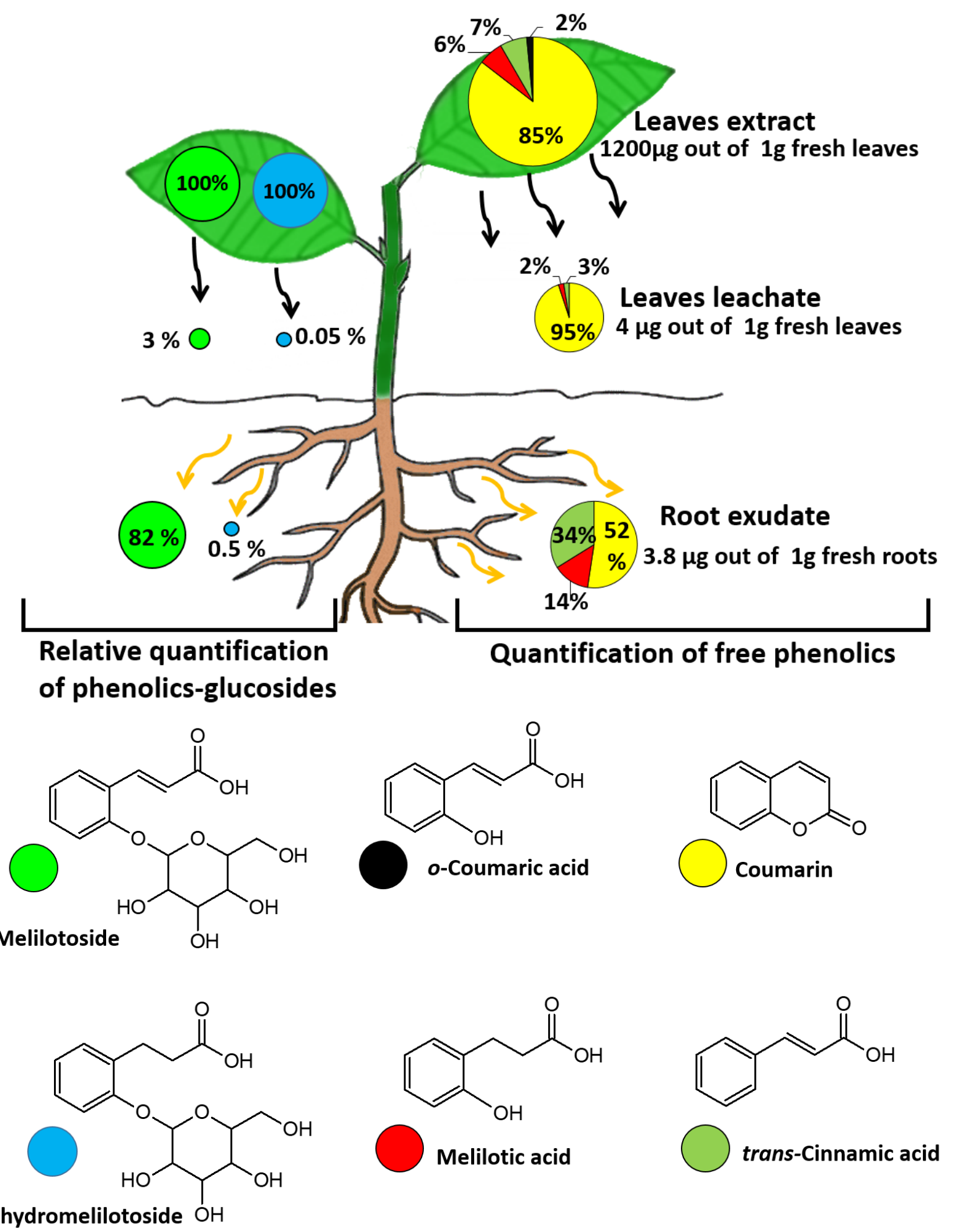

Figure 5. identification and quantification of the potentially phytotoxic compounds. In leaf leachates and root exudates and leaves $\mathrm{MeOH} /$ Water (50:50) extract, quantified depending on standards using HPLC-MS(right). Relative quantification of the Melilotosied and dihydromelilotoside depending on the peak area (left) 


\subsection{Allelochemicals leaching in soil and their impact on microorganisms}

The tracking of the movement of allelochemicals in soil showed that they varied in their ability to leach into the soil. However, Coumarin accumulated mainly in the upper $2 \mathrm{~cm}$ layer (Figure. 6).

Applying a mixture of sweet clover allelochemicals on upper layer of soil (0-2 cm depth) revealed a significant inhibition effect against three bacterial groups (Gammaproteobacteria, Bacteroidetes, and Gemmatimonadetes) ( $p=0.005, p=0.012$ and $p=0.042)$ respectively at two different significant levels; $\alpha=0.05, \alpha=0.01$ )(Figure 7). The inhibitory effects were not visible when monitoring total bacteria and fungi. Among bacteria, the other investigated bacterial groups (Alphaproteobacteria, Betaproteobacteria, Actinobacteria, Verrucomicrobia, Firmicutes, and Acidobacteria) showed no significant inhibition. The inhibitory effects were also not visible at a soil depth of 2-4 cm (Figure 7).

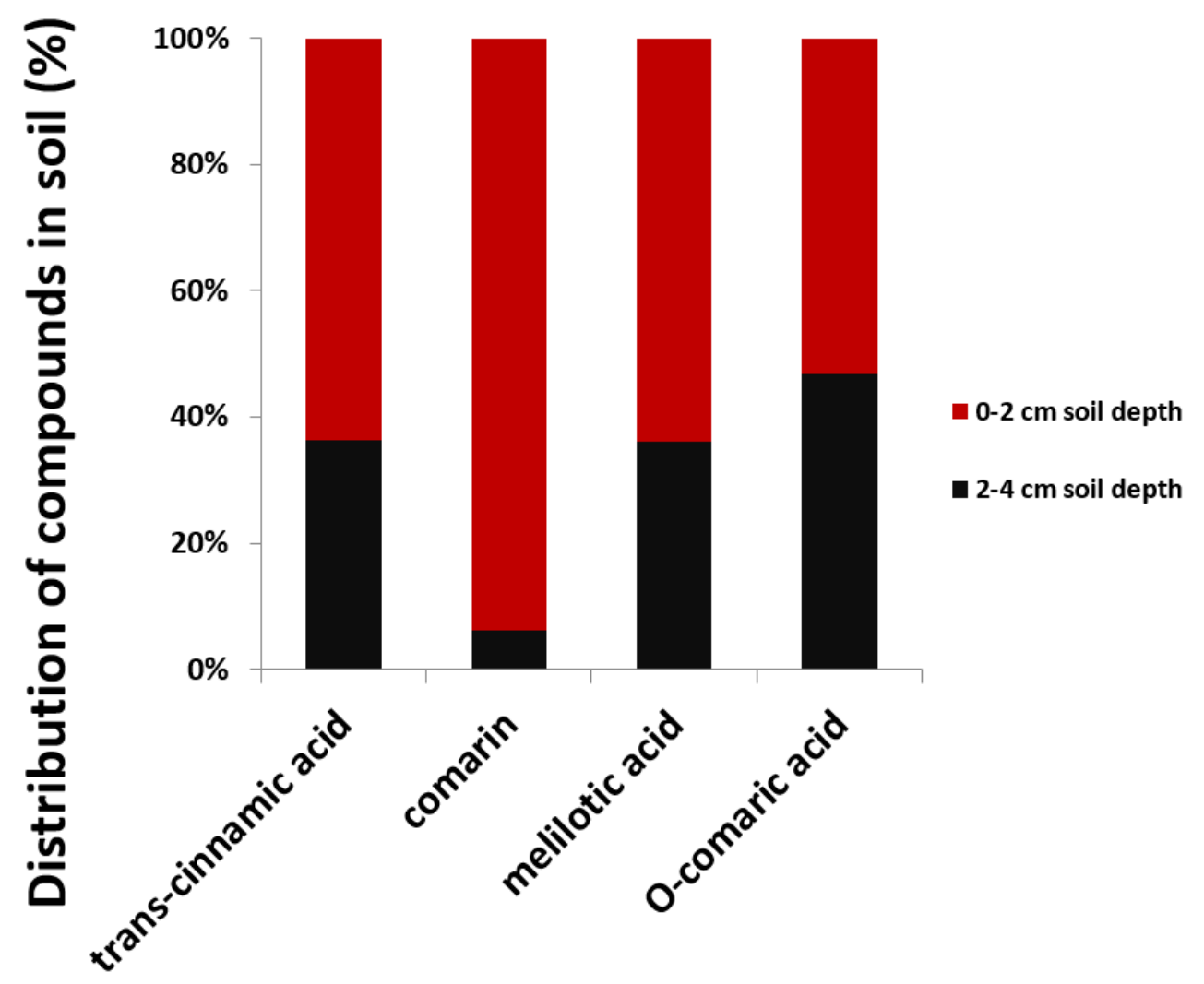

Figure 6. relative abundance of the investigated compounds at two different soil depths $(0-2 \mathrm{~cm}$ and $2-4 \mathrm{~cm})$ one day after pouring them on the surface of the soil. 

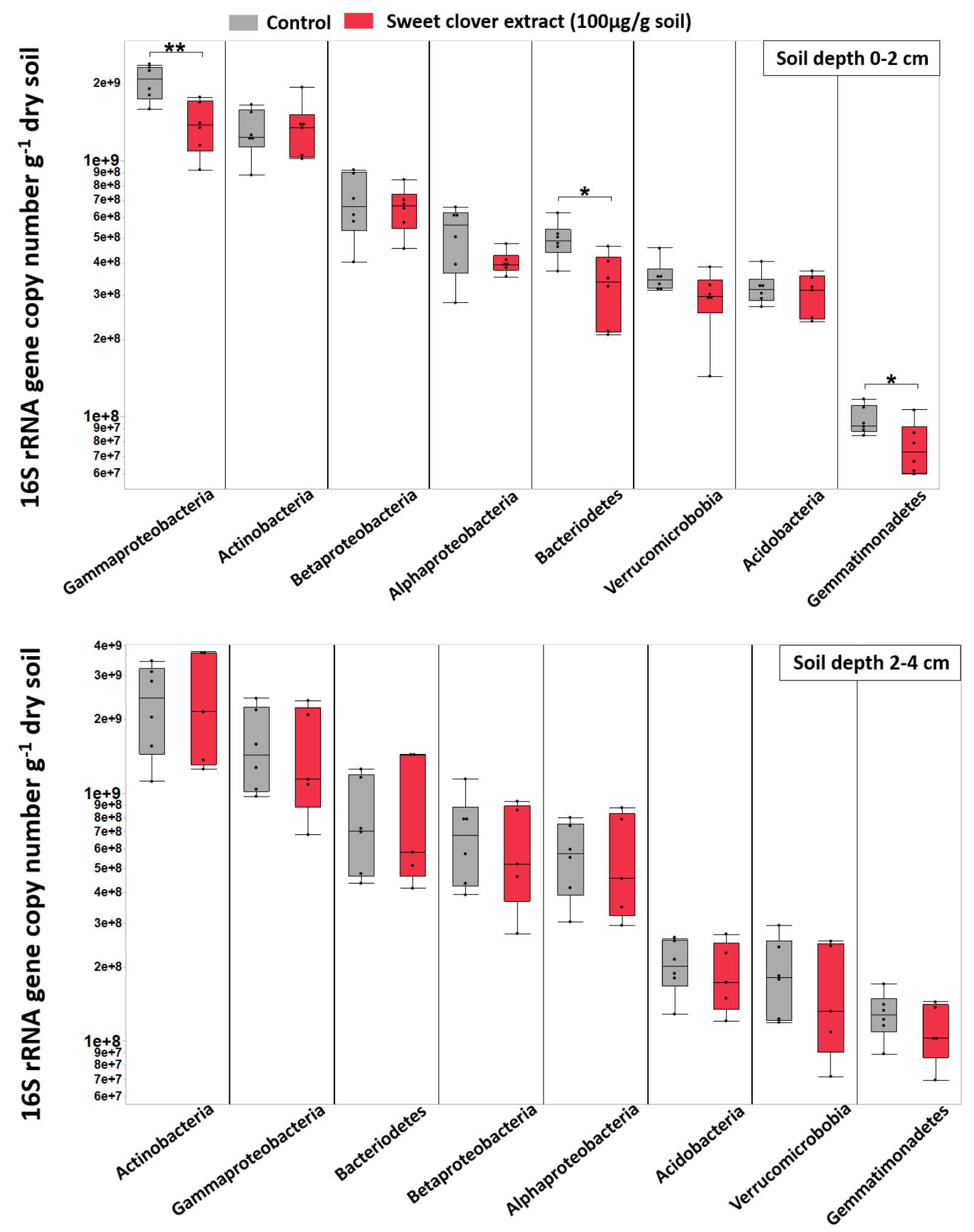

Figure 7. Number of $16 \mathrm{~S}$ rRNA genes of various soil bacterial groups per g dry soil at two different soil depths $(0-2 \mathrm{~cm}$ and 2-4cm). Asterisks refer to the significance level of differences between water control and a mixture of allelochemicals from sweet clover within one bacterial group (t-test or Mann-Whitney U test, $\mathrm{n}=5-7)$. ${ }^{*} p \leq 0.05$ and ${ }^{* *} p<0.01$. Boxes represent the $75^{\text {th }}$ percentile, median, and the $25^{\text {th }}$ percentile. Whiskers range from the $75^{\text {th }}$ percentile to the 
maximum value and from the $25^{\text {th }}$ percentile to the minimum value. Black dots represent individual data points.

\section{Discussion}

The plant tissues are rich in secondary metabolites, but only those compounds that are released into the environment may contribute to an allelopathic effect on another organism. Li et al. (2010). These authors also pointed out that water is the only solvent existing in nature and, therefore, should be preferred to any other solvents for the extraction of phenolic compounds. This study aimed to investigate the leachates from sweet clover and explore the ecological function of its allelochemicals. Consequently, the extraction was conducted only with water to mimic nature, at least to some extent.

The results of bioassay-guided fractionation and chemical analysis (Figures 1,2) showed that the source of the phytotoxicity was a mixture of the following compounds: 3-(2hydroxyphenyl)-propanoic acid (melilotic acid), trans-cinnamic acid, coumarin, and $o$ coumaric acid. Structurally, the compounds are highly similar. That may explain the elution of the metabolites at almost the same retention time.

All identified compounds are involved in the coumarin biosynthesis, as shown in (Figure 8).

Figure 8. The proposed biosynthesis of coumarin from phenylalanine, as described by<smiles>NC(Cc1ccccc1)C(=O)O</smiles>

Phenylalanine<smiles>C1CCCCC1</smiles><smiles>O=C(O)/C=C/c1ccccc1</smiles>

trans-Cinnamic acid<smiles>O=c1ccc2ccccc2o1</smiles>

Coumarin<smiles>O=C(O)/C=C/c1ccccc1O</smiles>

o-Coumaric acid<smiles>CCC(C)=O</smiles>

Melilotic acid<smiles>COc1ccccc1CCC(=O)O</smiles>

Melilotic acid Glucoside

Gestetner and Conn( 1974) and Stoker and Belleis (1962). Some glycosylated compounds are not shown for clarity 
Coumarin, $o$-coumaric acid, and melilotic acid have been identified previously as the main phytotoxic compounds in sweet clover Nicollier and Thompson (1982).

The results of the phytotoxicity on radish (Figures 3A, 3B) revealed that coumarin and melilotic acid have a strong inhibitory effect on radish seed germination. These results also confirmed the study of Nicollier and Thompson (1982), in which coumarin and melilotic acid also were identified as a phytotoxic principle in assays on radish and tomato. Dornbos and Spencer (1990) tested the phytotoxicity of coumarin on alfalfa (Medicago sativa), annual ryegrass (Lolium multiflorum) with two different assays methods. The standard germination test in Petri dishes, which was similar to one that we used, showed that the $\mathrm{LD}_{50}$ values of coumarin on $M$. sativa and L. multiflorum were respectively 60 and $65 \mu \mathrm{g} \mathrm{ml}^{-1}$. In the second assay, which utilized agar as a medium, the $\mathrm{LD}_{50}$ values for $M$. sativa and L. multiflorum were 6-9- fold lower than on filter paper in Petri dishes. Such strong phytotoxicity may contribute to coumarin, causing weed suppression in the field.

trans-Cinnamic acid suppressed germination only weakly, and $o$-coumaric acid showed no effect at all. However, both compounds inhibited root growth in a dose-dependent fashion. In congruence, Reigosa et al. (1999) reported that phenolic acids affect seedling growth more than seed germination in general. Our results also indicated that the mixture of the active compounds was more phytotoxic than the individual allelochemicals except for coumarin, which made up $20 \%$ of the mixture. This suggests the synergistic effects of melilotic acid, trans-cinnamic, and $o$-coumaric acid. Many authors supposed that in nature, the combinations of allelochemicals can cause more pronounced effects through synergistic activity (Blum, Gerig, and Weed 1989; Einhellig and Rasmussen 1978; Al-Naib and Rice 1971; Reigosa et al. 1999). The incorporation of sweet clover in soil caused a noticeable delay in seed germination and a significant reduction in survival plants. Our results support the notion that coumarin and related compounds, which are still present in the residues or accumulate as plant leachates in the soil, can trigger the observed effects. Generally, it is well documented that phytotoxic metabolites that are released from plant residues during decomposition can produce inhibitory effects on other plants such as delay or inhibition of seed germination, reduction of growth of seedlings, root injury, wilting, stunting and chlorosis, amongst others (Patrick, Toussoun, and Koch 1964).

Other assays showed that, besides phytotoxic effects, the sweet clover allelochemicals mixture significantly inhibits three of the investigated bacterial groups, one of the major components of the soil bacterial community, Gammaproteobacteria. This class from the phylum 
Proteobacteria represented the highest abundant group of bacteria in our tested soil. Generally, the phylum Proteobacteria is the most dominant soil bacteria across the globe, and particularly Alpha-, Beta-, and Deltaproteobacteria (Delgado-Baquerizo et al. 2018). Although Gammaproteobacteria represents only one of many classes of soil bacteria, it includes more genera than most of the other bacterial phyla. It is classified as gram-negative bacteria and comprises many medically and ecologically important genera, such as Escherichia, Salmonella, Pseudomonas, Xanthomonas, Nitrococcus, Acidithiobacillus, Yersinia, and Vibrio.

Furthermore, It includes crucial insect endosymbionts, such as Buchnera in aphids, Hamiltonella in whiteflies, and Blochmannia in ants (Garrity et al. 2005; Williams et al. 2010). According to Mansfield et al. (2012), eight out of the top ten bacterial plant pathogens belong to the genera Pseudomonas, Xanthomonas, Erwinia, Xylella, Dickeya, and Pectobacterium. All of these eight plant pathogens classify as Gammaproteobacteria. To our knowledge, until today, no studies report that sweet clover is susceptible to Pseudomonas and Xanthomonas. Although many species from the genera Medicago and Trifolium, which are phylogenetically closely related to the genus Melilotus in the tribe Trifolieae, are susceptible to Pseudomonas and Xanthomonas infection (Nemchinov et al. 2017; Nelson and Campbell 1993; Esnault et al. 1993; Steele and Wojciechowski 2003). Zhang and Nan (2014) studied the pathogenicity of the bacterial legume pathogen Erwinia persicina against 22 species of legumes and found the least severe effect showing in M. albus and M. officinalis.

This additional information supports our findings that coumarin and related allelochemicals inhibit Gammaproteobacteria, to which the most important plant pathogens classify. Likewise, no reports exist that sweet clover is a host plant for bacterial pathogens.

Another critical issue that merits consideration is that sweet clover is a legume species. Rhizobium bacteria from Alphaproteobacteria, such as Ensifer, Phyllobacterium, and Rhizobium, form a symbiotic association with sweet clover (Bromfield et al. 2010). Accordingly, we hypothesize that the leaching of allelochemicals into the soil might favor nodule initiation by Rhizobium bacteria by concomitantly inhibiting the antagonists from Gammaproteobacteria.

The phyla Bacteroidetes and Gemmatimonadetes were also significantly inhibited by the investigated allelochemicals. Both phyla are gram-negative bacteria and have been widely reported in soil and sediment. Depending on the 16S rRNA genes in libraries prepared from soil bacteria, Bacteroidetes and Gemmatimonadetes have been ranked in the most dominant nine bacterial phyla in soil globally (Janssen 2006; Delgado-Baquerizo et al. 2018). 
Conversely, the other investigated bacterial groups showed no significant differences, which indicates that the antimicrobial effect may be very selective.

Furthermore, the total fungal quantification indicates that some treated samples are colonized more abundantly than the control, but not statistically significant. In this context, it is known that some fungal species, such as Aspergillus ssp. Moreover, Penicillium spp. can use transcinnamic acid, coumarin, o-coumaric acid, and melilotic acid as substrate (Bocks 1967; Murray, Méndez, and Brown 1982; Costa, Tavares, and de Oliveira 2016).

\section{Conclusion}

The investigated allelochemicals, trans-cinnamic acid, coumarin, o-coumaric acid, and melilotic acid, exerted potent inhibition on germination and growth of radish. Moreover, they are released into the environment in root exudate and leaf leachates. Furthermore, incorporating sweet clover residues into the soil caused a delay in germination and a significant reduction in plant survival. Furthermore, the same allelochemical mixture caused manipulation of the abundance of the bacterial groups in the upper soil layer. Here the question arises, whether the phytotoxic effect which we observed when incorporating the plant residues into the soil are caused (1) by direct toxicity of the allelochemicals; or (2) as a result of a modulated soil microbial community; or (3) by a combination of both factors. Lou et al. (2016) found that allelochemicals of Trifolium pratense provided weed suppression only for a short time and mostly in the absence of microorganisms suggesting that allelochemicals and soil microbes could antagonize each other. Moreover, the incorporation of fresh Trifolium pratense residues in the soil showed stronger weed suppressive even in the presence of microorganisms. Our study not only confirms previous observations on sweet clover allelochemicals but also paints a much complex picture of their potential interactions in soil by unraveling specific interactions with different members of the soil bacterial community.

\section{References}

\footnotetext{
Al-Naib, Falah Abdul-Ghani, and Elroy L. Rice. 1971. "Allelopathic effects of Platanus occidentalis." Bulletin of the Torrey Botanical Club 98 (2): 75-82. https://doi.org/10.2307/2483770.

Blum, Udo, Thomas M. Gerig, and Sterling B. Weed. 1989. "Effects of mixtures of phenolic acids on leaf area expansion of cucumber seedlings grown in different $\mathrm{PH}$ portsmouth $\mathrm{A} 1$ soil materials." Journal of Chemical Ecology 15 (10): 2413-23. https://doi.org/10.1007/BF01020372.
} 
Bocks, Sheila M. 1967. "Fungal metabolism-I.: The transformations of coumarin, o-coumaric acid and trans-cinnamic acid by Aspergillus Niger." Phytochemistry 6 (1): 127-30.

https://doi.org/10.1016/0031-9422(67)85017-9.

Brandfass, Christoph, and Petr Karlovsky. 2008. "Upscaled CTAB-based DNA extraction and realtime PCR assays for Fusarium Culmorum and F. Graminearum DNA in plant material with reduced sampling error.” International Journal of Molecular Sciences 9 (11): 2306-21. https://doi.org/10.3390/ijms9112306.

Bromfield, E. S. P., J. T. Tambong, S. Cloutier, D. Prévost, G. Laguerre, P. van Berkum, T. V. Tran Thi, R. Assabgui, and L. R. Barran. 2010. "Ensifer, phyllobacterium and Rhizobium Species occupy nodules of Medicago sativa (Alfalfa) and Melilotus alba (Sweet Clover) grown at a Canadian site without a history of cultivation." Microbiology (Reading, England) 156 ( $\mathrm{Pt} 2$ ): 505-20. https://doi.org/10.1099/mic.0.034058-0.

CABI. 2019. "CABI, current year.Melilotus albus . In: Invasive Species Compendium. Wallingford, UK: CAB International. Www.Cabi.Org/Isc.” 2019. https://www.cabi.org/isc/datasheet/33693\#C1994850-5656-45BF-9B13-9FED3C22A7A0.

Cantor, Aaron, Alison Hale, Justin Aaron, M. Brian Traw, and Susan Kalisz. 2011. "Low allelochemical concentrations detected in garlic mustard-invaded forest soils inhibit fungal growth and AMF spore germination." Biological Invasions 13 (12): 3015-25. https://doi.org/10.1007/s10530-011-9986-x.

Conn, Jeffery S., Nancy R. Werdin-Pfisterer, Katherine L. Beattie, and Roseann V. Densmore. 2011. "Ecology of invasive Melilotus albus on Alaskan glacial river floodplains." Arctic, Antarctic, and Alpine Research 43 (3): 343-54. https://doi.org/10.1657/1938-4246-43.3.343.

Costa, Tania Maria, Lorena Benathar Ballod Tavares, and Débora de Oliveira. 2016. "Fungi as a source of natural coumarins production." Applied Microbiology and Biotechnology 100 (15): 6571-84. https://doi.org/10.1007/s00253-016-7660-z.

Delgado-Baquerizo, Manuel, Angela M. Oliverio, Tess E. Brewer, Alberto Benavent-González, David J. Eldridge, Richard D. Bardgett, Fernando T. Maestre, Brajesh K. Singh, and Noah Fierer. 2018. "A Global atlas of the dominant bacteria found in soil." Science 359 (6373): 320-25. https://doi.org/10.1126/science.aap9516.

Dornbos, D. L., and G. F. Spencer. 1990. "Natural products phytotoxicity A aioassay suitable for small quantities of slightly water-soluble compounds." Journal of Chemical Ecology 16 (2): 339-52. https://doi.org/10.1007/BF01021769.

Einhellig, Frank A. 1994. "Allelopathy: Current status and future goals." In Allelopathy, edited by Inderjit, K. M. M. Dakshini, and Frank A. Einhellig, 582:1-24. Washington, DC: American Chemical Society. https://doi.org/10.1021/bk-1995-0582.ch001.

Einhellig, Frank A., and James A. Rasmussen. 1978. "Synergistic inhibitory effects of vanillic andphydroxybenzoic acids on radish and grain sorghum." Journal of Chemical Ecology 4 (4): 425-36. https://doi.org/10.1007/BF00989499.

Esnault, Ropert, Dominique Buffard, Collete Breda, Christophe Sallaud, Joumana El Turk, and Adam Kondorosi. 1993. "Pathological and molecular characterizations of alfalfa interactions with compatible and incompatible bacteria, Xanthomonas campestris pv. alfalfae and Pseudomonas syringae pv. pisi.." The American Phytopathological Society 6 (5): 655-64. https://europepmc.org/abstract/med/8274775.

Evans, P:M, and G.A Kearney. 2003. "Melilotus Albus (Medik.) Is Productive and Regenerates Well on Saline Soils of Neutral to Alkaline Reaction in the High Rainfall Zone of South-Western Victoria." Australian Journal of Experimental Agriculture. https://www.researchgate.net/publication/240507674

Garrity, George, Don J. Brenner, Noel R. Krieg, and James R. Staley, eds. 2005. Bergey's Manual® of Systematic Bacteriology: Volume 2: The Proteobacteria, Part B: The Gammaproteobacteria. 2nd ed. Bergey's Manual of Systematic Bacteriology. Springer US. https://www.springer.com/de/book/9780387241449.

Gestetner, Benjamin, and Eric E Conn. 1974. "The 2-hydroxylation of trans-cinnamic acid by chloroplasts from Melilotus alba Desr - ScienceDirect." Archives of biochemistry and biophysics 163: 617-24. https://doi.org/10.1016/0003-9861(74)90522-0. 
Giraudoux, Patrick, Jean-Philippe Antonietti, Colin Beale, Renaud Lancelot, David Pleydell, and Mike Treglia. 2018. Pgirmess: Spatial Analysis and Data Mining for Field Ecologists (version 1.6.9). https://CRAN.R-project.org/package=pgirmess.

Janssen, Peter H. 2006. "Identifying the dominant soil bacterial taxa in libraries of 16S RRNA and 16S RRNA genes." Applied and Environmental Microbiology 72 (3): 1719-28. https://doi.org/10.1128/AEM.72.3.1719-1728.2006.

Li, Zhao-Hui, Qiang Wang, Xiao Ruan, Cun-De Pan, and De-An Jiang. 2010. "Phenolics and plant allelopathy." Molecules 15 (12): 8933-52. https://doi.org/10.3390/molecules15128933.

Lorenzo, Paula, Ana Palomera-Pérez, Manuel J. Reigosa, and Luís González. 2011. “Allelopathic interference of invasive Acacia Dealbata link on the physiological parameters of native understory species." Plant Ecology 212 (3): 403-12. https://doi.org/10.1007/s11258-0109831-9.

Lou, Yi, Adam S. Davis, and Anthony C. Yannarell. 2016. "Interactions between allelochemicals and the microbial community affect weed suppression following cover crop residue incorporation into soil." Plant and Soil 399 (1): 357-71. https://doi.org/10.1007/s11104-015-2698-8.

Mansfield, John, Stephane Genin, Shimpei Magori, Vitaly Citovsky, Malinee Sriariyanum, Pamela Ronald, Max Dow, et al. 2012. "Top 10 plant pathogenic bacteria in molecular plant pathology." Molecular Plant Pathology 13 (6): 614-29. https://doi.org/10.1111/j.13643703.2012.00804.x.

Murray, R. D. H., J. Méndez, and S. A. Brown. 1982. The Natural Coumarins: Occurrence, Chemistry, and Biochemistry. Wiley. https://books.google.de/books?id=G-7vAAAAMAAJ.

Nelson, S. C., and C. L. Campbell. 1993. "Comparative spatial analysis of foliar epidemics on white clover Ccaused by viruses, fungi, and a bacterium." Phytopathology. http://agris.fao.org/agris-search/search.do?recordID=US201301780997.

Nemchinov, Lev G., Jonathan Shao, Maya N. Lee, Olga A. Postnikova, and Deborah A. Samac. 2017. "Resistant and susceptible responses in alfalfa (Medicago sativa) to bacterial stem blight caused by Pseudomonas syringae Pv. syringae." PloS One 12 (12): e0189781. https://doi.org/10.1371/journal.pone.0189781.

Nicollier, Gilles F., and A. C. Thompson. 1982. "Phytotoxic compounds from Melilotus alba (White Sweet Clover) and isolation and identification of two new flavonoids." Journal of Agricultural and Food Chemistry 30 (4): 760-64. https://doi.org/10.1021/jf00112a034.

Patrick, Z A, T A Toussoun, and L W Koch. 1964. "Effect of crop-residue decomposition products on plant roots." Annual Review of Phytopathology 2 (1): 267-92. https://doi.org/10.1146/annurev.py.02.090164.001411.

Rasband, W.S. 1997. "ImageJ." U. S. National Institutes of Health, Bethesda, Maryland, USA,. https://imagej.nih.gov/ij/.

R Core Team (2019) R: A Language and Environment for Statistical Computing. R Foundation for Statistical Computing, Vienna, Austria. https://www.R-project.org/

Reigosa, M.J., X.C. Souto, and L. Gonz'lez. 1999. "Effect of phenolic compounds on the germination of six weeds species." Plant Growth Regulation 28 (2): 83-88. https://doi.org/10.1023/A:1006269716762.

Rice, E.L. 1984. Allelopathy. Physiological Ecology. Academic Press. https://books.google.de/books?id=0WKA6fxeXpwC.

Ritz, Christian, Florent Baty, Jens C. Streibig, and Daniel Gerhard. 2015. "Dose-response analysis using R.” PLOS ONE 10 (12): e0146021. https://doi.org/10.1371/journal.pone.0146021.

Song, Qingmei, Fangcuo Qin, He He, Hecong Wang, and Shixiao Yu. 2018. "Allelopathic potential of rain leachates from Eucalyptus urophylla on four tree species." Agroforestry Systems, May. https://doi.org/10.1007/s10457-018-0240-8.

Steele, K.P. and Wojciechowski, M.F. (2003). Phylogenetic analyses of tribes Trifolieae and Vicieae, based on sequences of the plastid gene, matK (Papilionoideae: Leguminosae). In: B.B. Klitgaard and A. Bruneau (editors). Advances in Legume Systematics, part 10, Higher Level Systematics, pp. 355-370. Royal Botanic Gardens, Kew

Stefanović, Olgica D., Jelena D. Tešić, and Ljiljana R. Čomić. 2015. "Melilotus albus and Dorycnium herbaceum extracts as source of phenolic compounds and their antimicrobial, antibiofilm, and 
antioxidant potentials." Journal of Food and Drug Analysis 23 (3): 417-24. https://doi.org/10.1016/j.jfda.2015.01.003.

Stoker, J. R, and D. M Belleis. 1962. "The Biosynthesis of Coumarin in Melilotus Alba. - PubMed NCBI.” THE JOURNAL. OF BIOLOGICAL CHEMISTRY 237 (7). https://www.ncbi.nlm.nih.gov/pubmed/13917373.

Turkington, Roy A, Paul B Cavers, and Erika Rempel. 1978. "The biology of Canadian weeds.: 29. Melilotus Alba Desr. and M. Officinalis (L.) Lam. - Canadian Journal of Plant Science.” 1978. http://www.nrcresearchpress.com/doi/abs/10.4141/cjps78-078\#.XHOnk8RReUk.

Wickham, H. 2016. Ggplot2: Elegant Graphics for Data Analysis. Springer-Verlag New York. https://ggplot2.tidyverse.org.

Williams, Kelly P., Joseph J. Gillespie, Bruno W. S. Sobral, Eric K. Nordberg, Eric E. Snyder, Joshua M. Shallom, and Allan W. Dickerman. 2010. "Phylogeny of Gammaproteobacteria." Journal of Bacteriology 192 (9): 2305-14. https://doi.org/10.1128/JB.01480-09.

Wolf, Rebecca B., Gayland F. Spencer, and William F. Kwolek. 1984. "Inhibition of Velvetleaf (Abutilon theophrasti) germination and growth by benzyl isothiocyanate, a natural toxicant." Weed Science 32 (5): 612-15. https://doi.org/10.1017/S004317450005966X.

Xiao, Zhongxiang, Chang Le, Zhenghao Xu, Zhefeng Gu, Junfei Lv, and Imran Haider Shamsi. 2017. "Vertical leaching of allelochemicals affecting their bioactivity and the microbial community of soil." Journal of Agricultural and Food Chemistry 65 (36): 7847-53. https://doi.org/10.1021/acs.jafc.7b01581.

Zhang, Zhenfen, and Zhibiao Nan. 2014. "Erwinia persicina, a possible new necrosis and wilt threat to forage or grain legumes production." European Journal of Plant Pathology 139 (2): 34958. https://doi.org/10.1007/s10658-014-0390-0. 


\section{Supplementary}

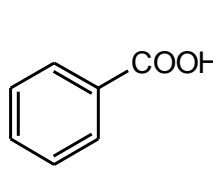

benzoic acid

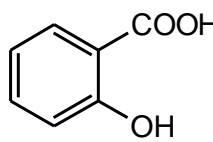

salicylic acid

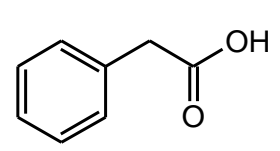

phenylacetic acid

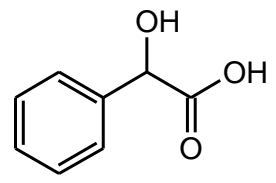

mandelic acid

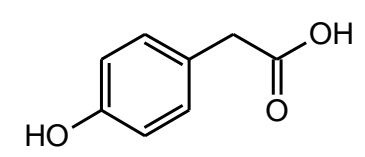

4-hydroxyphenylacetic acid
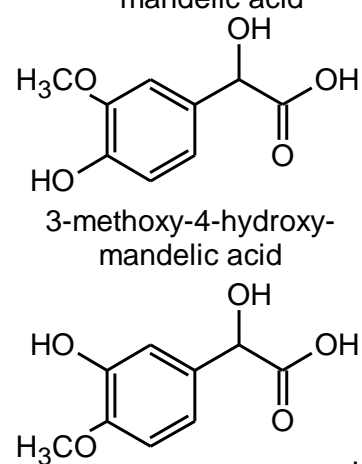

$\mathrm{H}$

3-methoxy-4-hydroxy-

p-hydroxybenzoic acid<smiles>COc1cc(C(=O)O)ccc1O</smiles>
phenylacetic acid

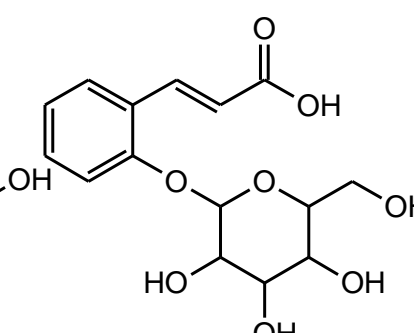

3,4,5-trihydroxyphenylacetic acid

melilotoside

4-methoxy-3-hydroxymandelic acid

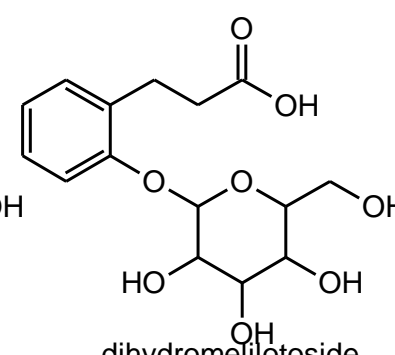

dihydromelilotoside<smiles>COc1cc(/C=C/C(=O)O)ccc1O</smiles>

ferulic acid

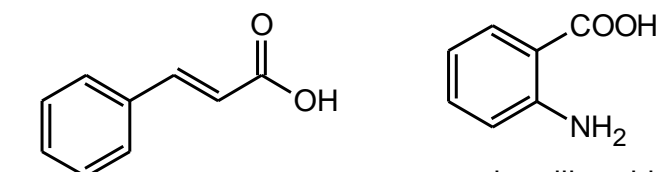

anthranilic acid

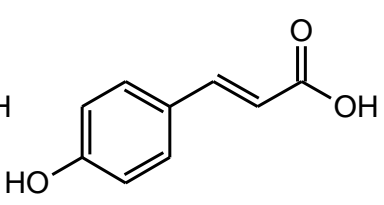

p-coumaric acid

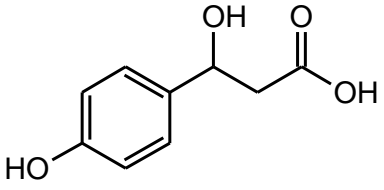

3-(3-hydroxyphenyl)

-3-hydroxypropionic acid

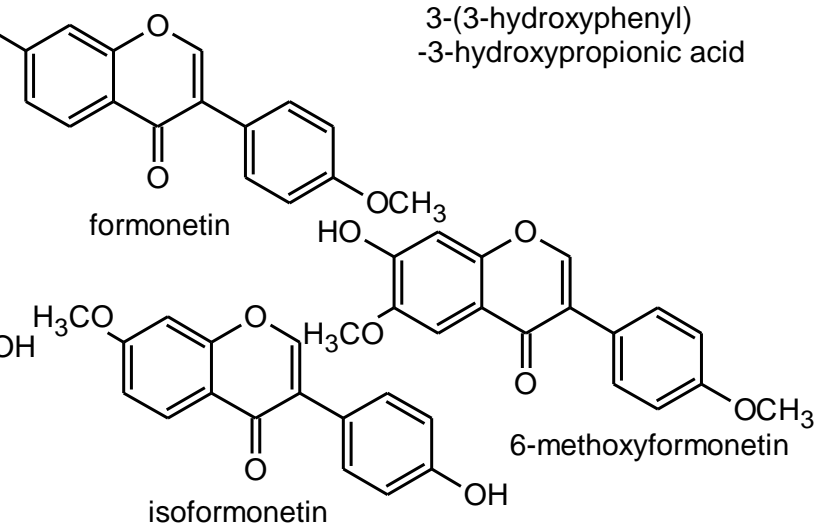

Suppl. Figure.1 Phenolics detected in leachate and root exudate of Melilotus albus using GC-MS 


\begin{tabular}{|c|c|c|c|c|c|c|c|c|}
\hline $\mathrm{Al}$ & $\mathrm{Ca}$ & $\mathrm{Fe}$ & $\mathrm{K}$ & $\mathrm{Mg}$ & $\mathrm{Mn}$ & $\mathrm{Na}$ & effective cation exchange capacity & $\mathrm{pH}$ \\
\hline $\begin{array}{l}\mathrm{mg} \mathrm{kg}^{-1} \\
\text { dry soil }\end{array}$ & $\begin{array}{l}\mathrm{mg} \mathrm{kg}^{-1} \\
\text { dry soil }\end{array}$ & $\begin{array}{l}\mathrm{mg} \mathrm{kg}^{-1} \\
\text { dry soil }\end{array}$ & $\begin{array}{l}\mathrm{mg} \mathrm{kg}^{-1} \\
\text { dry soil }\end{array}$ & $\begin{array}{l}\mathrm{mg} \mathrm{kg}^{-1} \\
\text { dry soil }\end{array}$ & $\begin{array}{l}\mathrm{mg} \mathrm{kg}^{-1} \\
\text { dry soil }\end{array}$ & $\begin{array}{l}\mathrm{mg} \mathrm{kg}^{-1} \\
\text { dry soil }\end{array}$ & mmol $_{\mathrm{c}} \mathrm{kg}^{-1}$ dry soil & \\
\hline 0 & 5177 & 0 & 336 & 369 & 3 & 10 & 298 & 7.5 \\
\hline
\end{tabular}

Suppl. table.1 Soil characteristics

Suppl. table.2 Primers and standard organisms used for each quantified target taxonomic group.

\begin{tabular}{|c|c|c|c|c|}
\hline $\begin{array}{c}\text { Forward primer } \\
\text { (sequence) }\end{array}$ & $\begin{array}{c}\text { Reverse Primer } \\
\text { (sequence) }\end{array}$ & Reference & $\begin{array}{c}\text { Target taxonomic } \\
\text { group }\end{array}$ & $\begin{array}{l}\text { Organism used } \\
\text { for standard }\end{array}$ \\
\hline $\begin{array}{c}\text { Eub338 } \\
\text { (ACTCCTACGGGAGGCAGCAG) }\end{array}$ & $\begin{array}{c}\text { Eub518 } \\
\text { (ATTACCGCGGCTGCTGG) }\end{array}$ & $\begin{array}{c}\text { (Lane } \\
\text { 1991)(Muyzer, } \\
\text { Waal, and } \\
\text { Uitterlinden 1993) }\end{array}$ & Bacteria & $\begin{array}{l}\text { Pseudomonas } \\
\text { stutzeri }^{a}\end{array}$ \\
\hline
\end{tabular}


Chapter 3

\begin{tabular}{|c|c|c|c|c|}
\hline & & $\begin{array}{c}\text { Waal, and } \\
\text { Uitterlinden 1993) }\end{array}$ & & \\
\hline $\begin{array}{c}\text { Act920F3 } \\
\text { (TACGGCCGCAAGGCTA) }\end{array}$ & $\begin{array}{c}\text { Act1200R } \\
\text { (TCRTCCCCACCTTCCTCCG) }\end{array}$ & $\begin{array}{l}\text { (Bacchetti De } \\
\text { Gregoris et al. } \\
2011)\end{array}$ & Actinobacteria & $\begin{array}{c}\text { Clavibacter } \\
\text { michiganensis }{ }^{a}\end{array}$ \\
\hline $\begin{array}{c}\alpha 682 \mathrm{~F} \\
\text { (CIAGTGTAGAGGTGAAATT) }\end{array}$ & $\begin{array}{c}908 \alpha \mathrm{R} \\
(\mathrm{CCCCGTCAATTCCTTTGAGTT})\end{array}$ & $\begin{array}{c}\text { (Bacchetti De } \\
\text { Gregoris et al. } \\
\text { 2011) }\end{array}$ & Alphaproteobacteria & $\begin{array}{l}\text { Rhizobium } \\
\text { rhizogenes }\end{array}$ \\
\hline $\begin{array}{c}\text { Cfb319 } \\
\text { (GTACTGAGACACGGACCA) }\end{array}$ & $\begin{array}{c}\text { Eub518 } \\
\text { (ATTACCGCGGCTGCTGG) }\end{array}$ & $\begin{array}{c}\text { (Muyzer, Waal, } \\
\text { and Uitterlinden } \\
\text { 1993)(Manz et al. } \\
\text { 1996) }\end{array}$ & Bacteriodetes & $\begin{array}{c}\text { Amplified from } \\
\text { environmental } \\
\text { DNA }\end{array}$ \\
\hline $\begin{array}{c}\text { Eub338 } \\
\text { (ACTCCTACGGGAGGCAGCAG) }\end{array}$ & $\begin{array}{c}\text { Bet680 } \\
\text { (TCACTGCTACACGYG) }\end{array}$ & $\begin{array}{l}\text { (Overmann, } \\
\text { Coolen, and } \\
\text { Tuschak 1999) }\end{array}$ & Betaproteobacteria & $\begin{array}{l}\text { Burkholderia } \\
\text { cepacia }^{a}\end{array}$ \\
\hline $\begin{array}{c}1080 \gamma \mathrm{F} \\
\text { (TCGTCAGCTCGTGTYGTGA) }\end{array}$ & $\begin{array}{c}\gamma 1202 \mathrm{R} \\
\text { (CGTAAGGGCCATGATG) }\end{array}$ & $\begin{array}{c}\text { (Bacchetti De } \\
\text { Gregoris et al. } \\
2011)(\text { Lane 1991) }\end{array}$ & Gammproteobacteria & $\begin{array}{l}\text { Escheria coli } \\
\text { DH5 } \alpha\end{array}$ \\
\hline $\begin{array}{c}\text { G1G3-673F } \\
\text { (GAATGCGTAGAGATCC) }\end{array}$ & $\begin{array}{c}907 \mathrm{R} \\
\text { (CCGTCAATTCMTTTRAGTTT) }\end{array}$ & $\begin{array}{l}\text { (DeBruyn et al. } \\
\text { 2011)(Lane et al. } \\
\text { 1985) }\end{array}$ & Gemmatimonadetes & $\begin{array}{c}\text { Amplified from } \\
\text { environmental } \\
\text { DNA }\end{array}$ \\
\hline
\end{tabular}


Chapter 3

\begin{tabular}{|c|c|c|c|c|}
\hline $\begin{array}{c}\text { Lgc353 } \\
\text { (GCAGTAGGGAATCTTCCG) }\end{array}$ & $\begin{array}{c}\text { Eub518 } \\
\text { (ATTACCGCGGCTGCTGG) }\end{array}$ & $\begin{array}{c}\text { (Meier et al. } \\
\text { 1999)(Muyzer, } \\
\text { Waal, and } \\
\text { Uitterlinden 1993) }\end{array}$ & Firmicutes & $\begin{array}{l}\text { Bacillus } \\
\text { licheniformis }\end{array}$ \\
\hline $\begin{array}{c}\text { Verr349 } \\
\text { (GYGGCASCAGKCGMGAAW) }\end{array}$ & $\begin{array}{c}\text { Eub518 } \\
\text { (ATTACCGCGGCTGCTGG) }\end{array}$ & $\begin{array}{c}\text { (Philippot et al. } \\
\text { 2009)(Muyzer, } \\
\text { Waal, and } \\
\text { Uitterlinden 1993) }\end{array}$ & Verrucomicrobia & $\begin{array}{c}\text { Amplified from } \\
\text { environmental } \\
\text { DNA }\end{array}$ \\
\hline $\begin{array}{c}\text { FR1 } \\
\text { (AICCATTCAATCGGTAIT) }\end{array}$ & $\begin{array}{c}\text { FF390 } \\
\text { (CGATAACGAACGAGACCT) }\end{array}$ & $\begin{array}{c}\text { (Vainio and } \\
\text { Hantula 2000) }\end{array}$ & Fungi & $\begin{array}{c}\text { Verticillium } \\
\text { longisporum }^{b}\end{array}$ \\
\hline $\begin{array}{c}\text { ITS4Asco } \\
\text { (CGTTACTRRGGCAATCCCTGTTG) }\end{array}$ & $\begin{array}{c}\text { ITS5 } \\
\text { (GGAAGTAAAAGTCGTAACAAGG) }\end{array}$ & $\begin{array}{c}\text { (White et al. } \\
\text { 1990)(Nikolcheva } \\
\text { and Bärlocher } \\
\text { 2004) }\end{array}$ & Ascomycota & $\begin{array}{c}\text { Fusarium } \\
\text { graminearum }\end{array}$ \\
\hline $\begin{array}{c}\text { ITS4b } \\
\text { (CAGGAGACTTGTACACGGTCCAG) }\end{array}$ & $\begin{array}{c}5.8 \mathrm{sr} \\
\text { (TCGATGAAGAACGCAGCG) }\end{array}$ & $\begin{array}{c}\text { (Vilgalys and } \\
\text { Hester 1990; } \\
\text { Gardes and Bruns } \\
\text { 1993) }\end{array}$ & Basidiomycota & $\begin{array}{c}\text { Commercial } \\
\text { Agaricus } \\
\text { bisporus }\end{array}$ \\
\hline
\end{tabular}

a provided by A. Mavridis (University of Goettingen), ${ }^{\text {b }}$ provided by A. von Tiedemann (University of Goettingen). 
Suppl. table.3Real-time PCR conditions for each target taxonomic group.

\begin{tabular}{|c|c|c|c|c|c|c|c|}
\hline \multirow{2}{*}{$\begin{array}{c}\text { Target taxonomic } \\
\text { group }\end{array}$} & \multirow[b]{2}{*}{ Reaction buffer ${ }^{a}$} & \multirow{2}{*}{$\begin{array}{c}\text { DNA } \\
\text { Polymerase }^{b}\end{array}$} & \multirow[b]{2}{*}{ Final $\mathrm{MgCl} 2$} & \multirow[b]{2}{*}{ Initial denaturation } & \multicolumn{3}{|c|}{35 cycles } \\
\hline & & & & & $\begin{array}{c}\text { Denaturatio } \\
\mathbf{n}\end{array}$ & Annealing & Extension \\
\hline Bacteria & $\begin{array}{l}\text { 1X ThermoPol® } \\
\text { Reaction Buffer }\end{array}$ & $\begin{array}{c}\text { Taq DNA } \\
\text { Polymerases }\end{array}$ & 2.0 & $95^{\circ} \mathrm{C}, 120 \mathrm{~s}$ & $94^{\circ} \mathrm{C}, 20 \mathrm{~s}$ & $57^{\circ} \mathrm{C}, 30 \mathrm{~s}$ & $68^{\circ} \mathrm{C}, 20 \mathrm{~s}$ \\
\hline Actinobacteria & $\begin{array}{c}\text { 1X FastGene }{ }^{\circledR} \\
\text { Taq HotStart } \\
\text { Buffer }\end{array}$ & $\begin{array}{c}\text { FastGene }{ }^{\circledR} \text { Taq } \\
\text { DNA } \\
\text { Polymerase }\end{array}$ & 2.0 & $95^{\circ} \mathrm{C}, 120 \mathrm{~s}$ & $94^{\circ} \mathrm{C}, 20 \mathrm{~s}$ & $62^{\circ} \mathrm{C}, 30 \mathrm{~s}$ & $72^{\circ} \mathrm{C}, 20 \mathrm{~s}$ \\
\hline Bacteriodetes & $\begin{array}{c}\text { 1X FastGene }{ }^{\circledR} \\
\text { Taq HotStart } \\
\text { Buffer }\end{array}$ & $\begin{array}{c}\text { FastGene }{ }^{\circledR} \text { Taq } \\
\text { DNA } \\
\text { Polymerase }\end{array}$ & 2.0 & $95^{\circ} \mathrm{C}, 120 \mathrm{~s}$ & $94^{\circ} \mathrm{C}, 20 \mathrm{~s}$ & $62^{\circ} \mathrm{C}, 30 \mathrm{~s}$ & $72^{\circ} \mathrm{C}, 20 \mathrm{~s}$ \\
\hline
\end{tabular}


Chapter 3

\begin{tabular}{|c|c|c|c|c|c|c|c|}
\hline Betaproteobacteria & $\begin{array}{c}\text { 1X FastGene }{ }^{\circledR} \\
\text { Taq HotStart } \\
\text { Buffer }\end{array}$ & $\begin{array}{c}\text { FastGene® Taq } \\
\text { DNA } \\
\text { Polymerase }\end{array}$ & 2.0 & $95^{\circ} \mathrm{C}, 120 \mathrm{~s}$ & $94^{\circ} \mathrm{C}, 20 \mathrm{~s}$ & $58^{\circ} \mathrm{C}, 30 \mathrm{~s}$ & $72^{\circ} \mathrm{C}, 25 \mathrm{~s}$ \\
\hline $\begin{array}{c}\text { Gammproteobacteri } \\
\mathrm{a}\end{array}$ & $\begin{array}{l}\text { 1X ThermoPol® } \\
\text { Reaction Buffer }\end{array}$ & $\begin{array}{c}\text { Taq DNA } \\
\text { Polymerases }\end{array}$ & 2.0 & $95^{\circ} \mathrm{C}, 120 \mathrm{~s}$ & $94^{\circ} \mathrm{C}, 20 \mathrm{~s}$ & $60^{\circ} \mathrm{C}, 30 \mathrm{~s}$ & $68^{\circ} \mathrm{C}, 20 \mathrm{~s}$ \\
\hline Firmicutes & $\begin{array}{l}\text { 1X ThermoPol® } \\
\text { Reaction Buffer }\end{array}$ & $\begin{array}{c}\text { Taq DNA } \\
\text { Polymerases }\end{array}$ & 2.0 & $95^{\circ} \mathrm{C}, 120 \mathrm{~s}$ & $94^{\circ} \mathrm{C}, 20 \mathrm{~s}$ & $57^{\circ} \mathrm{C}, 30 \mathrm{~s}$ & $68^{\circ} \mathrm{C}, 20 \mathrm{~s}$ \\
\hline Ascomycota & $\begin{array}{l}\text { 1X Standard Taq } \\
\text { Reaction Buffer }\end{array}$ & $\begin{array}{c}\text { Hot Start Taq } \\
\text { DNA } \\
\text { Polymerase }\end{array}$ & 1.5 & $95^{\circ} \mathrm{C}, 120 \mathrm{~s}$ & $94^{\circ} \mathrm{C}, 20 \mathrm{~s}$ & $55^{\circ} \mathrm{C}, 30 \mathrm{~s}$ & $68^{\circ} \mathrm{C}, 40 \mathrm{~s}$ \\
\hline
\end{tabular}




\begin{tabular}{|c|c|c|c|c|c|c|}
\hline Basidiomycota & $\begin{array}{c}\text { 10X Standard Taq } \\
\text { Reaction Buffer }\end{array}$ & $\begin{array}{c}\text { Hot Start Taq } \\
\text { DNA } \\
\text { Polymerase }\end{array}$ & 1.5 & $95^{\circ} \mathrm{C}, 120 \mathrm{~s}$ & $94^{\circ} \mathrm{C}, 20 \mathrm{~s}$ & $59^{\circ} \mathrm{C}, 30 \mathrm{~s}$ \\
$68^{\circ} \mathrm{C}, 40 \mathrm{~s}$ \\
\hline
\end{tabular}

${ }^{a}$ 1X ThermoPol@ Reaction Buffer: $20 \mathrm{mM}$ Tris-HCl, $10 \mathrm{mM}$ (NH4)2SO4 ,10 mM KCl, $2 \mathrm{mM} \mathrm{MgSO} 4,0.1 \%$ Triton® X-100, pH 8.8 at 25ㄷ (New England Biolabs, Beverly, MA, USA); 1X FastGene® Taq HotStart Buffer (NIPPON Genetics Europe, Düren, Germany); 1X Standard Taq Reaction Buffer: $10 \mathrm{mM}$ Tris-HCl, $50 \mathrm{mM} \mathrm{KCl}, 1.5 \mathrm{mM} \mathrm{MgCl} 2, \mathrm{pH} 8.3$ at $25^{\circ} \mathrm{C}$ (New England Biolabs, Beverly, MA, USA) 


\title{
Chapter 4. Chemical composition and biological effects of volatiles released by heated henbane (Hyoscyamus niger) seeds used in folk medicine
}

\author{
Mohammad Alhussein ${ }^{1}$, Zana Jamal Kareem ${ }^{1,2}$, Michael John ${ }^{3}$ Petr Karlovsky ${ }^{1}$ \\ ${ }^{1}$ Molecular Phytopathology and Mycotoxin Research, University of Göttingen, Göttingen, Germany, ${ }^{2}$ College of \\ Agricultural Sciences, University of Sulaimani, Kurdistan Region, Iraq, ${ }^{3}$ Institute of Organic and Biomolecular \\ Chemistry, University of Göttingen, Göttingen, Germany
}

\section{Summary}

Fumigation with heated henbane (Hyoscyamus niger) seeds has been used in folk medicine since the time of the ancient Egyptians. In northern Iraq, authorized practitioners in folk medicine state that henbane has been used as an antiparasitic drug. However, the therapeutic properties of henbane smoke have been linked mainly to the tropane alkaloids (hyoscyamine and scopolamine). In this study, we found only a few traces of hyoscyamine and scopolamine in the fume released from heated henbane seeds, which questions their role in the antiparasitic activity of the fume. Still, we proved the nematicidal effect of the fume released from heated henbane seeds. Furthermore, among the potentially toxic metabolites, mixtures of toxic aldehydes that could have been formed during the heating process, mainly $\alpha, \beta$-unsaturated aldehydes, were identified.

\section{Introduction}

Natural products have provided therapeutic agents to humankind since their early beginnings. Hyoscyamus niger (henbane) is an annual or biennial weed, which is native to a broad region of Eurasia (Mitich 1992). It is one of the oldest medicinal plants recorded in history. Ancient Egyptians were versed with medicinal plants (Kelly 2009). They practiced the inhaling of the vapor of the heated henbane to treat asthma-like disorders (Barnes 2006). The Greek physician Dioscorides (A.D. ca. 60) recommended henbane for toothache, and in the Middle Ages, 
henbane was used widely as a narcotic drug (Hocking 1947). The Arab physician Ibn Al Jazzar reported in the 10th-century the use of henbane for toothache, earache, respiratory disorders, and eye inflammation. Inhalation of henbane seeds smoke was one of Ibn al Jazzar's prescriptions for a toothache (Almahdi 2003). Fenwick and Omura (2015) found archaeological evidence for medicinal henbane fumigation in Turkey dated to ca. 1450-1640. Tabata et al. (1994) mention that fumigation with henbane seeds is practiced in some regions of Turkey by spreading the seeds on a hot iron plate and inhale the smoke through the mouth. Moreover, smoking a mixture of the herbs rich in tropane alkaloids, mainly stramonium with henbane and belladonna, was recommended as a medical treatment for asthma in the United States and Europe until the early decades of the 20th century (Jackson 2010).

We surveyed the use of henbane in northern Iraq. The survey included practitioners of folk medicine in rural areas. In addition to the healing effects stated above, many practitioners mentioned that the smoke released from burned henbane seeds is used as a treatment against eye worms.

The literature points out tropane alkaloids such as hyoscyamine and scopolamine as active compounds of henbane. This hypothesis seems correct when consuming henbane parts or their extracts, but it does not explain the biomedical activity of the henbane volatiles. Furthermore, to our knowledge, no studies are confirming the existence of tropane alkaloids as volatiles of any plant species.

The objectives of this study are as follows:

i. To investigate the toxicity of VOCs released by heated henbane seeds in worms and other invertebrates.

ii. To test whether tropane alkaloids are present in the fume released from heated henbane seeds.

iii. To purify and characterize the active VOCs released by heated henbane seeds.

\section{Materials and methods}

\subsection{Plant materials}

Approximately $1 \mathrm{~kg}$ of Hyoscyamus niger. L (henbane) seeds were collected from native plants

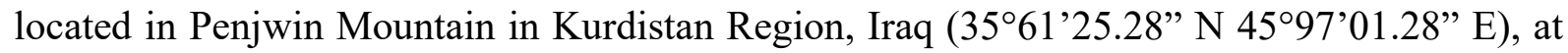
an altitude of $1404 \mathrm{~m}$ above sea level. The seeds were cleaned from plant residues and saved in glass bottles in the dark at room temperature. 


\subsection{Experimental setup}

\subsubsection{Exposure to volatiles released by heated seeds}

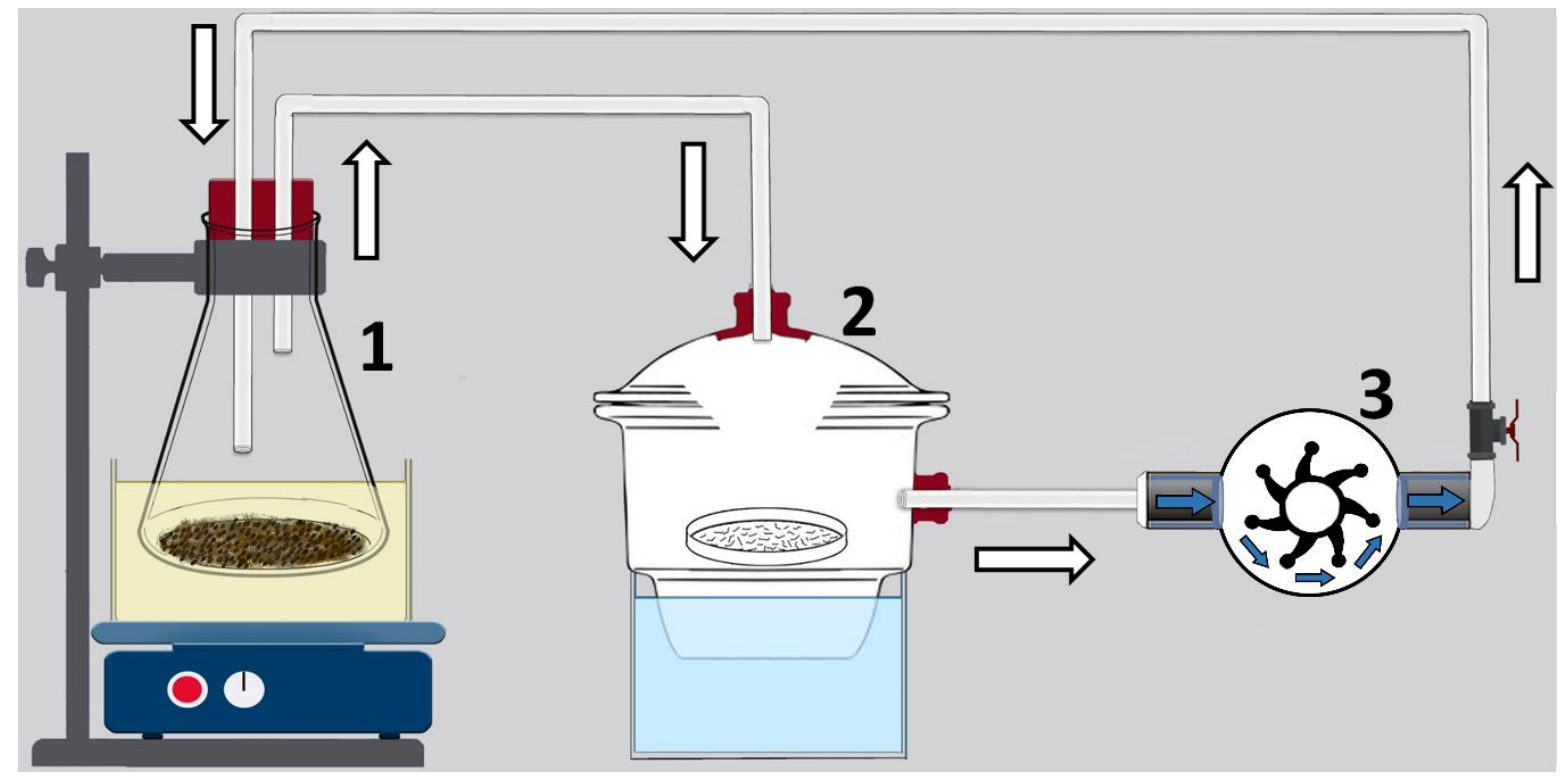

Figure 1. Apparatus for exposure to thermally released volatiles. 1 Heating unit consisting of Erlenmeyer flask and heating bath; $\mathbf{2}$ exposure chamber immersed in a water bath; $\mathbf{3}$ closed air circulation system.

The apparatus consisted of a heating unit, exposure chamber, and closed air circulation system (Figure 1). The ground seeds were placed in an Erlenmeyer flask $250 \mathrm{ml}$, which was immersed in Rotitherm® M 150 (Carl Roth, Karlsruhe, Germany). The medium was heated by a heating plate. The volatiles released by the heating were continuously transferred from the flask to the exposure chamber through a closed air circulation system. The air system consisted of an air pump VP 86 (VWR, France), a flow control valve, and connection tubes. The tested organisms were placed in the exposure chamber, which consisted of a desiccator equipped with an air inlet and outlet. A piece of paper tape was pasted as $U$ form in front of the air inlet to distribute the air stream and avoid the direct flow on the organism tested. The tape was renewed for each sample tested. The exposure chamber was cooled down at approximately $23{ }^{\circ} \mathrm{C}$ using a cold water bath. The exposure to the volatiles released by heated seeds lasted for $1 \mathrm{~h}$. The heating temperature, airflow rate, and seed amounts were optimized before starting the tests. The temperature was measured by a digital thermometer (Type K - 800023, Sper Scientific, USA) coupled to the measured area with a wired sensor. The airflow rate was measured by a mass flowmeter (TSI Series 4100, USA). The total air volume inside the device was $1050 \mathrm{~mL}$. 


\subsubsection{Volatiles trapping from heated seeds}

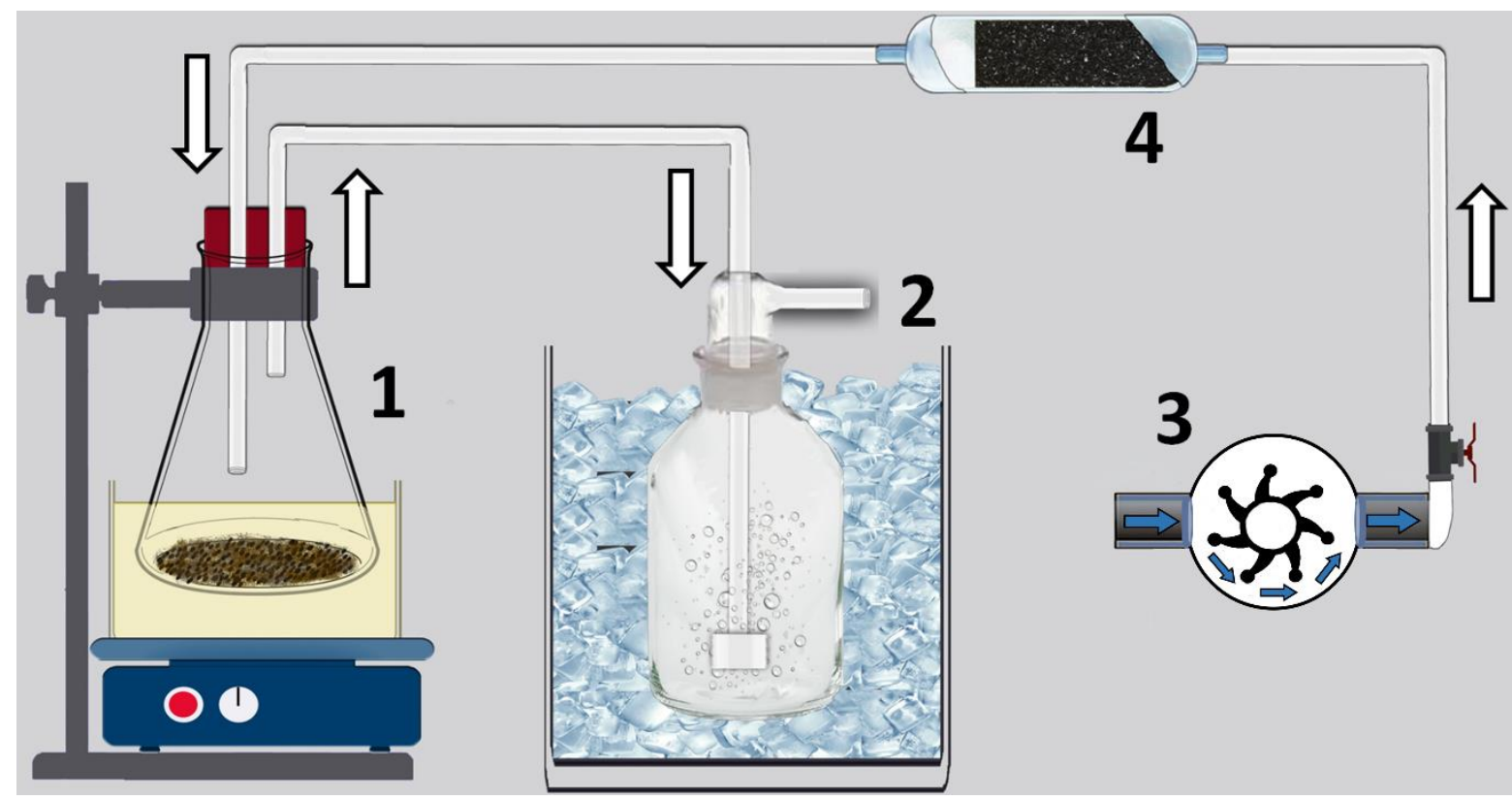

Figure 2. Apparatus for capturing thermally released volatiles. 1 Heating unit consists of Erlenmeyer flask and heating bath; 2 organic solvent trap immersed in an ice bath; $\mathbf{3}$ air ventilation system; $\mathbf{4}$ activated charcoal with glass wool filter

The apparatus consisted of a heating unit, volatiles capturing trap, and air ventilation system (Figure 2). The volatiles released by heating were continuously transferred from the flask to the capturing trap through a ventilation system similar to what has been described above in 2.2.1. However, ventilation was provided by an open one-way system. The system was equipped with an air cleaning charcoal column to ensure the pureness of the pressurized air before entering the heating unit. The cleaning column consisted of a glass column filled with activated charcoal (1 mm Norit ${ }^{\circledR}$, Sigma-Aldrich GmbH, Steinheim, Germany). The capturing trap consisted of a glass bottle filled with pure methanol and placed in an ice bath to keep the methanol cold. The volatiles were bubbled into the methanol through a glass tube equipped with a porous end, thus making the air bubbles smaller and the contact surface larger. The capturing process continued for $3 \mathrm{~h}$ for each seed sample. 


\subsection{Purification and chemical analysis}

\subsubsection{Preparative-HPLC}

Preparative high-pressure liquid chromatography (HPLC) was applied to fractionate the captured volatiles fraction. The separation was achieved in a reverse-phase column (Nucleodur C18 pyramid, $5 \mu \mathrm{m}, 250 \times 21 \mathrm{~mm}$, Macherey-Nagel, Düren, Germany) coupled with a guard column (VP10/16, Nucleodur C18 pyramid, Macherey-Nagel, Düren, Germany). A flow rate

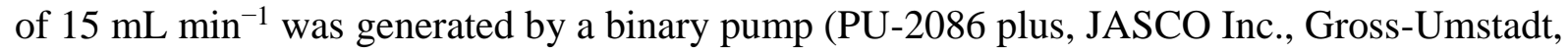
Germany). Solvent A consisted of water with $0.25 \%$ acetic acid (v/v) and B of methanol $(\mathrm{MeOH})$ with $0.25 \%$ acetic acid (v/v). The gradient was as follows: 0-5 min, $5 \% \mathrm{~B} ; 5-75 \mathrm{~min}$, from $5 \%$ to $98 \% \mathrm{~B} ; 75-90 \mathrm{~min}, 98 \% \mathrm{~B} ; 90-105 \mathrm{~min}$, from $98 \%$ to $5 \% \mathrm{~B} ; 105-120 \mathrm{~min}, 5 \%$ B. The fractions were collected using a fraction collector (CHF122SC, Advantec MFS Inc., Japan). Aliquots of $30 \mathrm{mg}$ volatiles crude dissolved in $3 \mathrm{~mL} \mathrm{MeOH} / \mathrm{water}(1: 1, \mathrm{v} / \mathrm{v})$ were injected. The separation process was monitored using a UV/VIS detector (Jasco UV-970, JASCO Inc., Gross-Umstadt, Germany) at $280 \mathrm{~nm}$ UV absorption. The system was operated by the software JASCO ChromPass 1.8.6.1.

\subsubsection{Recovery of purified VOCs by SPE}

To avoid volatilization of the captured metabolites, samples were not concentrated using conventional drying methods. Alternatively, the purified compounds and the fractions collected from preparative- HPLC were diluted with distilled water $(1: 3, \mathrm{v} / \mathrm{v})$. The diluted samples were filtered through a self-packed capturing column (C18, $50 \mu \mathrm{m}, 10 \times 30 \mathrm{~mm})$ connected to the top of a filtration flask. The filtration was performed with the help of a vacuum pump V-100 (Büchi, Switzerland). Afterward, 3-10 $\mathrm{ml}$ methanol was applied to the column to elute the captured metabolites, and the fraction was collected in falcon tubes placed inside the filtration flask. Samples for NMR were prepared with the same method except for the last elution step, where the column was dried by the vacuum to get rid of the solvent residues. Afterward, the captured volatiles was eluted with $3 \mathrm{~mL}$ of deuterated methanol $\mathrm{CD}_{3} \mathrm{OD}$ (Sigma-Aldrich Chemie GmbH, Steinheim, Germany).

\subsubsection{HPLC-MS-QTOF data acquisition and analysis}

The captured fraction was subjected to a high-performance liquid chromatography system coupled to a quadrupole time-of-flight mass detector (HPLC-MS-QTOF, Agilent, Darmstadt, Germany). The HPLC system based on Agilent 1290 Infinity II series equipment and consisted of a quaternary pump, autosampler, thermostatted column compartment, and diode-array 
detector (DAD). The HPLC coupled to a quadrupole time-of-flight high-resolution mass detector (Agilent 6545 LC/Q-TOF, Agilent, Darmstadt, Germany) with dual Jet Stream electrospray ionization (AJS ESI). The column was (Zorbax Eclipse plus C18, 2.1 x $50 \mathrm{~mm}$, $1.8 \mu \mathrm{m}$, Agilent) with a guard column (Zorbax Eclipse plus C18, $2.1 \mathrm{x} 5 \mathrm{~mm}, 1.8 \mu \mathrm{m}$ ). The system was operated by the software (Mass Hunter Workstation Software, LC/MS Data Acquisition for 6500 Series Q-TOF, version B.08.00, Agilent). The mobile phase A was water with $0.1 \%$ formic acid (v/v), and B was methanol with $0.1 \%$ formic acid (v/v). The injection volume was $2 \mu \mathrm{L}$, and the flow rate of $0.4 \mathrm{~mL} / \mathrm{min}$. The initial condition was $5 \%$ of $\mathrm{B}$ and increased linearly to $95 \%$ in $10 \mathrm{~min}$ and was held for $2 \mathrm{~min}$ for purging then decreased to the initial condition in $1 \mathrm{~min}$ and re-equilibrated for $3 \mathrm{~min}$. The samples were measured in positive ionization mode with full MS and MS/MS scans. The results were analyzed using the software (Mass Hunter Workstation Software, Qualitative Analysis Navigator Version B.08.00, Agilent).

Acquired raw data files were processed with Agilent MassHunter Qualitative Analysis Software (version B08.00, Agilent Technologies). Results were exported as compound exchange file (CEF) format. Comparative data analysis was performed using MassProfiler Professional (version 14.9-Build 11939, Agilent Technologies) and MassHunter Profinder (Version B.08.00, Agilent Technologies). Details concerning the feature finding and the algorithm employed are given by Hansler et al. (2014). No statistical tests were applied, but the most abundant characteristic features for the treatment $(\mathrm{m} / \mathrm{z}$, retention time, and ion abundance) were selected manually.

\subsubsection{Nuclear Magnetic Resonance spectroscopy.}

The chemical structures of the purified compounds were determined by Dr. Michael John (Institute of Organic and Biomolecular Chemistry, University of Göttingen, Göttingen, Germany).

\subsection{Toxicity assays}

\subsubsection{Nematode Caenorhabditis elegans}

The model nematode Caenorhabditis elegans (C. elegans) was subjected to the volatiles released from heated seeds. C. elegans nematodes and Escherichia coli OP50 were kindly provided by Prof. Jiafu Hu, Zhejiang Agriculture and Forestry University, China. C. elegans was re-cultured weekly onto freshly prepared nematode growth medium (NGM) inoculated with $E$. coli OP50, which served as a feed source for nematodes, using the "chunking" method 
as described by Stiernagle (2006). C. elegans were transferred onto $3 \mathrm{~cm}$ NGM plates (Ten adults per plate). They were incubated at $18^{\circ} \mathrm{C}$ in the dark. After 3 days, age-synchronous nematodes that dominated in growth stage L4 were ready to use. One plate was placed in the exposure chamber of the apparatus described above in (2.2.1). The toxicity of the heated seeds was evaluated after $1 \mathrm{~h}$ of the continued exposure to the volatiles released from seeds.

\subsubsection{Brine shrimp Artemia salina}

Brine shrimp bioassay was performed as described by Molina-Salinas et al. (2006) with some modifications. A commercial mixture of salt and dry Artemia cysts (Artemio ${ }^{\circledR}$ Mix, JBL, Neuhofen, Germany) was bought from a local shop. The method was optimized and validated before use. Depending on the optimization results, $30 \mathrm{~g}$ of the shrimps salt mixture was dissolved in $1 \mathrm{~L}$ demineralized water in a separation funnel and incubated at $28{ }^{\circ} \mathrm{C}$ under a classic light $55 \mathrm{~W}$. Air was bubbled continuously through the solution. After $24 \mathrm{~h}$, the hatched naupliae were collected at the bottom of the funnel.

The total $\mathrm{MeOH}$ crude was concentrated. To avoid the drying of the volatile crude solution, its weight was estimated by drying a small portion. The concentrated $\mathrm{MeOH}$ crude was diluted with the filtrated shrimp's water to the final $\mathrm{MeOH}$ concentration of $1.25 \%(\mathrm{v} / \mathrm{v})$. The assay was performed in 96-well plates. In each well, $50 \mu \mathrm{L}$ of shrimp solution was placed containing approximately 30 individuals. The number of dead shrimps was recorded before the application of the compound solution. In each well, $150 \mu \mathrm{L}$ of the compound solution was added. Concentrations were prepared in a 1:1 dilution series (from 1000 to $31 \mu \mathrm{g} \mathrm{mL}^{-1}$ final shrimpscompounds mixture) with a constant $\mathrm{MeOH}$ content of $1.25 \%(\mathrm{v} / \mathrm{v})$. Ten replicates from each concentration were prepared. Filtrated shrimp medium with $1.25 \% \mathrm{MeOH}(\mathrm{v} / \mathrm{v})$ served as control. The plates were incubated at $28{ }^{\circ} \mathrm{C}$ in the light. The number of dead shrimps was recorded after $2 \mathrm{~h}$ of the treatment, and the number of dead and total shrimps was recorded after $24 \mathrm{~h}$ of treatment to calculate the mortality rate.

\subsubsection{Drosophila melanogaster}

Drosophila melanogaster was kindly provided by Prof. Marko Rohlfs, University of Bremen, Institute of Ecology. Fruit fly was reared using the method described by Trienens et al. (2010). Approximately 25 healthy adult flies were collected in cylindrical insect cages $(\varnothing: 4 \mathrm{~cm}$, height: $3 \mathrm{~cm}$ ) with mesh walls to allow air to enter freely. One cage was placed in the exposure chamber of the apparatus described above in (2.2.1). In each treatment, 3 replicates were tested. The exposure to the heated seeds volatiles lasted for one hour. The mortality and health status of the flies were reported one minute and one hour after the treatment. The volatiles effect was tested 
on the larval stage as well. Female laid eggs on a thin layer of Drosophila growth medium in Petri dishes $(\varnothing: 5 \mathrm{~cm})$, and the plates were incubated at room temperature. After 3 days, the plates were dominated by the second instar flies and were ready to use in the toxicity test. The plates were exposed to the volatiles as described above. Three replicates were tested for each plant species. The mortality of the larva was recorded after the exposure.

\subsection{Statistics}

Dose-response curves were estimated using a four-parameter logistic model in SigmaPlot 14.0 (Systat Software, San Jose, CA).

\section{Results}

\subsection{Ethnopharmacological uses of henbane in northern Iraq}

We performed a survey about the use of henbane in traditional medicine in northern Iraq, including the area shown in (Suppl. Figure. 1). The survey included many authorized practitioners of folk medicine. The results showed that henbane is used for several diseases such as spasms of the digestive system, eczema, urinary tract disorders, asthma, and toothache. Interestingly, the vast majority of the practitioners mentioned a unique use of henbane as a treatment against eye inflammation and eye worms. The treatment is applied by burning henbane plants and exposing the patient's eye to the smoke.

\subsection{Biological effect of volatiles released by heated seeds}

\subsubsection{Toxicity in C. elegans}

The nematicidal activity of the volatiles released from heated seeds was tested against the model nematode $C$. elegans. The method was validated before performing the test. At each time, $2 \mathrm{~g}$ of the seeds were heated, and the air circulation rate was adjusted to $3.5 \mathrm{~L} \mathrm{~min}^{-1}$. The optimal seed temperature range was $120-150{ }^{\circ} \mathrm{C}$. At this temperature, no mortality on nematodes after $1 \mathrm{~h}$ of continued exposure to soybean volatiles was observed, while henbane volatiles caused $100 \%$ mortality (Suppl. Table 1). In addition to henbane and soybean, 13 different plant species were tested under the same conditions (Table.1). All tested species except henbane did not cause any mortality on C. elegans. The minimum lethal dose of henbane seeds was $1.8 \mathrm{~g}$. 
Table.1 Mortality of the nematode $C$. elegans caused by the exposure to volatiles released from heated seeds. C. elegans was continually exposed (for $1 \mathrm{~h}$ ) to the volatiles released from $2 \mathrm{~g}$ of each species tested. The seeds' temperature was $120-150{ }^{\circ} \mathrm{C}$. Five replicates from each species were tested.

\begin{tabular}{llllc} 
Scientific Name & Common & Family & Part tested & Mortality (\%) \\
& Name & & Seed & 0 \\
\hline Datura stramonium & Jimson weed & Solanaceae & Seed & $\mathbf{1 0 0}$ \\
Hyoscyamus niger & Henbane & Solanaceae & Seed & 0 \\
Oryza sativa & Rice & Poaceae & Seed & 0 \\
Triticum aestivum & Wheat & Poaceae & Seed & 0 \\
Zea mays & Maize & Poaceae & Seed & 0 \\
Glycine max & Soybean & Fabaceae & Seed & 0 \\
Cicer arietinum & Chickpea & Fabaceae & Seed & 0 \\
Phaseolus vulgaris & Common bean & Fabaceae & Seed & 0 \\
Brassica napus & Rapeseed & Brassicaceae & Seed & 0 \\
Raphanus sativus & Radish & Brassicaceae & Seed & 0 \\
Pimpinella anisum & Anise & Apiaceae & Seed & 0 \\
Foeniculum vulgare & Fennel & Apiaceae & Seed & 0 \\
Carum carvi & Caraway & Apiaceae & bulbs & 0 \\
Galanthus nivalis & Snowdrop & Amaryllidaceae & Seed & 0 \\
Sesamum indicum & Sesame & Pedaliaceae & & \\
\hline
\end{tabular}

\subsubsection{Toxicity in Drosophila melanogaster}

Drosophila melanogaster was assayed similarly to the nematodes. Each replicate consisted of $4 \mathrm{~g}$ of seeds. The exposure to henbane volatiles caused a significant reduction in the movement of the adult flies immediately after the treatment (Figure. 3), upon which $67 \%$ of the flies tested were static (either dead or narcotized). Interestingly, approximately $17 \%$ of the flies restored the ability to move after $1 \mathrm{~h}$ of the treatment, and the individuals who were still immobile were considered as dead. On the other hand, the movement of the flies treated with soybean volatiles was not affected. Moreover, the toxicity of the volatiles was tested in the larval stage as well. In contrast to the observed effect in the adults, the volatiles released from heated henbane and soybean seeds did not cause any death or any observed effect on the movement of the larvae. 


\subsubsection{Toxicity in brine shrimps}

The toxicity of the volatiles was tested in a brine shrimp bioassay. The volatiles were captured in cold $\mathrm{MeOH}$, and the crude was concentrated and applied on shrimps. The concentrated volatiles crude was toxic to brine shrimps with an estimated $\mathrm{EC}_{50}$ value of $75 \mu \mathrm{g} \mathrm{mL}^{-1}$ after 16 $\mathrm{h}$ of the incubation (Figure 3B).

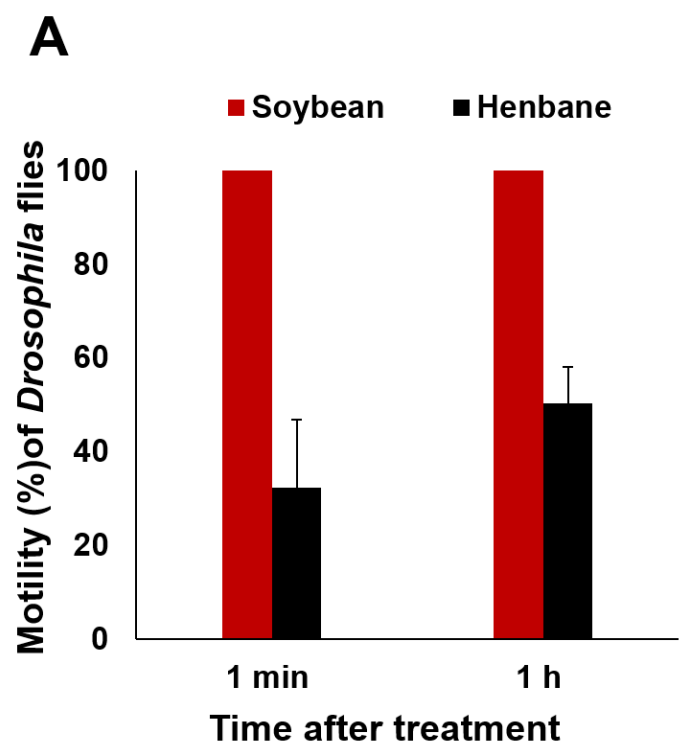

\section{B}

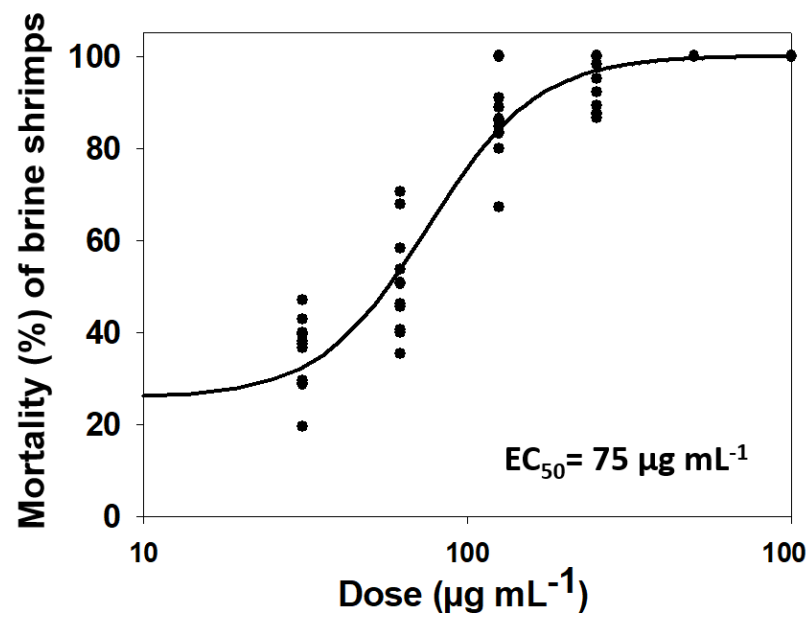

Figure 3: Effect of henbane volatiles on Drosophila melanogaster and brine shrimps. Drosophila melanogaster flies were exposed to the volatiles released from heated henbane seeds. The static flies were either dead or narcotic after 1 min of treatment, and they were dead after $1 \mathrm{~h}$. The error bars represent the standard error, $\mathrm{n}=3$ (A). The toxicity of the captured volatiles was tested in brine shrimps. The mortality was recorded $16 \mathrm{~h}$ after treatment. Curve fitting by non-linear regression using a four-parameter logistic model $(n=10)$. Black dots represent individual data points $(\mathbf{B})$.

\subsection{Bioassay-guided fractionation}

The captured crude was fractionated into 5 fractions using preparative-HPLC (Figure. 4A). The toxicity of the fractions was tested in brine shrimps at a dose of $100 \mu \mathrm{g} \mathrm{mL} \mathrm{L}^{-1}$. Fraction 5 caused $68 \%$ mortality in brine shrimps after $16 \mathrm{~h}$ of incubation, while the other fractions did not show any significant effect (Figure. 4b). Hence, the toxic component is assumed to be fraction 5 . 


\subsection{Analysis of tropane alkaloids}

The tropane alkaloids hyoscyamine and scopolamine were identified tentatively based on the accurate mass and MS/MS fragmentation (Suppl. Figure. 2). The compounds were relatively quantified in the methanolic seeds extract and in the captured volatiles released from seeds. Traces of both compounds were detected in the captured volatiles comparing to the original content in the seed extract. However, the content of hyoscyamine and scopolamine detected in the volatiles was respectively 0.2 and $0.5 \%$ of its content in the methanolic seed extract (Figure. $5)$.
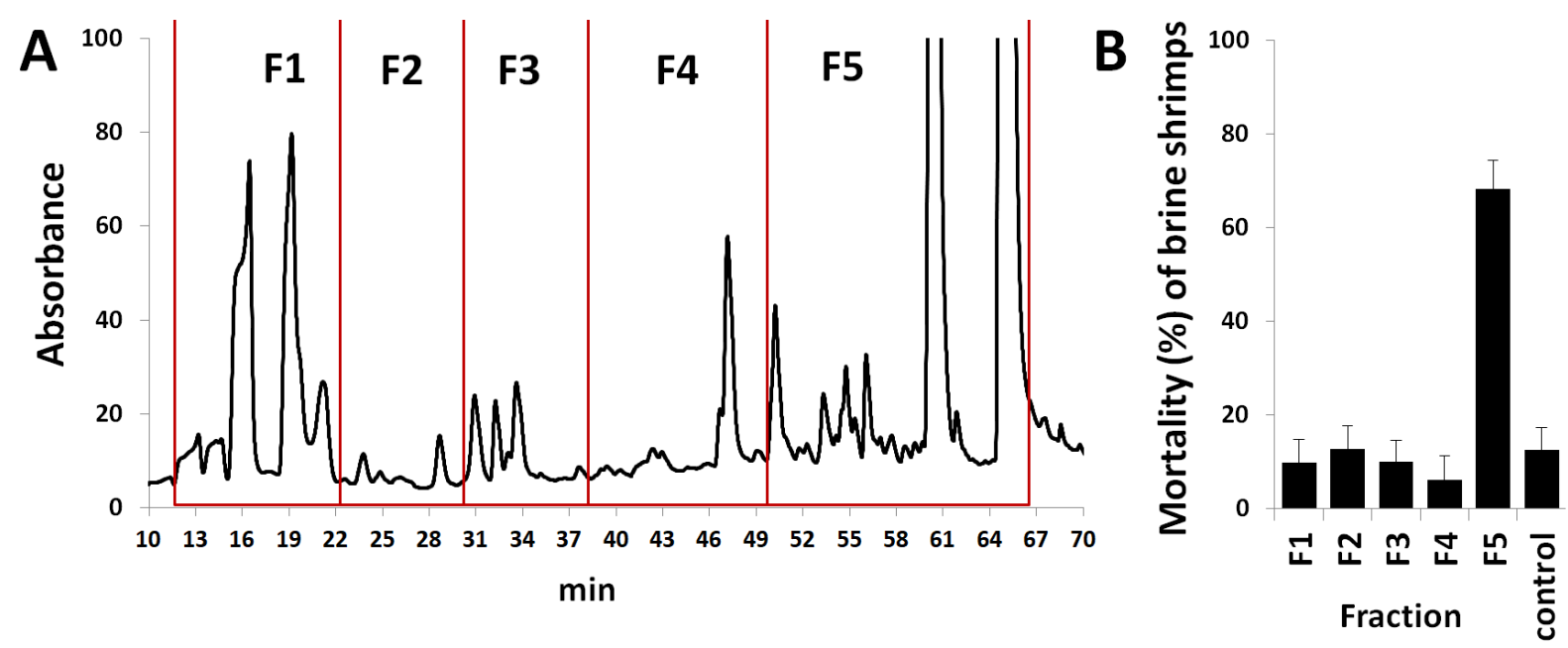

Figure 4. Preparative-HPLC and toxicity of henbane volatiles in brine shrimps. The volatiles released from heated henbane seeds were captured in cold $\mathrm{MeOH}$. The captured volatiles crude was concentrated and fractionated into 5 fractions (F1 to F5) using preparative HPLC (A). The toxicity of each fraction was tested in brine shrimps. The error bars represent the standard deviation, $\mathrm{n}=8-10(\mathbf{C})$. 


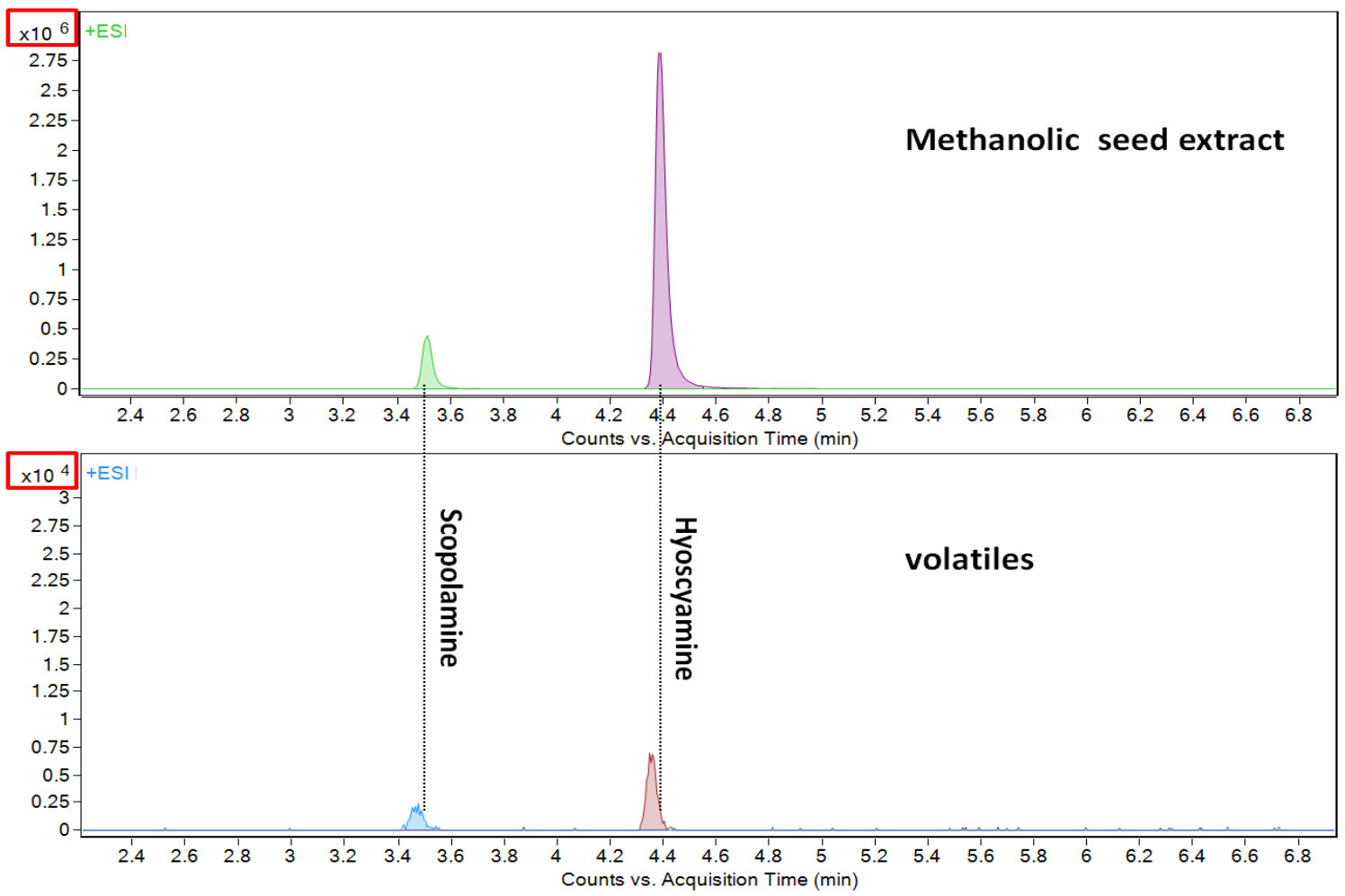

Figure. 5 Hyoscyamine and scopolamine content. Comparison between the methanolic henbane seed extract and the captured volatiles in cold methanol. $10 \mathrm{~g}$ seeds were extracted with $200 \mathrm{~mL}$ methanol, and fumes released from $10 \mathrm{~g}$ seeds at $120-150^{\circ} \mathrm{C}$ were captured in 200 $\mathrm{mL}$ cold methanol. $4 \mu \mathrm{l}$ of each extract was injected into $\mathrm{C} 18$ columns and analyzed by TOFMS. Extracted ions with m/z of 304 (scopolamine) and 290 (hyoscyamine) are shown.

\subsection{Investigation of the volatilization and polarity}

In order to investigate the properties of the toxic component (volatilization and polarity), the crude volatiles was modified by drying and defatting with cyclohexane. The following treatments were prepared: concentrated crude, concentrated and defatted crude using cyclohexane, dried crude, and defatted and dried crude. The toxicity of each treatment was assessed in brine shrimps bioassay (Figure. 6). The concentrated crude showed acute toxicity where the mortality reached $85 \%$ after $2 \mathrm{~h}$ of the treatment with $125 \mu \mathrm{g} \mathrm{mL} \mathrm{m}^{-1}$. The concentrated and defatted treatment was slightly toxic, with an anesthetic effect. This effect was evident at the dose of 250 and $125 \mu \mathrm{g} \mathrm{mL}^{-1}$, which caused a potent inhibition of the movement after $2 \mathrm{~h}$ of the treatment. Interestingly, the majority of the paralyzed shrimps restored the ability to move after $24 \mathrm{~h}$ of the treatment. The dried fractions showed no toxicity in brine shrimps. Depending on these results, the toxic component assumed to be volatile and lipophilic metabolites 

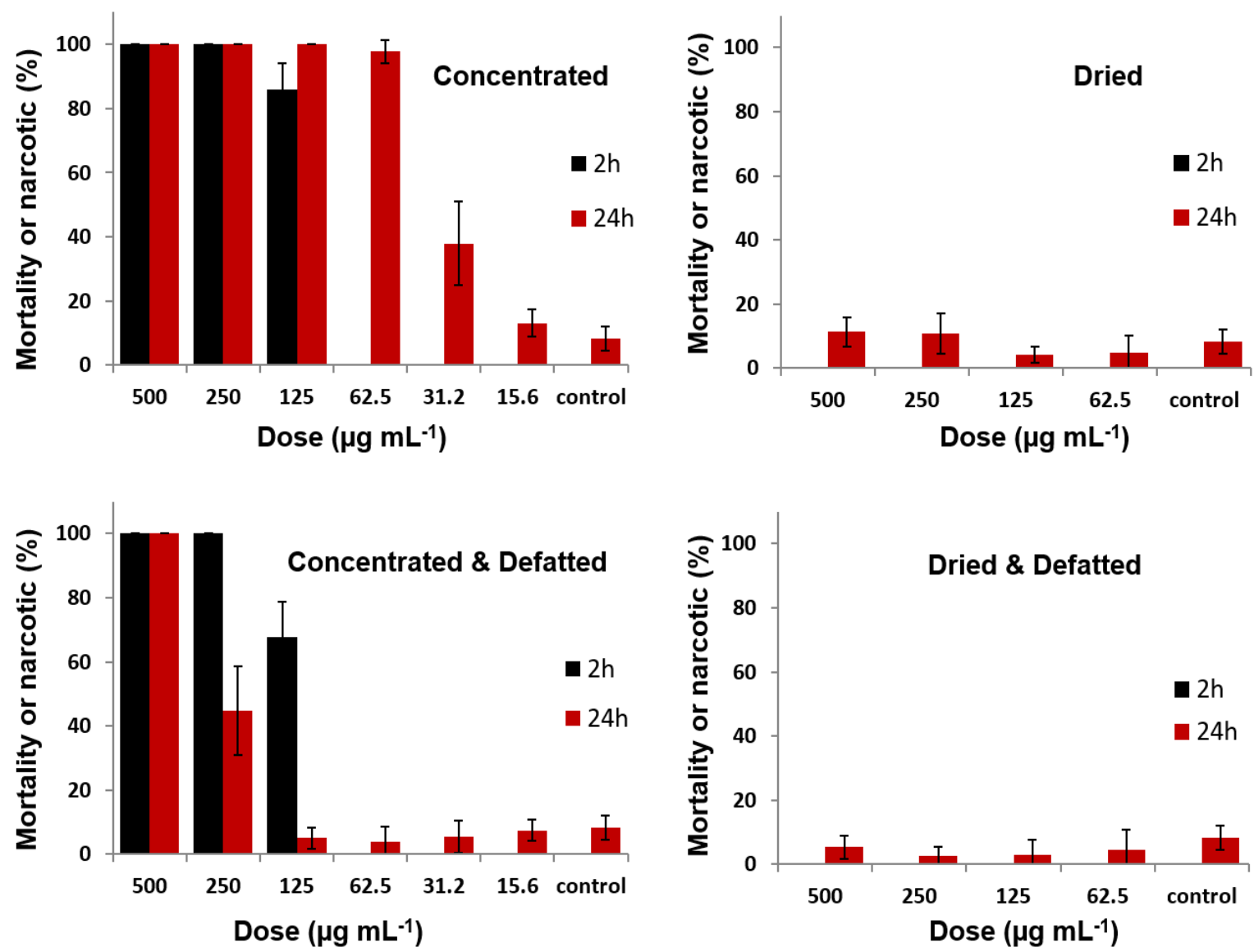

Figure 6. Toxicity of modified fractions from henbane volatiles crude. The volatiles were captured in cold $\mathrm{MeOH}$. The crude was modified by drying and defatting with cyclohexane. The toxicity of each modified fraction was evaluated in the brine shrimps assay. The error bars represent the standard deviation, $\mathrm{n}=10$.

\subsection{Metabolite profiling}

Metabolite profiling was performed for the modified fractions and pure crude using HPLCQTOF. Depending on the results of the toxicity of each treatment in brine shrimps (Figure. 6), the candidate metabolites were the shared metabolites among the crude, concentrated crude, and concentrated \& defatted (Figure. 7A). The metabolites were excluded from further investigations once they were detected at high abundance in the dried, dried \& defatted fractions and the species with nontoxic VOCs (soybean and Datura stramonium). Based on the above criteria, seven metabolites were determined as potential candidates (Figure. 7B). 


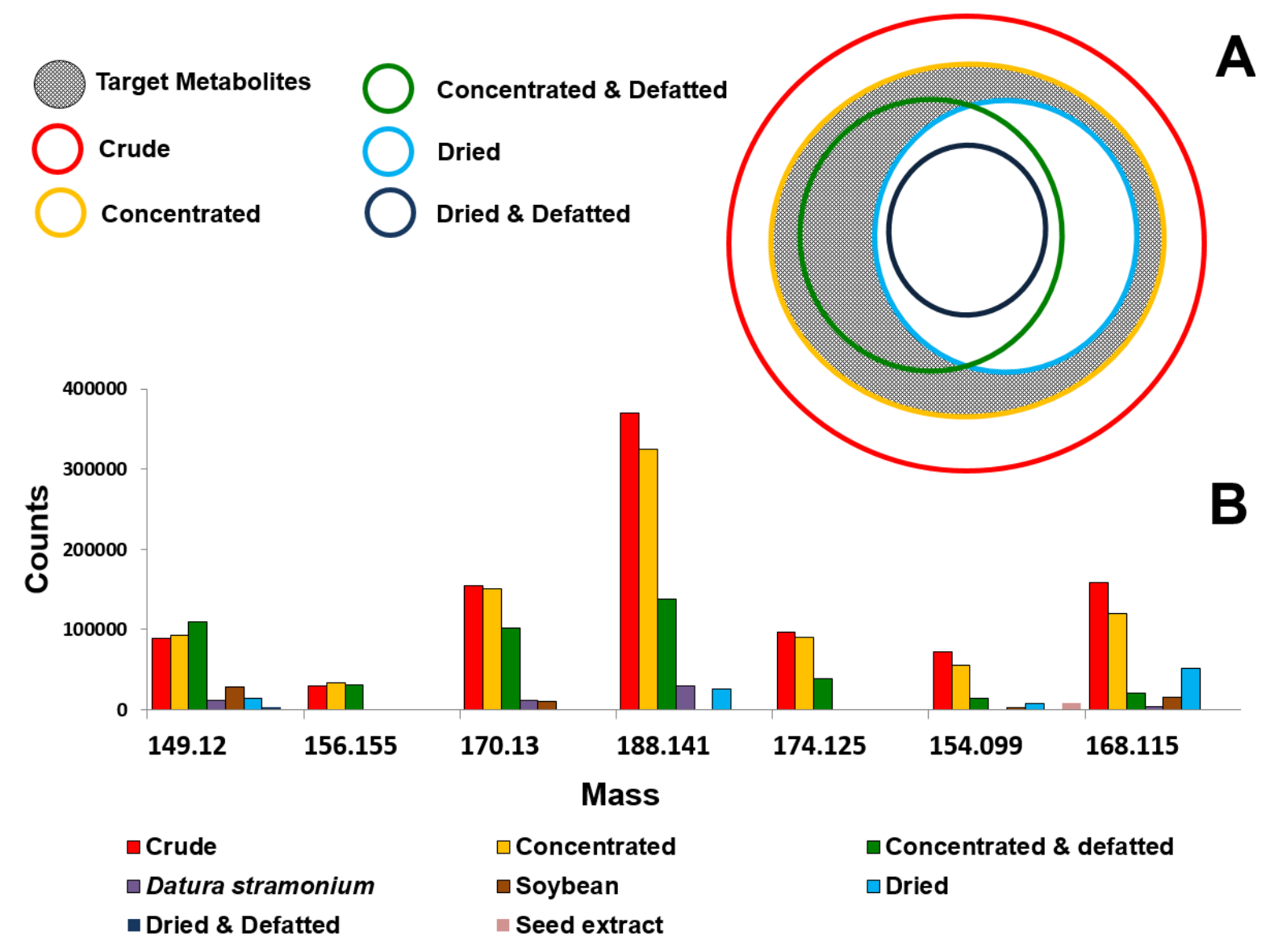

Figure 7. Potentially bioactive metabolites in captured fume of heated henbane seeds. (A) Fractionation of metabolites from captured fumes for HPLC-MS analysis. The candidate metabolites (gray) were selected depending on the results of the toxicity bioassay shown above. (B) Putative molecular mass of the candidate metabolites and their abundance in each fraction based on HPLC-QTOF analysis.

\subsection{Purification and characterization of the potentially bioactive metabolites}

The target metabolites were purified using preparative-HPLC into four fractions (Figure.8). To avoid volatilization of the metabolites, fractions were captured in C18 column and were eluted immediately with deuterated methanol $\left(\mathrm{CD}_{3} \mathrm{OD}\right)$ to be used in NMR. 


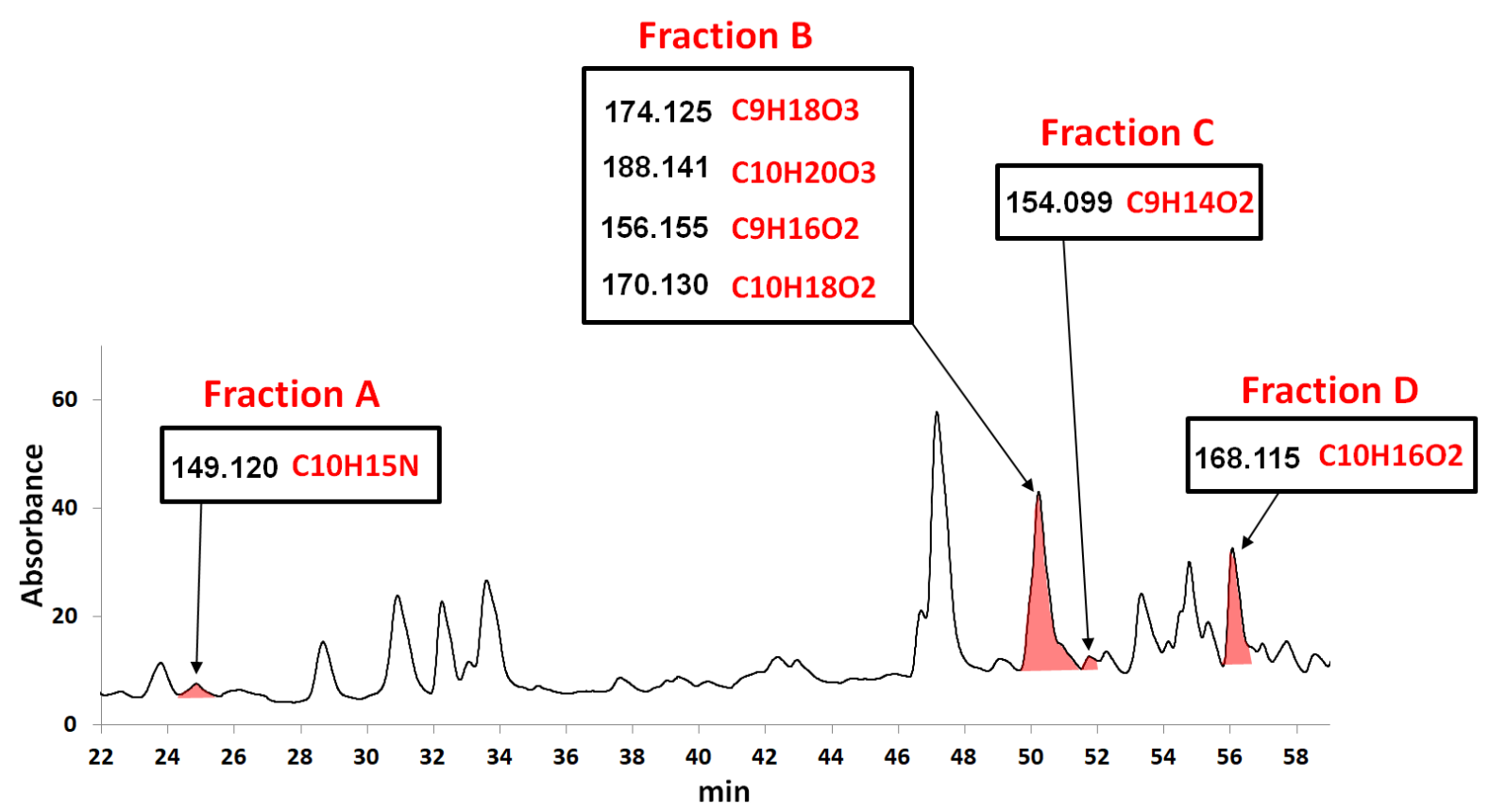

Figure.8 Purification of the potentially bioactive metabolites. Crude captured fumes from $H$. niger seeds were fractionated by preparative-HPLC on a C18 column. 25 fractions were collected and analyzed by HPLC-TOF. Four fractions containing compounds with target molecular weights (Figure 7) were selected for further work.

\subsection{Structure elucidation of the purified fractions}

The characterized metabolites are shown in (figure.9)

The relative toxicity of the purified fractions dissolved in CD3OD after NMR analysis was evaluated in brine shrimps. Based on our previous experiences, $1.25 \%$ methanol is the highest concentration that does not harm the brine shrimps. Therefore we added $12.5 \mu$ lof each fraction in deuterated methanol to $1 \mathrm{~mL}$ growth medium and incubated with the animals for $24 \mathrm{~h}$. Only fraction $\mathrm{C}$ exerted toxicity to shrimps (Figure.9). 

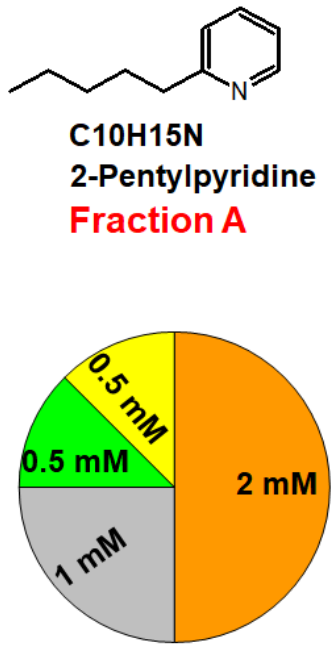

Fraction B

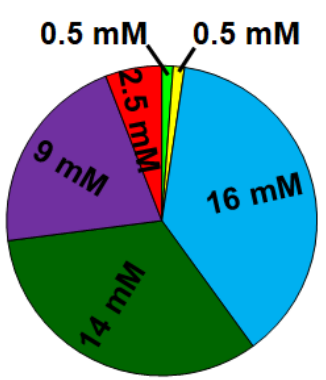

Fraction C
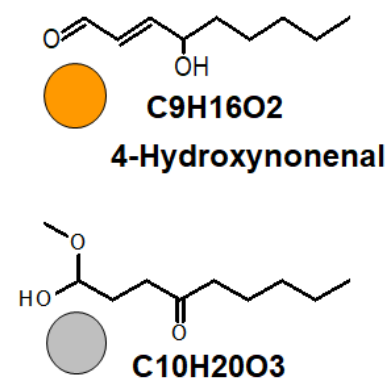

Methylhemiacetal of

4-Oxononanal

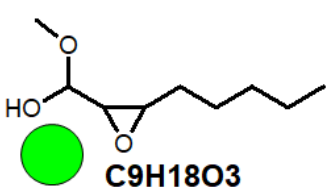

Methylhemiacetal of a 2,3 epoxyoctylaldehyde

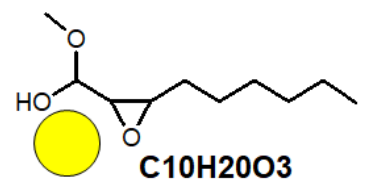

Methylhemiacetal of a 2,3epoxynonylaldehyde
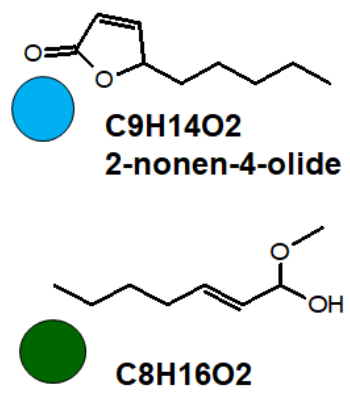

Methylhemiacetal of 2heptenal
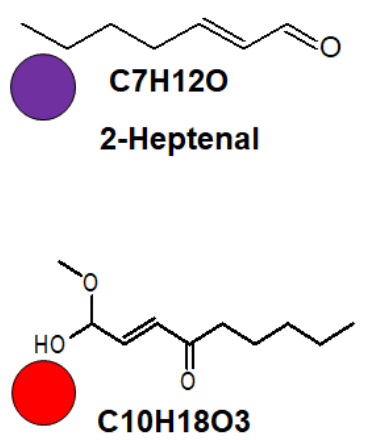

Methylhemiacetal of 4-Oxo-2-nonenal

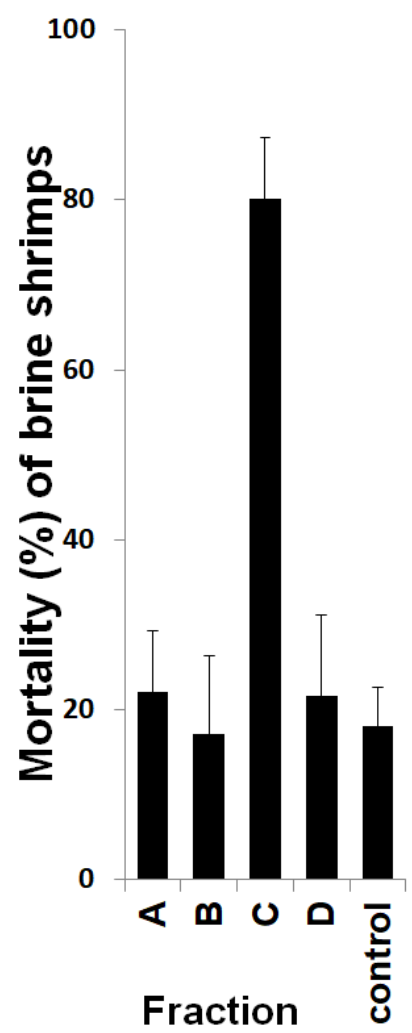

Figure. 9 Structures of the potentially toxic henbane volatiles and their toxicity in brine shrimps. Four fractions were purified using Preparative-HPLC (A, B, C, and D) and dissolved in $\mathrm{CD}_{3} \mathrm{OD}$. Structures were elucidated by NMR. The relative quantification is based on the terminal methyl group fragment. The toxicity of the purified fractions was assessed in brine shrimps. $12.5 \mu \mathrm{L}$ of each fraction was diluted in $1 \mathrm{~mL}$ shrimps solution. Water with $1.25 \%$ methanol (v/v) served as a control. The mortality was recorded $24 \mathrm{~h}$ after treatment. The error bars represent the standard deviation, $\mathrm{n}=10$.

\section{Discussion}

The survey about the use of henbane in folk medicine in northern Iraq revealed numerous pharmaceutical properties. In this study, we validated the statements of some practitioners about the unique use of henbane smoke as a treatment against eye worms. Many studies revealed that a wide range of parasitic nematodes can infest the human eye, such as the genera Ascarids and Thelazia, and genera from the family Onchocercidae. (Orihel and Eberhard 1998; Shen et al. 2006; Otranto and Dutto 2008; Otranto et al. 2011). We tested the nematicidal activity of the 
volatiles released from heated henbane seeds using a special apparatus that mimicked the traditional application. Only henbane was toxic to the nematodes C.elegans; none of the other tested 15 plant species. The result is consistent with the statements of the practitioners. It is worth mentioning that (Dulger and Dulger 2015) mentioned the use of henbane in Turkey to remove the worms from the eye, and that may support our results. Furthermore, it has been reported that henbane was used as antiparasitic medicine in Tibet (Kletter and Kriechbaum 2001; Tsarong 1994).

Tropane alkaloids, mainly atropine, hyoscyamine, and scopolamine, are linked to the therapeutic properties of plants from Solanaceae such as Atropa belladonna, Datura stramonium, and Hyoscyamus niger (Grynkiewicz and Gadzikowska 2008; Griffin and Lin 2000). Tropane alkaloids are believed to be the reason behind the pharmacological properties of asthma cigarettes, which were recommended in the United States and Europe as a treatment for asthma until the early decades of the 20th century. The cigarette was a mixture of herbs rich in tropane alkaloids such as Datura, belladonna, and henbane. However, the principle of the direct intake through cigarette smoking is not quite comparable to the inhalation of the fume released from heated seeds, where the active ingredients are inhaled volatiles. Generally, the volatility decreases with increasing the molecular mass. Therefore, tropane alkaloids with molecular masses of about 300 daltons are unlikely to be volatiles. In our study, we detected traces of hyoscyamine and scopolamine in the captured fume. Still, the quantities of those alkaloids in the fume were respectively 200 and 500 times lower than the seed content. Therefore, the small amount of those alkaloids in the fume reduces the probability of causing an apparent biological effect. However, the detectable traces of alkaloids might have been caused by the faster airflow in the capturing apparatus, which does not compare to inhalation. The fume released from heated henbane seeds caused a toxic and narcotic effect on Drosophila melanogaster adults. On the other hand, the larvae of Drosophila were not affected by the fume. The difference in the respiratory strategies may explain the contrasting effect of the volatiles. Callier et al. (2015) found that larval Drosophila melanogaster could tolerate oxygen deprivation in the medium. Furthermore, they mentioned that the larvae could move in anoxia for several minutes while adults were quickly paralyzed.

Furthermore, we used brine shrimp assay in this study to evaluate the cytotoxicity of the captured volatiles from heated henbane seeds. Brine shrimp bioassay is a simple and reliable tool for cytotoxicity prescreening (Anderson et al. 1991). Ruebhart et al. (2008) reviewed various studies in which brine shrimp have been used. They mentioned that brine shrimp was used in a broad range of toxicological assays, such as screening bioactive compounds in natural 
products, environmental toxicology, and drug discovery. However, the captured volatile mixture showed strong toxicity against brine shrimps with an $\mathrm{EC}_{50}$ value of $75 \mu \mathrm{g} \mathrm{mL}^{-1}$.

Furthermore, bioassay-guided fractionation showed that the lipophilic fraction was the only toxic fraction to brine shrimps. The investigation of the properties of the toxic components (volatilization and polarity) showed that the untreated fraction with heating and cyclohexane was the highly toxic fraction. A dosage of $125 \mu \mathrm{g} \mathrm{mL}-1$ caused acute toxicity with $85 \%$ of the individuals dead after $2 \mathrm{~h}$ of incubation. The concentrated and defatted fraction was slightly toxic with an anesthetic effect, while the dried fractions proved to be not toxic at all. Hence, the toxic ingredients had to be lipophilic and volatile

Based on metabolite profiling, the potentially toxic metabolites were separated into 4 fractions. Fraction A consisted of the pure compound 2-pentylpyridine, which is a Maillard product that resulted from the thermal interaction of 2,4-decadienal and amino acids. It is an odor compound detected in the aroma of various grilled meat and roasted seeds (Yannai 2008). However, fraction A was not toxic in brine shrimp bioassay, and this can be compatible with the facts above.

Fraction B consisted of a mixture from at least 4 metabolites. The first metabolite was 4hydroxynonenal (4-HNE). 4-HNE is the primary product of lipid peroxidation in living organisms. It is also produced during meat processing and deep frying (Zanardi et al. 2002). 4$\mathrm{HNE}$ is considered to be very toxic. It can cause unspecific cytotoxicity and rapid cell death at a concentration of $\geq 100 \mu \mathrm{M}$ (Esterbauer et al. 1991). The second metabolite in fraction B was methyl hemiacetal of 4-oxononanal. It is known that alcohols interact with aldehydes and ketones to form hemiacetal adducts. In an acidic medium, the interaction can continue beyond the hemiacetal stage to form acetal adducts (Vollhardt and Schore 2011). Therefore, we considered all compounds with hemiacetal as adducts of the corresponded aldehydes formed during the trapping process in methanol. Thus, 4-oxononanal was probably the original metabolite. 4-Oxononanal was reported as a toxic aldehyde that can be formed during the deepfrying process (Guillén and Uriarte 2012; Zhang et al. 2015). Fraction B and Fraction C included methyl hemiacetal 2,3-epoxy-alkanals. We excluded the hemiacetal group, as mentioned above. Thus 2,3-epoxyoctanal and 2,3-epoxyononanal could represent the original compounds in fractions B and C. Previous studies mention that some epoxyalkanals have been detected among other oxygenated aldehydes released during the heating of some oils (Guillén and Uriarte 2012; Guillén et al. 2005).

Moreover, Guillén and Uriarte (2012) suggested that the abundance of 2,3-epoxyoctanal and 4oxononanal is related to the amount of linoleic acid. This suggestion may explain the occurrence 
of those compounds as volatiles of heated henbane, especially when taken into account that linoleic acid is the major fatty acid in henbane seeds (Nejadhabibvash et al. 2012). Furthermore, diglycerides, which include at least one linoleic acid chain such as 1-O-(9Z,12Zoctadecadienoyl)-3-O-(9Z-octadecenoyl) glycerol, were detected in henbane seeds (Ma, Liu, and Che 2002). To our knowledge, the toxicity of 2,3-epoxyoctanal and 2,3 epoxyononanal has not been reported yet. Generally, alkanals are less reactive and toxic than other aldehydes, which possess double bonds and other reactive functional groups (Guillén and Uriarte 2012; Grootveld et al. 1998).

The most abundant compound in fraction $\mathrm{C}$ was 2-heptenal, which is a product of lipid peroxidation (Guillén and Uriarte 2012). Nishikawa et al. (1992) proved that the toxicity of 4HNE to rats is almost similar to the toxicity of trans-2-heptenal. The second detectable metabolite in fraction C was 2-nonen-4-olide. Dai et al. (2012) reviewed the research history on this metabolite. It is classified as a food odor and approved as a safe food additive. Based on the above, we excluded 2-nonen-4-olide from the potentially toxic metabolites. The last characterized metabolite in fraction $\mathrm{C}$ is 4-oxo-2-nonenal (4-ONE), a very toxic aldehyde formed by lipid peroxidation. 4-ONE is an electrophilic aldehyde that can bind to proteins and polynucleotides and trigger cell death. It is more neurotoxic and more protein reactive than 4HNE (Lin et al. 2005). 4-ONE can form imines faster than 4-ONE, which could explain its higher toxicity (Kovacic 2006). Picklo et al. (2011) revealed that 4-ONE could actively alter mitochondrial function by uncoupling mitochondrial respiration and causing lipid peroxidation. Generally, the toxic volatiles that we purified from heated henbane seeds are mixtures of aldehydes formed by lipid peroxidation. Depending on results from published studies, the toxicity of the purified metabolites can be ranked as follows: 4-oxo-2-nonenal > 4hydroxynonenal > 2-heptenal >4-oxo-nonanal. The toxicity of 2,3-epoxyoctanal and 2,3 epoxyononanal remains uncertain. By contrast, 2-pentylpyridine and 2-nonen-4-olide are assumed to be non-toxic compounds. However, the online in silico ProTox-II program (Banerjee et al. 2018) predicts toxicity for 2-nonen-4-olide and 2-pentylpyridine. Interestingly, 2-nonen-4-olide was proposed to be toxic with predicted $\mathrm{LD}_{50}$ of $34 \mathrm{mg} / \mathrm{kg}$ oral toxicity and with a good possibility to bind to prostaglandin G/H synthase 1 (see Suppl. Link 1). Binding to this target may contribute to the painkiller activity of henbane volatiles. 2-Pentylpyridine was proposed as a possible ligand to histamine receptor H1 (Suppl. Link 2). Proposals from this modeling recommend further studies on these compounds. 


\section{References}

Almahdi, Salma. 2003. "Muslim scholar contribution in restorative dentistry." International Society for the History of Islamic Medicine 2 (4).

Anderson, J. E., C. M. Goetz, J. L. McLaughlin, and M. Suffness. 1991. "A blind comparison of simple bench-top bioassays and human tumour cell cytotoxicities as antitumor prescreens." Phytochemical Analysis 2 (3): 107-11. https://doi.org/10.1002/pca.2800020303.

Banerjee, Priyanka, Andreas O Eckert, Anna K Schrey, and Robert Preissner. 2018. "ProTox-II: A webserver for the prediction of toxicity of chemicals." Nucleic Acids Research 46 (W1): W257-63. https://doi.org/10.1093/nar/gky318.

Barnes, Peter J. 2006. "Drugs for asthma." British Journal of Pharmacology 147 (S1): S297-303. https://doi.org/10.1038/sj.bjp.0706437.

Callier, Viviane, Steven C. Hand, Jacob B. Campbell, Taylor Biddulph, and Jon F. Harrison. 2015. "Developmental changes in hypoxic exposure and responses to anoxia in Drosophila melanogaster" The Journal of Experimental Biology 218 (18): 2927. https://doi.org/10.1242/jeb.125849.

Dai, Yi-feng, Hong-yu Tian, Bao-guo Sun, Yu-mei Sun, Hai-tao Chen, and Xiao-yu Liu. 2012. "Efficient synthesis of the odourant, 2-nonen-4-olide." Journal of Chemical Research 36 (8): 495-96. https://doi.org/10.3184/174751912X13402955389383.

Dulger, G. Avanoglu, and Başaran Dulger. 2015. "Antimicrobial activity of the seeds of Hyoscyamus niger L. (Henbane) on microorganisms isolated from urinary tract infections." J Med Plants Stud 2015;3(5):92-95M

Esterbauer, Hermann, Rudolf Jörg Schaur, and Helmward Zollner. 1991. "Chemistry and biochemistry of 4-hydroxynonenal, malonaldehyde and related aldehydes." Free Radical Biology and Medicine 11 (1): 81-128. https://doi.org/10.1016/0891-5849(91)90192-6.

Fenwick, Rohan S. H., and Sachihiro Omura. 2015. "Smoke in the Eyes? Archaeological Evidence for Medicinal Henbane Fumigation at Ottoman Kaman-Kalehöyük, Kırşehir Province, Turkey." Antiquity. August 2015. https://doi.org/10.15184/aqy.2015.56.

Griffin, William J., and G.David Lin. 2000. "Chemotaxonomy and geographical distribution of tropane alkaloids.” Phytochemistry 53 (6): 623-37. https://doi.org/10.1016/S00319422(99)00475-6.

Grootveld, M, M D Atherton, A N Sheerin, J Hawkes, D R Blake, T E Richens, C J Silwood, E Lynch, and A W Claxson. 1998. "In Vivo absorption, metabolism, and urinary excretion of alpha,betaunsaturated aldehydes in experimental animals. Relevance to the development of cardiovascular diseases by the dietary ingestion of thermally stressed polyunsaturate-rich culinary oils." Journal of Clinical Investigation 101 (6): 1210-18. https://doi.org/10.1172/JCI1314.

Grynkiewicz, G., and M Gadzikowska. 2008. "Tropane alkaloids as medicinally useful natural products and their synthetic derivatives as new drugs." Pharmacological Reports 60 (4): 439. https://www.ncbi.nlm.nih.gov/pubmed/18799813.

Guillén, María D., Nerea Cabo, María L. Ibargoitia, and Ainhoa Ruiz. 2005. "Study of both sunflower oil and its headspace throughout the oxidation process. occurrence in the headspace of toxic oxygenated aldehydes." Journal of Agricultural and Food Chemistry 53 (4): 1093-1101. https://doi.org/10.1021/jf0489062.

Guillén, Maria D., and Patricia S. Uriarte. 2012. "Aldehydes contained in edible oils of a very different nature after prolonged eating at frying temperature: Presence of toxic oxygenated $\alpha, \beta$ unsaturated aldehydes." Food Chemistry 131 (3): 915-26. https://doi.org/10.1016/j.foodchem.2011.09.079.

Hansler, Alex, Qiuying Chen, Jason D. Gray, M. Elizabeth Ross, Richard H. Finnell, and Steven S. Gross. 2014. "Untargeted metabolite profiling of murine embryos to reveal Metabolic Perturbations Associated with Neural Tube Closure Defects." Birth Defects research part A: Clinical and Molecular Teratology 100 (8): 623-32. https://doi.org/10.1002/bdra.23272.

Hocking, George M. 1947. "Henbane-Healing Herb of Hercules and of Apollo." Economic Botany 1 (3): 306. https://doi.org/10.1007/BF02858575. 
Jackson, Mark. 2010. “'Divine stramonium': The rise and fall of smoking for asthma.” Medical History 54 (2): 171-94. https://doi.org/10.1017/S0025727300000235.

Kelly, Kate. 2009. The History of Medicin_early Civilization_prehistoric Times. https://www.scribd.com/doc/26657174/The-History-of-Medicine-2009.

Kletter, Christa, and Monika Kriechbaum, eds. 2001. Tibetan Medicinal Plants. 1 edition. Boca Raton, FL: Medpharm.

Kovacic, Peter. 2006. "Novel electrochemical approach to enhanced toxicity of 4-Oxo-2-nonenal vs. 4-Hydroxy-2-nonenal (Role of Imine): Oxidative stress and therapeutic modalities." Medical Hypotheses 67 (1): 151-56. https://doi.org/10.1016/j.mehy.2005.10.034.

Lin, De, Hyoung-gon Lee, Quan Liu, George Perry, Mark A. Smith, and Lawrence M. Sayre. 2005. "4-Oxo-2-nonenal is both more neurotoxic and more protein reactive than 4-hydroxy-2nonenal." Chemical Research in Toxicology 18 (8): 1219-31. https://doi.org/10.1021/tx050080q.

Ma, Cui-Ying, Wing Keung Liu, and Chun-Tao Che. 2002. "Lignanamides and nonalkaloidal components of Hyoscyamus niger seeds." Journal of Natural Products 65 (2): 206-9. https://doi.org/10.1021/np010073b.

Mitich, Larry W. 1992. "Black Henbane." Weed Technology 6 (2): 489-91. https://doi.org/10.1017/S0890037X00035120.

Molina-Salinas, Gloria, Salvador Said-Fernández, División De, Biología Celular, Instituto Mexicano, Seguro Social, Dos De Abril, et al. 2006. "A modified microplate cytotoxicity assay with brine shrimp larvae (Artemia Salina)." Pharmacology on Line 3 (January): 633-38.

Nejadhabibvash, Fatemeh, Fatemeh Rahmani, Reza Heidari, and Rashid Jamei. 2012. "Heritability and correlation studies of fatty acid composition within Hyoscyamus accessions." International Research Journal of Applied and Basic Sciences 3 (9): 1837-44.

Nishikawa, Akiyoshi, Rama Sodum, and Fung-Lung Chung. 1992. "Acute toxicity oftrans-5-hydroxy2-nonenal in fisher 344 rats." Lipids 27 (1): 54-58. https://doi.org/10.1007/BF02537060.

Orihel, Thomas C., and Mark L. Eberhard. 1998. "Zoonotic Filariasis." Clinical Microbiology Reviews 11 (2): 366. https://doi.org/10.1128/CMR.11.2.366.

Otranto, Domenico, and Moreno Dutto. 2008. "Human thelaziasis, Europe." Emerging Infectious Diseases 14 (4): 647-49. https://doi.org/10.3201/eid1404.071205.

Otranto, Domenico, Nermin Sakru, Gabriella Testini, Vuslat P. Gürlü, Konuralp Yakar, Riccardo P. Lia, Filipe Dantas-Torres, and Odile Bain. 2011. "First evidence of human zoonotic infection by Onchocerca lupi (Spirurida, Onchocercidae)." The American Journal of Tropical Medicine and Hygiene 84 (1): 55-58. https://doi.org/10.4269/ajtmh.2011.10-0465.

Picklo, Matthew J., Alexander Azenkeng, and Mark R. Hoffmann. 2011. "Trans-4-Oxo-2-nonenal potently alters mitochondrial function." Free Radical Biology and Medicine 50 (2): 400-407. https://doi.org/10.1016/j.freeradbiomed.2010.11.014.

Ruebhart, David R., Ian E. Cock, and Glen R. Shaw. 2008. "Brine shrimp bioassay: importance of correct taxonomic identification of Artemia (Anostraca) Species.” Environmental Toxicology 23 (4): 555-60. https://doi.org/10.1002/tox.20358.

Shen, Jilong, Robin B. Gasser, Deyong Chu, Zengxian Wang, Xiaosong Yuan, Cinzia Cantacessi, and Domenico Otranto. 2006. "Human thelaziosis: A neglected parasitic disease of the eye." The Journal of Parasitology 92 (4): 872-75. http://www.jstor.org/stable/40058593.

Stiernagle, T. 2006. Maintenance of C. Elegans (February 11, 2006), WormBook, Ed. The C. Elegans Research Community, WormBook, Doi/10.1895/Wormbook.1.101.1, Http://Www.Wormbook.Org. Reprinted from Pp. 51-67, Maintenance of C. Elegans, by T. Steiernagle.

Tabata, Mamoru, Ekrem Sezik, Gisho Honda, Erdem Yeşilada, Hiroshi Fukui, Katsumi Goto, and Yasumasa Ikeshiro. 1994. "Traditional medicine in Turkey III. Folk medicine in east Anatolia, Van and Bitlis provinces." International Journal of Pharmacognosy 32 (1): 3-12. https://doi.org/10.3109/13880209409082966.

Trienens, Monika, Nancy P. Keller, and Marko Rohlfs. 2010. "Fruit, flies and filamentous fungi experimental analysis of animal-microbe competition using Drosophila Melanogaster and Aspergillus mould as a model system - Trienens - 2010 - Oikos - Wiley Online Library." Oikos 119 (11): 1765. https://doi.org/doi: 10.1111/j.1600-0706.2010.18088.x.

Tsarong, Tsewang J. 1994. Tibetan Medicinal Plants. Tibetan Medical Publications. 
Vollhardt, Peter, and Neil Schore. 2011. Organic Chemistry: Structure and Function 6th Edition. W. H. Freeman and Company New York. https://www.amazon.com/Organic-ChemistryStructure-Function-Book/dp/B00863F382.

Yannai, Shmuel. 2008. Dictionary of Food Compounds : [Additives, Flavors, and Ingredients /. Boca Raton, Chapman \& Hall/CRC.

Zanardi, Emanuela, Christian G. Jagersma, Sergio Ghidini, and Roberto Chizzolini. 2002. "Solid phase extraction and liquid chromatography-tandem mass spectrometry for the evaluation of 4-hydroxy-2-nonenal in pork products." Journal of Agricultural and Food Chemistry 50 (19): 5268-72. https://doi.org/10.1021/jf020201h.

Zhang, Qing, Wen Qin, Derong Lin, Qun Shen, and Ahmed S M Saleh. 2015. "The Changes in the volatile aldehydes formed during the deep-fat frying process." Journal of Food Science and Technology 52 (12): 7683-96. https://doi.org/10.1007/s13197-015-1923-z. 


\section{Supplementary data}

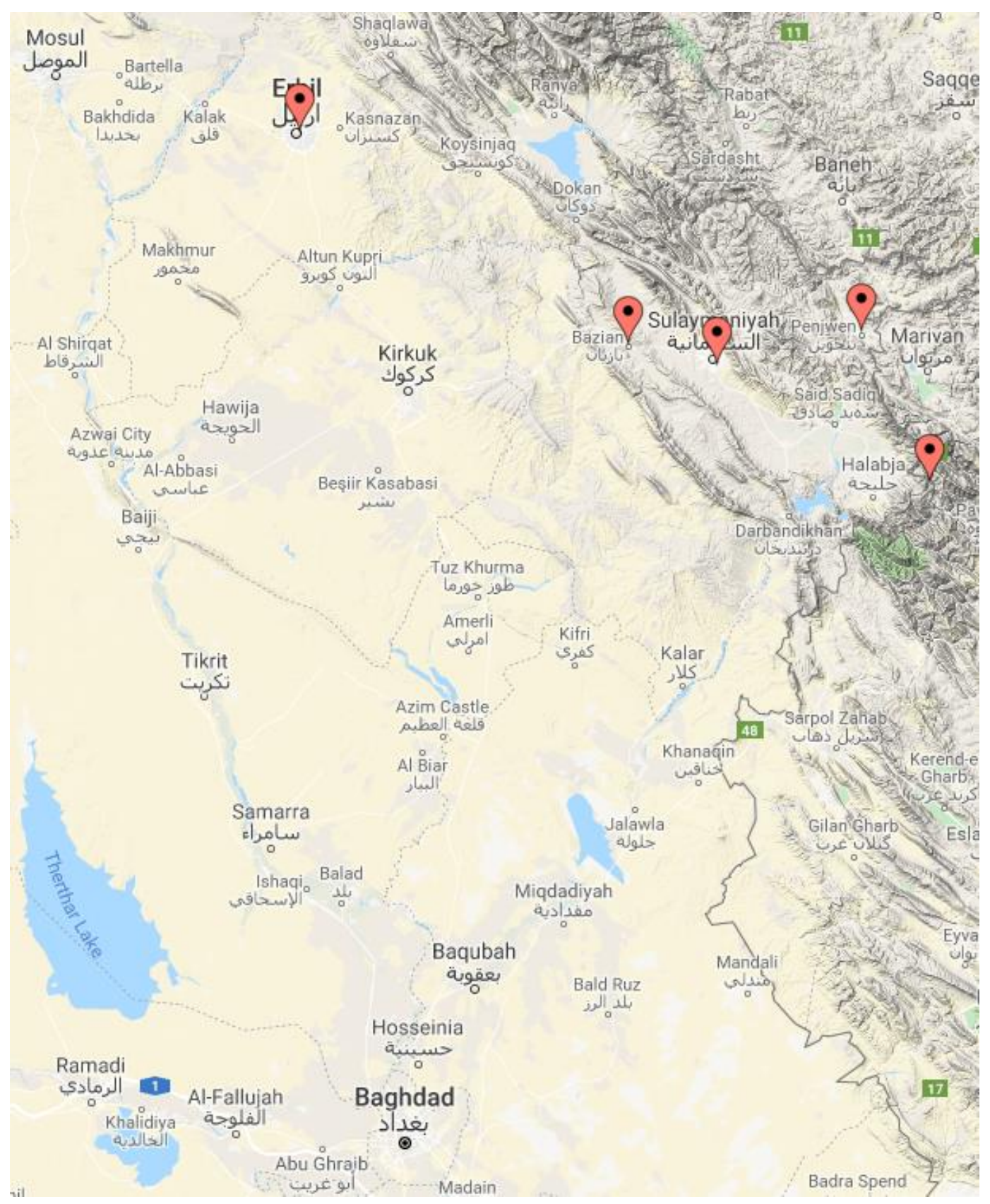

Suppl. Figure. 1. Map of the survey area about the ethnopharmacological uses of

henbane in northern Iraq. The survey exclusively covered authorized practitioners in folk medicine. Created using google maps 
Suppl.Table. 1 Mortality of $C$. elegans caused by volatiles released during the heating of $2 \mathrm{~g}$ of henbane and soybean seeds at different temperature ranges and exposure time

\begin{tabular}{|l|l|l|l|l|}
\hline Seeds & Time since the & Exposure to & \multicolumn{2}{|c|}{ Mortality \% } \\
\cline { 4 - 6 } & $\begin{array}{l}\text { Temperature } \\
\text { start of heating }\end{array}$ & volatiles (min) & Henbane & Soybean \\
\hline $80-110^{\circ} \mathrm{C}$ & 60 & 60 & 0 & 0 \\
\cline { 2 - 6 } & 75 & 15 & 0 & 0 \\
\hline $120-150^{\circ} \mathrm{C}$ & 60 & 60 & 100 & 0 \\
\cline { 2 - 6 } & 75 & 15 & 100 & 0 \\
\hline
\end{tabular}
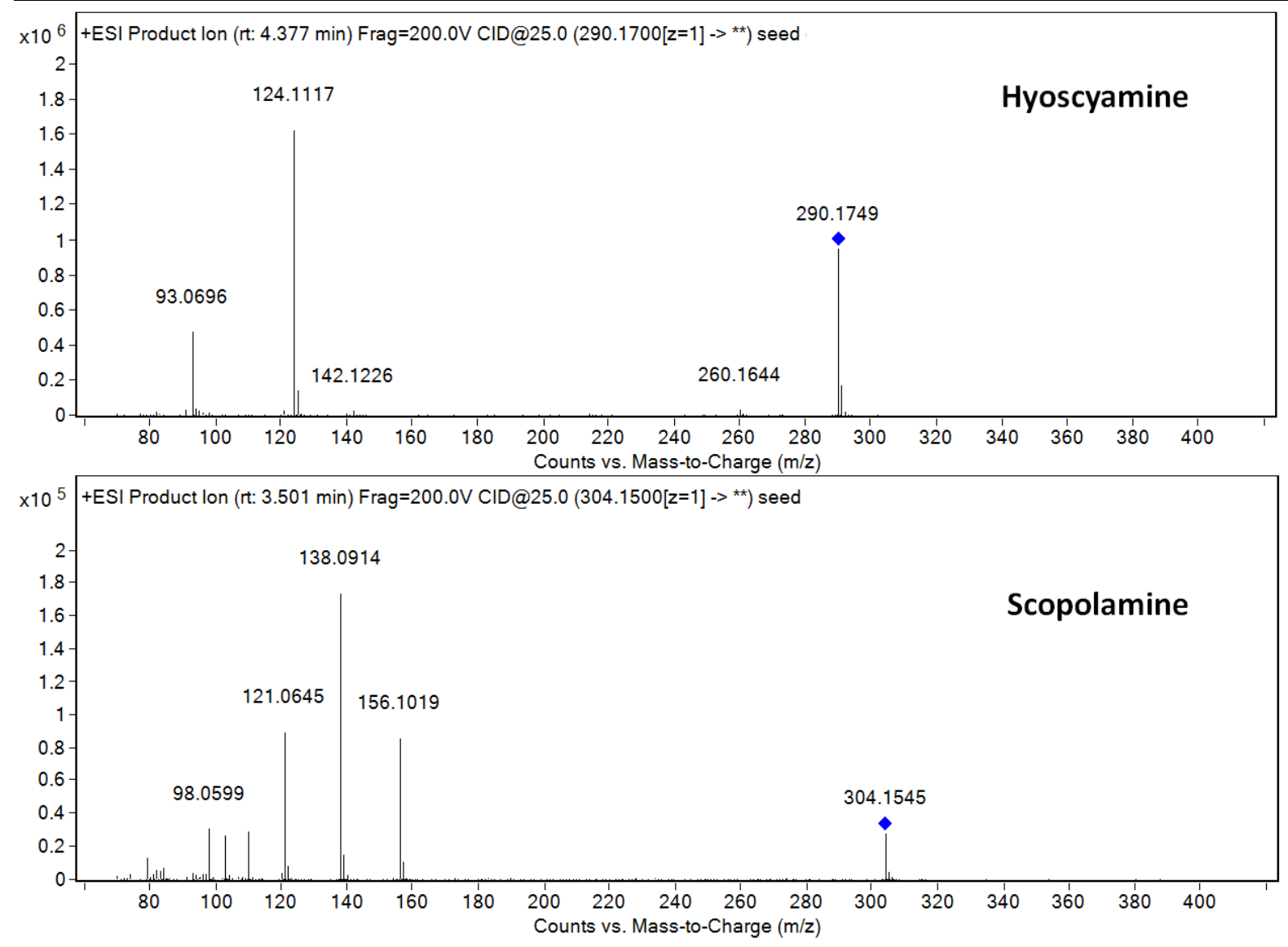

Suppl. Figure. 2. MS/MS Spectra for hyoscyamine and scopolamine @ 25V. Blue markers show the mother ions. 


\section{Suppl. Link 1: toxicity prediction of 2-nonen-4-olide}

http://tox.charite.de/protox_II/index.php?site=direct_load\&id=15590510266149\&models=dili ,carcino,immuno,mutagen,cyto,nr_ahr,nr_ar,nr_ar_lbd,nr_aromatase,nr_er,nr_er_lbd,nr_ppar_ gamma,sr_are,sr_hse,sr_mmp,sr_p53,sr_atad5

\section{Suppl. Link 2: toxicity prediction of 2-Pentylpyridine}

http://tox.charite.de/protox_II/index.php?site=direct_load\&id=15590501021573\&models=dili ,carcino,immuno,mutagen,cyto,nr_ahr,nr_ar,nr_ar_lbd,nr_aromatase,nr_er,nr_er_lbd,nr_ppar_ gamma,sr_are,sr_hse,sr_mmp,sr_p53,sr_atad5 


\section{Chapter 5. General discussion}

The purification of morphine from opium in 1905 by Friedrich Wilhelm Sertürner is considered the beginning of phytochemistry research (Hartmann 2007). Since then, more than 100,000 secondary metabolites have been isolated from plants (Wink 2010). The classical extraction includes techniques like maceration or boiling of dried and ground plants materials with organic solvents such as alcohols, ethyl acetate, dichloromethane, and chloroform (Jones and Kinghorn 2005). Generally, it is accepted that secondary plant metabolites cannot affect other surrounding organisms such as plants and soil microorganisms unless they are released into the environment through leaf leachates, root exudates, or volatilization (Cantor et al. 2011; Lorenzo et al. 2011; E.L. Rice 1984; Song et al. 2018).

Plenty of research reported the biological activity of allelochemicals in vitro using simple bioassays ( reviewed by Lorenzo et al. 2013). Despite all of those reports, only a few studies have clearly proved the allelopathy in natural settings (Inderjit et al. 2005). However, it is difficult to confirm their proposed function at the organism level (Bednarek et al. 2009). Recently, more advanced and realistic methods have been involved in allelopathy research, but their contribution is still limited (Gómez-Aparicio and Canham 2008).

Plants can avoid self-toxicity by keeping the toxic compounds away from the vital subcellular components through several mechanisms, such as excretion into the extracellular compartments, accumulation into vacuoles. It can also convert toxins into non-toxic forms (Sirikantaramas et al. 2007). The apoplast is considered the first line of defense against biotic and abiotic stresses. In addition, it can serve as a store where the components accumulated in it can be transported when needed either to the surrounding cells or exported to other plant parts (Clarkson 2007).

In our study, we isolated the secondary metabolites using a method that mimics nature. We extracted the compounds from the intact plant parts by water, which is the only solvent available in nature. Therefore, we assumed that the chance to isolate a compound that possesses an ecological role from apoplast using water extraction is higher than the chance of the classical total extraction with organic solvents.

Furthermore, we applied numerous bioassays and techniques to investigate the biological activity of secondary metabolites. For instance, we evaluate the phytotoxicity in the whole plant level (Lemna minor), cytotoxicity in brine shrimps, nematicidal activity, and insect 
antifeedants. We also studied the release of secondary metabolites through artificial rainfall, root exudates, and the rhizosphere. Moreover, we studied the leaching of the secondary metabolites in the soil and evaluate the effect of those metabolites on soil microorganisms using sophisticated molecular techniques such as qPCR and the profiling of soil bacteria communities with next-generation sequencing.

By applying the concept of aqueous extraction from apoplast and the wide range of bioassays, we succeeded in determining several secondary metabolites that may possess biological activity in the plant species we tested. Our results obviously showed that the secondary metabolites we isolated could be released spontaneously from the living plants to the environment under natural conditions. This supports our hypothesis about the higher probability of isolating a compound that possessed an ecological function using aqueous extraction apoplast.

The active metabolites we purified from the investigated plant species belong to three main chemical groups: alkaloids, phenolics, and aldehydes.

Alkaloids are one of the largest groups of plant secondary metabolites. Generally, it is believed that most plant Alkaloids contribute to the defense against herbivores and microorganisms (Zayed and Wink 2004; Levinson 1976; Wittstock and Gershenzon 2002; Wink 2008; Harborne 1993).

In our study, two groups of biologically active alkaloids were isolated. The first group was purified from Galanthus nivalis. They are specific alkaloids confined to the family Amaryllidaceae (Chase et al. 2009; Kilgore and Kutchan 2016). Berkov et al. (2008) detected 25 different alkaloids in G. nivalis, including the isolated alkaloids. However, the classical research of Amaryllidaceae alkaloids has mainly focused on their pharmaceutical properties and not ecological functions. Despite the vast number of Amaryllidaceae alkaloids that have shown pharmaceutical activities, galantamine is the only alkaloid that has been used as a commercial drug (Bastida et al. 2006; Berkov et al. 2012).

Using the concept of aqueous extraction coupled with relevant bioassays, we proved that pretazettine, trihydroxybutanoyl hamayne, and lycoricidinol alkaloids could play a defensive function against soil microorganisms, nematodes, and insects. Furthermore, the abundance of alkaloids in the root exudate was proportional to the increasing of the compound polarity. Thus, pretazettine, which is comparatively soluble in water, was the dominant alkaloid in the root exudates. Interestingly, we could not determine any ecological function in which galantamine was involved.

The second alkaloids group that we detected was tropane alkaloids. Tropane is an essential group of toxic chemical defenses in Solanaceae (Agrawal 2007). Finally, we found a high 
concentration of hyoscyamine and scopolamine in the seeds of Hyoscyamus niger, and that corresponded to what is already published.

It is worth mentioning that the biosynthesis of tropane alkaloids occurs mainly in the roots, and then they are transported to the leaves and seeds, where they are stored (Kohnen-Johannsen and Kayser 2019). However, it has been suggested that plant parts that are under a significant risk of attack or which of special importance may be protected through the accumulation of high constitutive levels of the toxins (Wittstock and Gershenzon 2002). Baldwin and Callahan (1993) reviewed studies about the transport of plant alkaloids from their synthesizing tissue to other tissues where they serve as a defense mechanism against pathogens and herbivores. The bulbs of $G$. nivalis and the seeds of $H$. niger both are fundamental for reproduction, and both can survive in the soil for years. Hence, the accumulation of numerous toxic alkaloids may protect them from decaying and from herbivores.

The second group of secondary metabolites that we investigated in our research was phenolics and particularly coumarins. They were isolated from Melilotus albus and possessed selective antimicrobial activity against some soil bacterial groups. However, coumarins are a known group of phenolics, and Zacchino et al. (2017) revealed that the majority of antibacterial plant secondary metabolites belong to phenolics and terpenoids. Furthermore, we proved that coumarins were involved in the phytotoxicity of the aqueous extract of M. albus. We suggested that the coumarins released from M. albus debris may contribute to the suppressiveness of weeds germination in the treated area. However, many phenolics have been reported as allelochemicals in natural and managed ecosystems. Moreover, the accumulation of phenolics in the rhizosphere may cause a reduction in the growth and yield of the crops (Li et al. 2010). We proved that the bioactive coumarins that we studied could be released from living plants into the environment through root exudation and leaching from leaves by rainfall. We found that $O$-coumaric acid and melilotic acid were mainly detected as glycosides in the rain leachates and root exudates. That can be explained by the high water solubility of the glycosides comparing to the free phenolic acids. However, it is known that several hydroxycinnamic acid derivatives can form esters with carbohydrates in the cell wall (reviewed by Agati et al. 2012). Moreover, glycosylation may reduce the toxicity of allelochemicals to prevent the self-toxicity in the producer plants (Sirikantaramas et al. 2007). For instance, it has been mentioned that glycosylation may be considered as a detoxification method to avoid the self-toxicity of benzoxazinoids in grasses (Sicker et al. 2000). On the other hand, when the glycosides reach into the soil, the hydrolysis of glycosidic bonds will occur thanks to soil microorganisms, and the corresponding aglycons will be released (Eivazi and Tabatabai 1988; DeBoy et al. 2008). 
Furthermore, we purified a mixture of toxic volatiles from heated $H$. niger seeds. The main potential toxic compounds were 4-oxo-2-nonenal 4-hydroxynonenal, 2-heptenal, 4-oxononanal, and 2,3-epoxyoctanal. Generally, they were aldehydes formed through lipid peroxidation. (Zanardi et al. 2002; Guillén and Uriarte 2012; Dai et al. 2012; Guillén et al. 2005). Those compounds were probably the source of the acute toxicity in brine shrimps. Where the doses of $125 \mu \mathrm{g} \mathrm{mL}^{-1}$ of the captured volatiles caused strong toxicity and almost total mortality in brine shrimps after $2 \mathrm{~h}$ of treatment, such severe toxicity has not been observed before with other secondary metabolites that studied.

\section{References}

Agati, Giovanni, Elisa Azzarello, Susanna Pollastri, and Massimiliano Tattini. 2012. "Flavonoids as antioxidants in plants: Location and functional significance." Plant Science 196 : 67-76. https://doi.org/10.1016/j.plantsci.2012.07.014.

Agrawal, Anurag A. 2007. "Macroevolution of plant defense strategies." Trends in Ecology \& Evolution 22 (2): 103-9. https://doi.org/10.1016/j.tree.2006.10.012.

Baldwin, Ian T., and Patrick Callahan. 1993. "Autotoxicity and chemical defense: Nicotine accumulation and carbon gain in solanaceous plants." Oecologia 94 (4): 534-41. http://www.jstor.org/stable/4220387.

Bastida, Jaume, Rodolfo Lavilla, and Francesc Viladomat. 2006. "Chemical and biological aspects of narcissus alkaloids." The Alkaloids. Chemistry and Biology 63: 87-179.

Berkov, Strahil, Jaume Bastida, Borijana Sidjimova, Francesc Viladomat, and Carles Codina. 2008. "Phytochemical differentiation of Galanthus nivalis and Galanthus elwesii (Amaryllidaceae): A Case Study." Biochemical Systematics and Ecology 36 (8): 638-45. https://doi.org/10.1016/j.bse.2008.04.002.

Berkov, Strahil, Carles Codina, and Bastida Jaume. 2012. "The Genus Galanthus: A source of bioactive compounds." In Phytochemicals_A Global Perspective of Their Role in Nutrition and Health, Ch. 11. Rijeka: IntechOpen. https://doi.org/10.5772/28798.

Cantor, Aaron, Alison Hale, Justin Aaron, M. Brian Traw, and Susan Kalisz. 2011. "Low allelochemical concentrations detected in garlic mustard-invaded forest soils inhibit fungal growth and AMF spore germination." Biological Invasions 13 (12): 3015-25. https://doi.org/10.1007/s10530011-9986-x.

Chase, MARK W., JAMES L. REVEAL, and MICHAEL F. FAY. 2009. "A Subfamilial classification for the expanded Asparagalean Families Amaryllidaceae, Asparagaceae and Xanthorrhoeaceae." Botanical Journal of the Linnean Society 161 (2): 132-36. https://doi.org/10.1111/j.1095-8339.2009.00999.x.

Clarkson, D.T. 2007. "The plant-leaf apoplast." In The Apoplast of Higher Plants: Compartment of Storage, Transport and Reactions. Springer Netherlands. http://link.springer.com/10.1007/9781-4020-5843-1.

Dai, Yi-feng, Hong-yu Tian, Bao-guo Sun, Yu-mei Sun, Hai-tao Chen, and Xiao-yu Liu. 2012. "Efficient synthesis of the odourant, 2-nonen-4-olide." Journal of Chemical Research 36 (8): 495-96. https://doi.org/10.3184/174751912X13402955389383.

DeBoy, R. T., E. F. Mongodin, D. E. Fouts, L. E. Tailford, H. Khouri, J. B. Emerson, Y. Mohamoud, et al. 2008. "Insights into plant cell wall degradation from the genome sequence of the soil bacterium Cellvibrio Japonicus." Journal of Bacteriology 190 (15): 5455-63. https://doi.org/10.1128/JB.01701-07.

Eivazi, F., and M.A. Tabatabai. 1988. "Glucosidases and galactosidases in soils." Soil Biology and Biochemistry 20 (5): 601-6. https://doi.org/10.1016/0038-0717(88)90141-1. 
Gómez-Aparicio, Lorena, and Charles D. Canham. 2008. "Neighbourhood analyses of the allelopathic effects of the invasive tree Ailanthus altissima in temperate forests." Journal of Ecology 96 (3): 447-58. https://doi.org/10.1111/j.1365-2745.2007.01352.x.

Guillén, María D., Nerea Cabo, María L. Ibargoitia, and Ainhoa Ruiz. 2005. "Study of both sunflower oil and its headspace throughout the oxidation process. Occurrence in the headspace of toxic oxygenated aldehydes." Journal of Agricultural and Food Chemistry 53 (4): 1093-1101. https://doi.org/10.1021/jf0489062.

Guillén, Maria D., and Patricia S. Uriarte. 2012. "Aldehydes contained in edible oils of a very different nature after prolonged heating at frying temperature: Presence of toxic oxygenated $\alpha, \beta$ unsaturated aldehydes.” Food Chemistry $131 \quad$ (3): 915-26. https://doi.org/10.1016/j.foodchem.2011.09.079.

Harborne, Jeffrey B. 1993. Introduction to Ecological Biochemistry (Fourth Edition). San Diego: Academic Press. https://doi.org/10.1016/B978-0-08-091858-7.50004-8.

Hartmann, Thomas. 2007. "From Waste Products to Ecochemicals: Fifty Years Research of Plant Secondary Metabolism." Phytochemistry $68 \quad$ (22-24): 2831-46. https://doi.org/10.1016/j.phytochem.2007.09.017.

Inderjit, Leslie A Weston, and Stephen O Duke. 2005. "Challenges, achievements and opportunities in allelopathy research." Journal of Plant Interactions 1 (2): 69-81. https://doi.org/10.1080/17429140600622535.

Jones, William P., and A. Douglas Kinghorn. 2005. "Extraction of plant secondary metabolites." In Natural Products Isolation, edited by Satyajit D. Sarker, Zahid Latif, and Alexander I. Gray, 323-51. Totowa, NJ: Humana Press. https://doi.org/10.1385/1-59259-955-9:323.

Kilgore, Matthew B, and Toni M Kutchan. 2016. "The amaryllidaceae alkaloids: Biosynthesis and methods for enzyme discovery." Phytochemistry Reviews : Proceedings of the Phytochemical Society of Europe 15 (3): 317-37. https://doi.org/10.1007/s11101-015-9451-z.

Kohnen-Johannsen, Kathrin, and Oliver Kayser. 2019. "Tropane alkaloids: Chemistry, pharmacology, biosynthesis and production." Molecules $24 \quad$ (4): 796. https://doi.org/10.3390/molecules24040796.

Levinson, H. Z. 1976. "The defensive role of alkaloids in insects and plants." Experientia 32 (4): 40811. https://doi.org/10.1007/BF01920763.

Li, Zhao-Hui, Qiang Wang, Xiao Ruan, Cun-De Pan, and De-An Jiang. 2010. "Phenolics and plant allelopathy." Molecules 15 (12): 8933-52. https://doi.org/10.3390/molecules15128933.

Lorenzo, Paula, M. Iftikhar Hussain, and Luís González, eds. 2013. "Role of allelopathy during invasion process by alien invasive plants in terrestrial ecosystems." In Allelopathy: Current Trends and Future Applications. Berlin Heidelberg: Springer-Verlag. https://www.springer.com/gp/book/9783642305948.

Lorenzo, Paula, Ana Palomera-Pérez, Manuel J. Reigosa, and Luís González. 2011. "Allelopathic interference of invasive Acacia Dealbata Link on the physiological parameters of native understory species." Plant Ecology 212 (3): 403-12. https://doi.org/10.1007/s11258-010-98319.

Rice, E.L. 1984. Allelopathy. Physiological Ecology. Academic Press. https://books.google.de/books?id=0WKA6fxeXpwC.

Sicker, Dieter, Monika Frey, Margot Schulz, and Alfons Gierl. 2000. "Role of natural benzoxazinones in the survival strategy of plants." In International Review of Cytology, 198:319-46. Academic Press. https://doi.org/10.1016/S0074-7696(00)98008-2.

Sirikantaramas, Supaart, Mami Yamazaki, and Kazuki Saito. 2007. "Mechanisms of resistance to selfproduced toxic secondary metabolites in plants." Phytochemistry Reviews 7 (3): 467. https://doi.org/10.1007/s11101-007-9080-2.

Song, Qingmei, Fangcuo Qin, He He, Hecong Wang, and Shixiao Yu. 2018. "Allelopathic potential of rain leachates from Eucalyptus urophylla on four tree species." Agroforestry Systems, May. https://doi.org/10.1007/s10457-018-0240-8.

Wink, Michael. 2008. "Plant secondary metabolism: Diversity, function and its evolution." Natural Product Communications 3 (8): $1934578 X 0800300801$. https://doi.org/10.1177/1934578X0800300801. 
Wink, Michael. 2010. "Introduction: Biochemistry, physiology and ecological functions of secondary metabolites." In Biochemistry of Plant Secondary Metabolism, edited by Michael Wink, 1-19. Oxford, UK: Wiley-Blackwell. https://doi.org/10.1002/9781444320503.ch1.

Wittstock, Ute, and Jonathan Gershenzon. 2002. "Constitutive plant toxins and their role in defense against herbivores and pathogens." Current Opinion in Plant Biology 5 (4): 300-307. https://doi.org/10.1016/S1369-5266(02)00264-9.

Zacchino, Susana A., Estefania Butassi, Melina Di Liberto, Marcela Raimondi, Agustina Postigo, and Maximiliano Sortino. 2017. "Plant phenolics and terpenoids as adjuvants of antibacterial and antifungal arugs." Hybrid Combinations 37 (December): 27-48. https://doi.org/10.1016/j.phymed.2017.10.018.

Zanardi, Emanuela, Christian G. Jagersma, Sergio Ghidini, and Roberto Chizzolini. 2002. "Solid phase extraction and liquid chromatography-tandem mass spectrometry for the evaluation of 4hydroxy-2-nonenal in pork products." Journal of Agricultural and Food Chemistry 50 (19): 5268-72. https://doi.org/10.1021/jf020201h.

Zayed, Rawia, and Michael Wink. 2004. "Induction of tropane alkaloid formation in transformed root cultures of Brugmansia suaveolens (Solanaceae)." Zeitschrift Für Naturforschung C 59 (1112): 863-67. https://doi.org/10.1515/znc-2004-11-1216. 


\section{Summary and outlook}

Plants produce secondary metabolites as an efficient defense mechanism against biotic stresses, and they can play a crucial role in tolerating abiotic environmental stresses as well. Secondary metabolites can contribute to the plant's survival in the ecosystem in various ways. They include allelochemicals that are involved in interactions with microorganisms, herbivores, and other plants sharing the same ecological niche.

Plenty of research reported the biological activity of allelochemicals in vitro, but only a few studies have proved the allelopathy in natural settings. Therefore, to mimic nature, we extracted secondary metabolites from the apoplast of the intact plant parts using water, which is the only solvent available in the environment. Furthermore, we applied numerous bioassays and sophisticated techniques to investigate the biological activity of the isolated secondary metabolites.

We characterized secondary metabolites in the bulbs of Galanthus nivalis and the metabolites secreted by the bulbs and roots into the soil. We revealed that Amaryllidaceae alkaloids secreted into soil strongly affect gram-negative soil bacteria, as shown by quantifying major groups of soil bacteria by taxon-specific real-time PCR and by sequencing amplified bacterial rRNA genes. On the other hand, non-secreted bulb metabolites did not affect bacteria and fungi but are toxic to invertebrates, which suggests that they may confer to protection against soildwelling herbivores. On the other hand, one of the investigated alkaloids (TBH) showed strong phytotoxicity against Lemna minor.

Furthermore, we found that coumarins were involved in the phytotoxicity of the aqueous extract of Melilotus albus. We proved that the phytotoxic coumarins were released from living plants into the environment through root exudates and leaf leachates. We suggested that the coumarins released from $M$. albus debris may contribute to the suppressiveness of weeds germination in the surrounding area. We also suggested that the presence of coumarins in root exudate might play an ecological role by modulating the rhizosphere to make it favorable for Rhizobia nodules initiation by inhibiting the antagonists. However, these speculations need to be proved through further experiments.

Apart from the direct ecological functions, secondary metabolites provide a vast source of lead structures for therapeutic agents to humankind. For example, fumigation with heated henbane (Hyoscyamus niger) seeds has been used in folk medicine since the time of the ancient 
Summary and outlook

Egyptians. In our study, we proved the nematicidal activity of the fume released from heated henbane seeds, and we characterized the potential toxic volatiles. Among the target metabolites, mixtures of toxic aldehydes that could have been formed during the heating process, mainly $\alpha, \beta$-unsaturated aldehydes, were identified. Further investigations are required to determine the active nematicidal ingredients and subject them to sophisticated drug discovery bioassays. 


\section{Acknowledgments}

I would like to express my deepest gratitude to my supervisor, Professor Dr. Petr Karlovsky, for his guidance, support, patience, and understanding. Throughout my doctoral work, he encouraged me to develop independent thinking and research skills. I would like to thank Dr. Franz Hadaceck for his great support, friendship, and encouragement during my studies. I am very grateful to Prof. Dr. Michael Rostás for being a member of my Ph.D. committee. I highly appreciate the support that I received from Dr. Katharina Pfohl and Dr. Anna Rathgeb. I wish to acknowledge the support of Ruth Pilot, Heike Rollwage, and Luciana for their technical advice, mentorship, and valuable experience, which were essential to completing this dissertation. I would like to thank Lukas Beule for his help and considerable support. Finally, my sincere appreciation goes to my colleagues and friends Zana, Rasoul, Zaheer, Simon, Riyan, Ana, Ling, Yang, Maria, and Nahid for their continuous support and encouragement during the different moments of my Ph.D. and for the great humor and friendship of all involved.

I am much thankful to my parents, who have always believed in me and helped me reach my goals. Finally, the greatest gratitude goes to my colleague and wife Albatol for her unlimited support, understanding, encouragement, and love. 


\section{Statutory declaration}

1. I, hereby, declare that this Ph.D. dissertation has not been presented to any other examining body either in its present or a similar form. Furthermore, I also affirm that I have not applied for a Ph.D. at any other higher school of education.

Göttingen,

Mohammad Alhussein

2. I, hereby, solemnly declare that this dissertation was undertaken independently and without any unauthorized aid.

Göttingen,

Mohammad Alhussein 